\title{
A Corrollary Discharge Circuit Modulates Olfactory Function During Flight In Manduca Sexta
}

Phillip David Chapman

Follow this and additional works at: https://researchrepository.wvu.edu/etd

\section{Recommended Citation}

Chapman, Phillip David, "A Corrollary Discharge Circuit Modulates Olfactory Function During Flight In Manduca Sexta" (2018). Graduate Theses, Dissertations, and Problem Reports. 7165.

https://researchrepository.wvu.edu/etd/7165

This Dissertation is protected by copyright and/or related rights. It has been brought to you by the The Research Repository @ WVU with permission from the rights-holder(s). You are free to use this Dissertation in any way that is permitted by the copyright and related rights legislation that applies to your use. For other uses you must obtain permission from the rights-holder(s) directly, unless additional rights are indicated by a Creative Commons license in the record and/ or on the work itself. This Dissertation has been accepted for inclusion in WVU Graduate Theses, Dissertations, and Problem Reports collection by an authorized administrator of The Research Repository @ WVU.

For more information, please contact researchrepository@mail.wvu.edu. 


\title{
A CORROLLARY DISCHARGE CIRCUIT MODULATES OLFACTORY FUNCTION DURING FLIGHT IN MANDUCA SEXTA
}

\author{
Phillip David Chapman \\ Dissertation submitted \\ to the Eberly College of Arts and Sciences \\ at West Virginia University \\ in partial fulfillment of the requirements for the degree of
}

Doctor of Philosophy in

Biology

Kevin Daly, Ph.D., Chair

Andrew Dacks, Ph.D.

Gary Marsat, Ph.D.

Sarah Farris, Ph.D.

Aric Agmon Ph.D.

Department of Biology

Morgantown, West Virginia

2018

Keywords: Corollary Discharge, Histamine, Olfaction, Ascending, Reafference Copyright 2018 Phillip David Chapman 


\title{
ABSTRACT \\ A Corollary Dishcarge Modulates Olfactory Function During Flight in Manduca sexta Phillip David Chapman
}

\begin{abstract}
Most sensory and motor networks have been relatively well characterized both anatomically and physiologically. However, the complex and ongoing interplay between motor network function (and the behavior it produces), and sensory network function is not well understood. We focused on showing that a pair of mesothoracic to deutocerebral histaminergic (MDH) neurons provide a wing-motor to olfactory corollary discharge (CD) that aids flying moths in detecting and discriminating odors possibly to enhance plume tracking behavior in insects that face difficult olfactory challenges. First, we performed axotomy experiments combined with immunohistochemistry to demonstrate that the MDHns are the sole source of histamine in the olfactory system. Next, by labeling for histamine receptors across larval (caterpillar) stages of development, we determined that histamine receptors aren't expressed until adulthood (Bradley et. al., 2016), the stage at which they acquire the ability to fly, suggesting that these neurons may be providing flight (wing beating) related information. Using comparative neuroanatomy, we demonstrated that these neurons only project to primary olfactory networks in species that were both night flying and plume tracking (Chapman et. al., 2017). Furthermore, only true moths and caddisflies (not butterflies) possess the histaminergic circuit to the olfactory system suggesting that because butterflies have a vastly different behavioral ecology they don't require flight modulated olfaction. By performing simultaneous electrophysiological recordings of MDHn and flight motor activity, we established that MDHn activity was indeed correlated to flight motor output on relatively short(i.e. $+/-50 \mathrm{~ms}$ ) and long (i.e. seconds) timescales but interestingly, there was no correlation at timescales that would indicate a precise motor copy (i.e. +/- 5ms). Furthermore, blocking histamine receptor function in the olfactory system reduced the discriminability of odors (Chapman et. al., 2018). Together, these results establish the MDHns as an olfactory CD circuit that informs the primary olfactory network of the general state of the wing motor output presumably during plume tracking.
\end{abstract}




\section{DEDICATION}

I would like to dedicate this thesis to two very important people in my life. First, I would like to dedicate this thesis to my mother, Martha Chapman, who has been the most supportive person I could ever know. Second, I would like to dedicate this thesis to my father, Dennis Chapman, who has taught me the value of hard work and persistence. Without their support and encouragement, this thesis would not have been possible. 


\section{ACKNOWLEDGEMENTS}

I have been fortunate to be surrounded by extremely supportive and intellectually stimulating people during my time at West Virginia University. Without these people, this thesis would not have been possible. I would first like to thank Kevin Daly. Without his advice, not only in the realm of science and education, but in life, health and balance, I wouldn't have made it this far. I would also like to thank the rest of my committee: Andrew Dacks, Gary Marsat, Sarah Farris and Aric Agmon for their insightful comments and discussions over the years. I would like to thank Samual Bradley, Rex Burkland, and Samantha Jusino, for being supportive and open about me joining the lab, for generally being helpful during my transition from undergraduate to graduate school, and for all of the fruitful collaborations we shared. I would like to thank Victoria Bullman, Ariel Thomas, Mouaz Haffar, Ahmed Mian, Kassie Riggs and Erica Haught for being excellent undergraduate students in the lab, that I taught, but who also taught me a great deal.

I would also like to thank my many friends I had during graduate school in no particular order. Kristyn Lizbinski, Kate Allen, Daniel Williamson, Brandon Baker, Yasi Etemadi, Kaleb Hatch, and Kevin Fielder for all the fun times that helped me keep my sanity.

I would like to thank all of those in my family who have helped me with things big or small: My parents, Dennis \& Martha Chapman, my oldest brother and his family, Stephen Chapman, Stephanie Gale, Eliot Chapman, John \& Jane and Adam Gale, my other brother and his wife Daniel Chapman, Sarah Chapman, and finally the loving memory of my grandparents Seymour and Helen McClure. 


\section{TABLE OF CONTENTS}

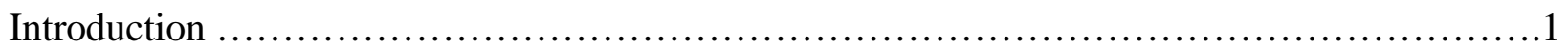

CDs Affect most Sensory Modalities............................................. 2

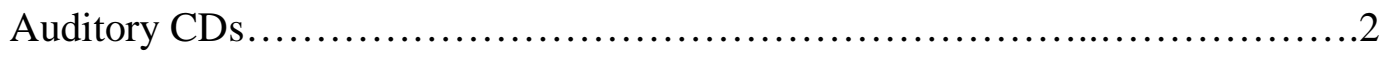

Visual CDs................................................................

Somatosensory CDs.......................................................

Electrosensory CDs.........................................................

Olfaction and CDs...................................................................

Pattern Generating Circuits and Inputs to CDs ......................................10

Active Sampling and Olfactory CDs...............................................13

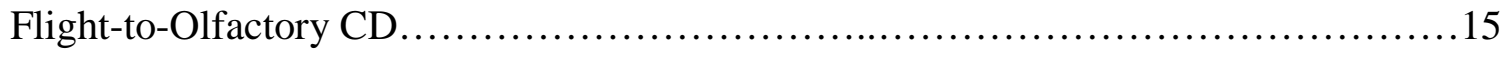

Chapter 1: MDH neurons are the sole source of histamine to the antennal lobe and receptors are only expressed in adult moths.

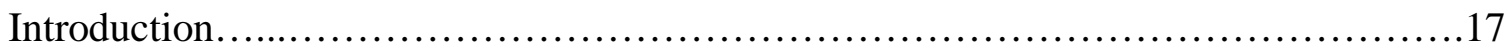

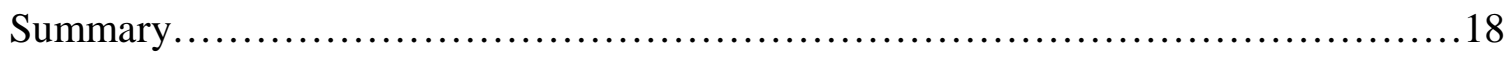

Chapter 2: Antennal lobe histamine across species is linked to behavioral ecology and ventral nerve cord histamine interconnects body segments

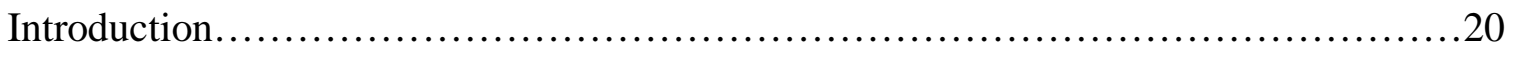

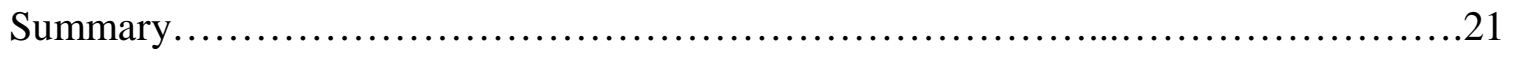


Chapter 3: MDHns provide a CD to the olfactory system in Manduca sexta.

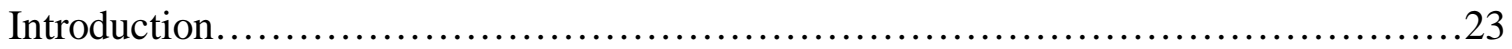

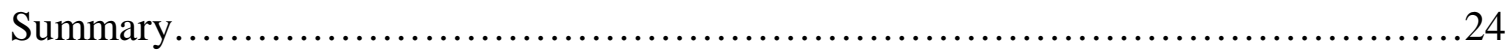

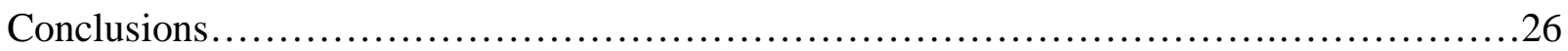

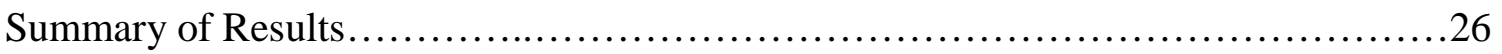

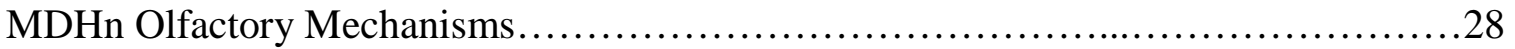

MDHn Inputs in CPG Neuropil..................................................30

MDHns Co-opted to Facilitate Plume Tracking.....................................31

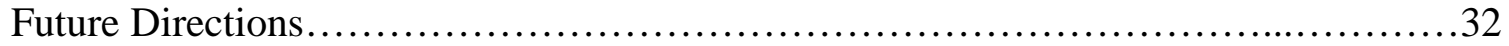

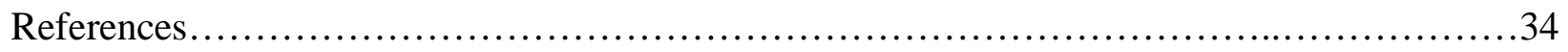

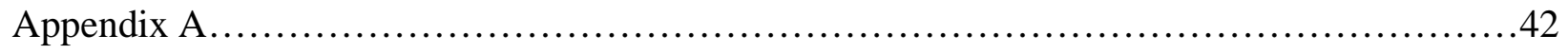

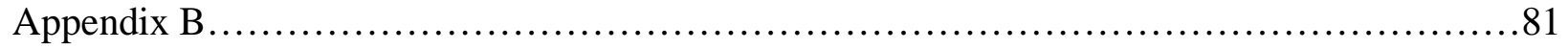

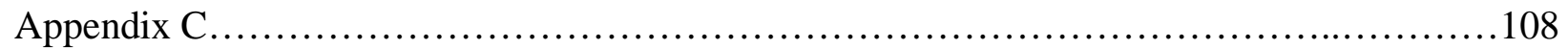

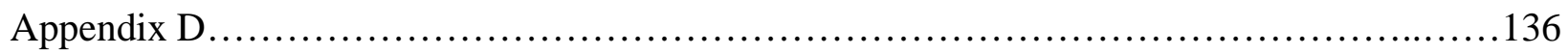




\section{INTRODUCTION}

Animal movement can directly activate sensory systems. As we walk, mechanoreceptors on our feet are activated. When we talk, our auditory system is activated. This creates a problem for nervous systems; nervous systems need to be able to discriminate between contextually different sensory activations. Sufficient selective pressures promoted the evolution of circuit types that provide motor information to sensory systems allowing effective discrimination between selfgenerated sensory activations (reafference), and sensory activations generated by the outside world (exafference). These circuits are called corollary discharge circuits (CDCs or CD), and their existence can have broad implications in all sensory neuroscience applications. A corollary discharge circuit has an important function, that is to compensate for, or otherwise exploit reafference to modify or stabilize sensory perception. For reafference to be compensated or exploited, corollary discharge circuits need to transmit information about ongoing motor commands to the sensory systems the reafference affects. The activity of a corollary discharge circuit can be as precise as an exact copy of motor neuron activity (efference copy), or merely correlated to motor activity. Therefore, we define the difference between efference copy, and corollary discharge by how the representation of motor output (either from single neurons or a population of neurons) is presented. An exact copy of motor neuron output (as for efference copy) or simply a corollary of motor output that is driven by the motor network (as for corollary discharge) would delineate these two terms. The effects that corollary discharge circuits have on their respective sensory systems can be classified into a simple dichotomy (Crapse \& Sommer 2008a). Lower order corollary discharges (LCDs) define a class of circuits that simply filter out the reafference generated by motor output, while higher order corollary discharges (HCDs) modify the sensory systems in more complex ways. Because circuits are rarely single neuron 
circuits, it becomes difficult to describe where the corollary discharge ends, and where sensorimotor integration in other circuitry begins. Irrespective of where in the circuit transformations are made, the consequence of $\mathrm{CD}$ on sensory systems can be accurately defined. Therefore, lower and higher order describe the function of the CD, and how it affects the sensory network, rather than the representation of motor output. Although rare, with these defining constraints, even efference copies could be HCDs, and corollary discharges be LCDs.

Corollary discharge circuits have been identified in many animals and sensory modalities. I will briefly describe several examples of corollary discharge categorically with respect to the sensory domain each CDC affects and describe their functional significance. As the purpose of this dissertation is to describe a novel corollary discharge circuit modulating olfaction, and its functional significance, I will describe olfaction, motor networks, and active sampling within a CD conceptual framework before introducing the CD circuit that was the focus of this dissertation.

\section{CDs Affect Most Sensory Modalities} Auditory CDs

During auditory guided behavior, reafference can generate signals that are necessary to discriminate, or otherwise ignore. For example, if an animal is moving in a "noisy" medium, the timing of the reafference is important, as it can provide information that would allow an animal to discriminate between self, and other. The mechanism by which crickets chirp is called stridulation, whereby toothed portions of their wings called the file, and scraper, are rubbed against one another to create sound. Male crickets chirp for various reasons, but the most studied is chirping to attract mates (Walker, 1962). Competition and predation interactions would suggest that both a need to chirp, and a need to detect other male crickets or predators is 
necessary, within close temporal proximity. Chirps can be so loud close to the animal that crickets’ auditory system could adapt, making detection between chirps problematic (Tunstall \& Pollack, 2005). The auditory ascending interneuron, AN1 was shown to exhibit hyperpolarizing current during chirps with one or two-winged chirping or during fictive chirping. It was determined that the drive for the CD was coupled to the chirping motor pattern. Subsequently, CD neurons were driven by the wing motor CPG (central pattern generator) to actively inhibit ascending auditory sensory neurons during each chirp, so between chirps, auditory sensory neurons can stay effectively sensitive (Poulet, 2005, Poulet \& Hedwig, 2006).

When mice move in a noisy medium, the reafference generated needs to be compensated for because reafferent noise could interfere with exafferent auditory processing. In mice, movement including locomotion actively suppresses excitatory auditory cortical neurons (Zhou et. al., 2014). Neurons from the secondary motor cortex that project to the auditory cortex (M2ACtx) (Nelson et. al., 2013) are active before and during movement. These neurons synapse onto parvalbumin $\left(\mathrm{PV}^{+}\right)$local neurons in the auditory cortex. $\mathrm{PV}^{+}$neurons were also shown to be depolarized before and during movement, and their activity suppressed the activity of excitatory neurons in the auditory cortex; interestingly, this suppression preceded movement by 200ms (Schneider et. al., 2014). In this case, corollary discharge neurons innervate a local sensory processing network to preemptively change cortical dynamics ahead of movement, thereby suppressing the subsequent reafference generated by locomotion.

\section{Visual CDs}

Visual systems in animals often employ saccades (moving the eye in a quick and directed way) to reduce visual adaptation as well as to quickly scan a visual scene. These quick and directed movements of the eye displace the visual field. With all of this fast shifting, how is it 
that animals aren't constantly seeing blurred vision of a panning scene during the saccades, and furthermore how is it that it doesn't seem like the entire world is jumping from one place to another during each saccade? These problems associated with instability of the image on the retina caused by self-generated eye movements are compensated for by CD circuits that originate in the oculomotor system (Guthrie et. al., 1983), and project to the superior colliculus in mammals (Wurtz \& Goldberg, 1972, Richmond \& Wurtz, 1980). During the saccade, CDs from the oculomotor system suppress retinal signals (Wurtz \& Albano, 1980). These suppressions act like a gate that dampens the sensation of motion and makes the viewer somewhat "blind" during the saccade. This type of gating activity would be considered a LCD, because it's only a correcting algorithm that does no calculations involving learning/planning or analysis (Crapse \& Sommer, 2008a). However, during the saccade, another problem exists. Every time the eye moves during a saccade, the visual scene is displaced on the retina. This is a problem because it is not the world that is moving around the viewer, it is the viewer's eyes that are moving instead. Without CD, every saccade would be perceived as a panning movement of the world around the viewer which could be very disorienting. This effect is especially profound during larger macro saccades, used to actively interrogate a visual scene. Stabilization of this effect is postulated to be solved by CD through two mechanisms. First, a CD provides information about the planned angular shift in receptive field in advance of the saccade. This sensorimotor planning causes the new receptive field to be sampled and projected to the frontal eye field so that a flawless leap from the receptive field before the saccade to the new receptive field after saccade can occur (Crapse \& Sommer, 2008b, Crapse \& Sommer, 2009, Crapse \& Sommer, 2012). This type of CD is a HCD because it requires planning in advance of the movement to create the streamlined 
perceptual scene. LCD saccadic suppression has been shown in many different species including invertebrates, however there hasn't been an instance of HCD in invertebrates shown to date.

\section{Somatosensory CDs}

A canonical example of CDs affecting the somatosensory system underlies the fact that you cannot tickle yourself. Although the mechanisms underlying this phenomenon aren't fully understood, it's obvious that reafferent touch is interpreted very differently than exafferent touch. In the rat whisker barrel system CDs play an integral role in calculating object position during active whisking. It had long been known that whisker motor centers send projections into the whisker barrel cortex, and disrupting these projections produce deficits in object localization (Veinante \& Deschenes, 2003). During active whisking, CDs from the motor cortex along with proprioception provide enough information that allows the calculation of the absolute position of the whisker at the time of the object touch (Cullen, 2004). Proprioceptive signals from the vibrissa system encode the phase of the whisker during each sample and CDs likely inform the

cortex of the amplitude of the whisk (Fee et. al., 1997). Together, CD and proprioception provide enough information to code the absolute position of the object at the time of the touch. This is a classic example of sensory analysis (HCD) by using movement intensity coding, rather than filtering out the animals own whisking induced reafference; its purpose is to aid the barrel sensory system in computing the location of objects.

\section{Electrosensory CDs}

The weakly electric mormyrid fish produces an electric field called an electric organ discharge (EOD) to probe its environment in the murky waters of African rivers. It can localize objects, communicate with other fish, and hunt using this sense (Gerhard Von Der Emde, 1999, Hopkins, 1980, Arnegard \& Carlson, 1980). The most interesting challenge faced by this sensory 
system is that producing an EOD imposes very predictable and redundant reafference to the electrosensory system (Bell, 1989). The mormyrid fish have three sets of electroreceptors that are subject to reafferent stimulation by the EOD. Knollenorgan receptors process electrocommunication signals, the mormyromast receptors receive active electrolocation signals, and the ampullary receptors receive passive electrolocation signals. These electroreceptors receive information about the electric field and project to a brain region called the electrosensory lateral line lobe (ELL) where sensory processing occurs (Meek et. al., 1999). There are two major CD types that occur in these fish. During communication EOD signals are transduced by Knollenorgan receptors and reafference is directly cancelled out by CDs originating from the EOD command nucleus. This would be an example of an LCD as it simply filters out the reafference. Reafference is also sensed by the ampullary receptors during electrolocation. In this CD circuit, a negative (anti-phase) image of previous EOD waveforms is stored using antiHebbian synaptic plasticity. This negative image results in an expectation of the animal's own EOD. During electrolocation, CD releases this stored image and subtracts it from the inputs to the ELL (Bell et. al., 1993). With these types of CDs, the EODs of other fish, objects, and conspecifics become more easily detectable. The CD in the ampullary pathway is an HCD because it performs predictive sensory analysis by modifying the CD based on past experience (Crapse \& Sommer 2008a).

It is evident that corollary discharges occur across a diverse set of sensory modalities. Although one may assume that CDs would be present in the omitted modalities, to date, there haven’t been any clear examples establishing CDs in olfaction or gustation. 


\section{Olfaction and CDs}

Olfactory systems, whether vertebrate or invertebrate, have a principal neural organization that varies little from species to species. While the major olfactory structures do vary between vertebrates and invertebrates, general themes of how chemosensory appendages are structured and interact with odor laden air are similar. For instance, both vertebrates and invertebrates employ a strategy of active sampling behaviors, which forcibly introduce samples of potentially odor laden air into the olfactory structures. These behaviors undoubtedly produce reafferent signals as these processes have been shown to cause sensory activation in the absence of odor (Walsh, 1956, Tripathy et. al., 2010, Macrides \& Chorover, 1972) In vertebrates, sniffing is a common way to introduce odor laden air to the olfactory epithelium and sniffing has been shown to increase the penetration of odorant molecules into deeper olfactory areas of the nasal cavity rather than non-olfactory areas (Schoenfield \& Cleland, 2005). Similarly, in invertebrates, wing beating and antennal flicking acts to facilitate the penetration of odorant molecules into the sensilla of the antennae (Loudon \& Koehl, 2000). These processes which may cause reafference clearly enhance the ability of odorants to interact with their cognate receptors, so the question remains whether active sampling is accompanied by $\mathrm{CD}$ to address the possible reafference. The remainder of this section will center around insect olfactory structures and organization, as the chief organizational principles in invertebrates do not differ significantly from vertebrates, then I will introduce other CD circuits that may affect olfactory systems.

The major olfactory structures in insects are the antennae, usually long appendages that serve several different functions. Aside from an olfactory purpose, antennae can also detect thermosensory, hygrosensory, mechanosensory (touch), and auditory sensory cues. The antennae are comprised of three antennal segments. The majority of olfactory receptor neurons are located 
in the flagellum (the third and longest segment) that is composed of many smaller segments called flagellomeres, or annuli. On the flagellum, olfactory receptor neurons are located in small protrusions or indentations called sensilla. Each sensillum houses usually two olfactory receptor neurons, and these neurons express different types of receptors that bind odorant molecules (Stocker, 2001).

Olfactory receptors are broadly segregated into two major groups. The main body of receptors in insects are odorant receptors (ORs) which require the odor receptor coreceptor (ORCO), to function (Suh et. al., 2015). The other major category of odorant receptors are ionotropic (IRs), and do not require ORCO to function, but do have specialized IR co-receptors (Rytz et. al., 2013). ORs binding affinity to certain odors occurs across a tuning spectrum, for example, pheromone receptors are very narrowly tuned, while some ORs bind a broader range of odors (Andersson et. al., 2015). When ORs bind their cognate ligand, they generally activate the neurons that express them. The primary sensory/receptor neurons (ORNs) of the olfactory systems express usually one OR and converge on a single synaptic zone in the antennal lobe (AL) called a glomerulus. The one-receptor:one-ORN:one-glomerulus principal organization allows for distributed expression of ORs across the antennal structure, while clustered processing can occur centrally (Wang et. al., 1998). Within the AL, ORNs synapse onto local processing neurons (LNs), and output projection neurons (PNs). LNs have been shown to be highly diverse in terms of their projection patterns, transmitter content, and response characteristics. The functional roles of LNs are not well understood, but it is generally accepted that LNs affect the tuning/sensitivity of the AL (Olsen \& Wilson, 2008). However, after odorant stimulation, PN population responses evolve over hundreds of milliseconds, indicating LN involvement, but because behavioral responses can generally occur within $50-150 \mathrm{~ms}$ it is likely the additional 
information is not relevant for odor identification (Daly et. al., 2004, Miura et. al., 2012). PNs are the output neurons of the AL, and are divided into two distinct projection categories: those that project to the mushroom bodies (associated with sensory integration and learning and memory), and then to the lateral horn (associated with innate behaviors and hedonic valence), and those that project directly to the lateral horn completely bypassing the mushroom bodies (Jefferis et. al., 2007). PN response profiles to different odors are diverse, many of which are activated early with short delay after odor stimulation, while other subsets are either inhibited by odor stimulation, and some are activated with longer delays (Daly et. al., 2016). This response profile diversity can be mostly attributed to the local network. However, a few PNs have dendritic structures in multiple glomeruli, and in some cases all glomeruli. Thus, heterogenous synaptic connectivity of PNs and LNs likely contributes to the diverse response properties of PNs. In Manduca sexta, PNs share a pre-excitation inhibitory phase (I1); this phase is $\mathrm{Cl}^{-}$ dependent, is variable in its onset and duration, and is odor dependent among PNs (Waldrop et. al., 1987). It is postulated that I1 performs a local (perhaps intraglomerular) synchronization function, so that all PN responses are aligned in time. However, many insect species appear to lack this I1 inhibitory phase. There is also a post-excitatory inhibitory phase (I2) in some PNs but this phase is more variable, and is thought to perform response termination, although it is less understood.

The three types of primary olfactory neurons (ORNs, PNs and LNs) make up the majority of cell types observed in the insect olfactory system’s input pathway. Centrifugal modulation of the olfactory systems is also apparent, but the full repertoire of context dependent modulation of the AL hasn’t been studied extensively. Immunohistochemical studies have shown that several different neurons enter the AL from other brain regions. For example: the contralaterally 
projecting, serotonin-immunoreactive deutocerebral (CSD) neuron, has axon terminals in the AL in many species, but it is unknown what information these neurons are providing (Dacks et. al., 2006). There is a diverse suite of serotonin receptors, and it appears that serotonin receptors are distributed in AL neurons in a predictable manner (i.e. excitatory PNs express excitatory serotonin receptors, and other serotonin receptors are expressed in subcategories of LNs). This indicates that the same information from the CSD neurons, while affecting excitatory PNs in the same way, differentially affect the local network which can contribute additional variability in PN responses (Sizemore \& Dacks, 2016).

Other centrifugal mechanisms of early olfactory modulation have been described. For example, reinforcement of olfactory stimuli modulates early olfactory processing (Hammer \& Menzel, 1998, Daly et. al., 2004). Cholinergic and noradrenergic inputs to the olfactory bulb in mammals are thought to increase odor discrimination and sensitivity respectively (Linster \& Devore, 2012). While many more examples of modulation of primary olfactory processing exist, the sources of correlated motor signals (whether sensory or motor) haven't been disentangled. For example, sniffing in mammals has been shown to adaptively transform sensory responses in the olfactory bulb (Verhagen et al., 2007), however, it is unknown whether it is the mechanosensory response of sniffing, the fact that sniffing increases odorant molecule interactions with receptors, or corollary discharge mechanisms mediating this transformation.

\section{Pattern Generating Circuits and Inputs to CDs}

Many CDs receive information through central pattern generators (CPGs). Therefore, for the purpose of understanding CDs in more depth, I will briefly discuss CPGs, and how oscillatory motor commands are generated. 
Individual neurons in pattern generating motor networks have very specific properties. Through expression of specific voltage gated ion channels, and reciprocal inhibition, individual neurons can demonstrate oscillatory membrane voltage dynamics (Marder \& Calabrese, 1996). Single neuron oscillators express a variety of voltage gated channels (Grillner, 2003), and modeling studies have shown that changing the expression pattern of channels (or conductances) can mediate the frequency and firing dynamics of oscillators (Lemasson et. al., 1993). Additionally, other neural components of some CPGs only respond when oscillator frequency passes a threshold, and this state switch can cause a diverse set of responses (Skinner et. al., 1993). For example, some quiescent neurons can become tonically active, some neurons burst when depolarized, and some generate bursts when hyperpolarized (Llinas, 1988). It is thought that many of these properties mediate switches between different motor modules in mice: as gait frequency increases, switching from a walk, to a trot, to a gallop occurs. Commissural interneurons (CINs) in the spinal cord coordinate the changes between gait patterns and are thought to play a role in the synchrony of different motor neurons observed in different gait patterns (Bellardita \& Kiehn, 2015). The changes observed are likely due to intrinsic properties of the CINs and different populations of CINs respond differentially to different gait frequencies (Zhong et. al., 2006). Experimental evidence exists that much of the circuitry that mediates different motor programs are shared, and that activity levels, unique activation patterns, and command architecture can all influence these switches (Kiehn, 2006).

Synaptic dynamics also significantly influence the generation of oscillatory motor commands. Modulatory inputs to oscillators can introduce novel currents presumably associated with opening a new diverse set of ion channels (Harris-warrick \& Marder, 1991). Modulatory substances include biogenic amines, and neuropeptides, and there are a diverse set of receptors 
associated with each of these substances. For example, there are seven known families of serotonin receptors, which can either increase/decrease intracellular cAMP/IP3/DAG levels, or directly depolarize the membrane in the case of the 5-HT3 receptors (Pytliak et. al., 2011). With this level of receptor diversity, modulation of pattern generating circuitry can also be quite diverse.

Many neurons in pattern generating circuits are electrically coupled to one another. This coupling is necessary to bias synchronization or influence neuronal firing, or to bind together the phasing of neurons that may have disparate functions, but must be active at the same time. Neurons that are coupled will have coupling ratios of influence on each other, and the coupling ratios do not have to be equal in both directions. For example: one neuron may be able to effectively influence another neuron's membrane potential, while the other neuron (coupled to it) may not be able to influence the original neuron. This unequal influence is attributed to a diverse set of gap junction proteins. Each pair of coupled neurons can either express the same or different half of a completed gap junction, and each of these gap junction pairs will allow current flow preferentially in one direction over the other. Combined with differential expression of several gap junction proteins in single neurons, almost any coupling ratio can be created (Phelan et al., 1998, Starich et. al., 2009). This is important because it shows the enormous flexibility of motor circuits, and their ability to adapt to the structural differences between species.

The central integration circuitry for locomotion is the CPG, however CD circuits can be influenced at any point in the motor sequence from central motor planning regions, to collaterals from individual motor neurons. Some CD circuits could be synaptically and electrically coupled to the CPG circuitry. Some CD circuits could also be part of the CPG itself, mediating feedback modulation of the CPG, especially if that CD circuit is a direct readout of the motor program 
(efference copy). Additionally, some CD circuits may be a combination of sensorimotor information i.e. both CPG activity, and reafferent proprioception may influence a given CD circuit. Given the potential opportunities for CPG circuit connections and inputs, the line between what constitutes a CD circuit, and what doesn't, becomes somewhat unclear. A general consensus across studies is that CD circuits all must meet two criteria: 1) The neurons in question must be influenced by motor activity (in isolation of sensory input) and 2) The neurons in question influence the processing of a sensory system in a way that is related to the reafference generated by the motor output.

\section{Active Sampling and Olfactory CDs}

Active sampling strategies are behaviors employed by animals to interact with their environment on discrete timescales and these behaviors often introduce reafferent sensory stimulation. However, active sampling has been shown to trigger nervous system synchronization, and subsequently optimization of the sensory percept, as well as optimize stimulus receptor interactions (Martin et. al., 2011). In mammals, visual micro-saccades interact with the visual scene on a sub-millisecond timescale to avoid photoreceptor adaptation (Martinez-Conde et. al., 2006). Echolocation in bats also involves active sampling performed on a discrete timescale. When timing is important, active sampling may be accompanied by corollary discharge circuits that can compensate for the disruptions active sampling causes (Schroeder et. al., 2010). Many Lepidopterans track plumes of odor to their source to find food, oviposition sites and reproductive partners (Baker, 1986); this plume tracking is an active sampling behavior. Moths cast back and forth across an odor plume presumably to engage in gradient or edge detection (Kennedy, 1983). Interestingly, mammals also perform this behavior, as dogs and even humans have been shown to cast across odor plumes and are able to find the source of odors (Porter et al., 2007). This casting 
behavior is also accompanied by sniffing, and rates of sniffing increase while directly in the plume (Porter et. al, 2007, Kahn et. al., 2011). Similarly, wing beating accompanies plume tracking in insects, where the wing beat frequency and biomechanics change based on the presence of odor (Charlton et. al., 1993). While casting to relocate an odor plume does not specifically require wing beating, the physical effects of wing beating are required to find the odor source (Obara, 1979). It has been shown that wing beating enhances penetration of odorants through the antennae (Loudon \& Koehl, 2000), and artificial systems mimicking the effects of wing beating have been demonstrated to be effective at increasing odorant/receptor interactions (Koehl, 2006). Additionally, the wing kinematics of Bombyx mori during odor tracking is similar to the wing kinematics of other moths during flight, suggesting that this behavior is retained in a moth that no longer flies (Kanzaki, 1998). Experimentally, pulsing odor at the mean wing beat frequency of Manduca sexta has been shown to be readily tracked (Tripathy et al., 2010), producing more stable, and distinctive representations at the level of the antennal lobe (Houot et. al, 2014). Pulsing odor also decreases behavioral detection thresholds in comparison to continuous odor streams, suggesting that the olfactory experience operates within stimulus parameters caused by flying (Daly et. al, 2013). PNs in the AL reliably track pulsed stimuli (Christensen \& Hildebrand 1988), and disrupting GABA completely abolishes PN pulse tracking (Christensen et al., 1998; Tripathy et al., 2010). Disrupting GABA also increases psychophysical thresholds for detection and discrimination (Mwilaria, 2008). This suggests that GABA plays an integral role in the ability of PNs to track discrete pulses of odor, and that this ability is necessary for proper odor guided behavior. While GABA is necessary for pulse tracking, possible CD from the ventral nerve cord may regulate this ability. Interestingly, in the classic "isolated head" preparations used to study Manduca olfaction for decades, the maximum pulse entrainment frequency was only $10 \mathrm{~Hz}$, 
whereas in intact preparations, where the neck connective is not cut as many as $25 \%$ of PNs entrain up to $30 \mathrm{~Hz}$ ( maximum wing beat frequency in Manduca sexta). Collectively, these findings suggests that rather than filtering out the reafferent sensory stimuli like most sensory modalities, olfactory systems may be exploiting the reafference and might be using CD to prime olfactory networks to receive intermittent stimuli on a more rapid timescale consistent with wing beating induced oscillatory flows across the antennae. It is becoming increasingly clear that there is a complex interaction between the networks that drive active sampling behaviors, and sensory processing, but how the nervous system modulates sensory processing during these active sampling behaviors is largely unexplored.

\section{Flight-Olfactory CD}

Since active sampling causes reafference in olfactory systems, it would stand to reason that if a CD existed that modulated olfactory processing during flight, there would be an anatomical connection between the neuropils housing the CPG for flight, and neuropils that process odorants. The mesothoracic to deutocerebral histaminergic neurons (MDHn) are the only known neurons connecting these neuropils in moths. Their dendrites reside in the dorsomedial aspect of the mesothoracic neuromere $(\mathrm{MsN})$, while their axon terminals ascend to the brain where arborizations are made in the subesophageal zone (SEZ), the antennal mechanosensory and motor center (AMMC) and the antennal lobes (AL) (Homberg, 1991). These neurons are best suited to provide a CD to the olfactory system within a flight context. Therefore, the goal of this dissertation is to demonstrate that the MDHns provide a CD that represents an adaptation to enhance olfactory acuity in species performing sensitive olfactory tasks. To do this, I first needed to characterize the anatomy and development of this circuit to establish that the MDHns were the exclusive source of HA to the AL. Next I determined phylogenetic distribution of this circuit to understand the 
behavioral ecologies that promoted the emergence of this circuit in plume tracking insects. Finally, I needed to describe the activity of these neurons to establish CD and examine consequences on behavior when disrupting the circuit. 


\section{CHAPTER 1: MDH neurons are the sole source of histamine to the antennal lobe and receptors are only expressed in adult moths.}

\section{INTRODUCTION}

Previous studies have suggested that the MDHns represent the only known histamine source within the AL. Although there likely are other neurons that are undiscovered connecting these two regions, the ease with which HA can be labeled, and the relatively sparse labeling of HA in the CNS make MDHns good candidates to facilitate the study of flight-olfactory circuits. As the ability for more advanced immunocytochemical imaging techniques have emerged, more detailed characterization of the MDHns’ morphology, as well as the identification of neurons within the AL expressing HA receptors is possible. In this chapter, I establish that the MDHns are the exclusive source of HA to the AL, and that the development of this circuit is finalized through receptor expression during metamorphosis.

The mesothoracic neuromere houses in part, the CPG for flight, but also houses a diverse set of neurons that process other information. For example, proprioceptive, and mechanosensory afferents terminate within the mesothoracic neuromere (presumably affecting CPG function), and many ascending and descending neurons also innervate this area. The positioning of CPG interneurons has been described (Vierk et. al., 2010), and therefore examining the positioning of the MDHns' dendrites could provide evidence that CPG circuitry is influencing MDHn activity. Ascending to the brain, the MDHns arborize in many areas, but it is unknown whether histamine receptors are expressed in all these areas. As histamine can potentially bind to receptors other than the classic histamine receptors it would be unclear what specific effects histamine may play in the absence of histamine receptors. 
There are at least 2 other pairs of HA neurons in posterior neuromeres, these cells receive distinct input and ascend through the neck connective. Although it has been postulated that the MDHns exclusively provide HA within the AL (Homberg, 1991), this hypothesis has not been resolved. Determining which among these HA neuron pairs ramify the AL is a necessary first step to determine what information is provided to the AL. Are the MDHns the sole source of HA in the AL, or do other HA neurons innervate the AL?

During metamorphosis, neurons can lose their synapses, change their architecture and dendritic organization, and change their innervation patterns completely (Tissot \& Stocker, 2000, Levine \& Truman, 1985). Some neurons (e.g. walking/flight motoneurons) can serve two distinct functions as larva and adults (Casaday \& Camhi, 1976). If the MDHns serve to modulate olfactory function during flight, then it stands to reason that the circuit may not exist in the larval state, which does have a simple but functioning olfactory neuropil yet does not possess the flight machinery found in adults. Thus, does this circuit exist in larva? More specifically, do the MDHns project to the AL and are the HA receptors expressed by AL LNs in the larva?

To answer these questions, we performed immunocytochemistry of both HA and the Manduca sexta histamine B receptor (MsClB) to describe the general architecture of the neurons in both the mesothoracic neuromere, and the AL. We also examined the architecture of the MDHns in both $5^{\text {th }}$ instar larvae and adults

\section{SUMMARY}

Details of the methods, results, and conclusions are presented in Appendix A and are described in Bradley et al, 2016. The following is a description of the most important results that were produced by the author of this dissertation. 
In order to determine which HA neurons in the ventral nerve cord (VNC) provide the AL with HA, axotomy experiments were performed and animals were kept alive to allow ascending histaminergic processes to degenerate. It was determined that all of the HA in the AL was from ascending inputs by cutting the connective between the brain and VNC, but it was unknown which of the ascending HA neurons provided HA to the AL. However, after repeating the experiment, this time sectioning between the meso- and metathoracic neuromeres so that only the MDHns remained intact, we were able to show that HA in the AL also remained intact. This indicated that MDHns exclusively provide HA to the AL because the MDHns are the only histaminergic neurons between the neck connective and the boundary between the mesothoracic and metathoracic neuromeres.

Next, to characterize the MDHn circuit during preflight development, an immunocytochemical labeling study of the MDHns in $5^{\text {th }}$ instar larval Manduca sexta was performed. Here we demonstrated that the MDHns were present, and produced HA, and that there was HA in the LAC (larval antennal center), suggesting that the circuit is present throughout development, but unresolved in this experiment was whether neurons within the LAC expressed the MsClB receptor. Therefore, immunocytochemical labeling of MsClB receptor was performed in juveniles at all larval stages. As adults, MsClB receptors are expressed widely within the AL, however, we demonstrated that the LAC was devoid of MsClB receptors at the last larval instar; an absence of these receptors as larvae suggests that the circuit is incomplete and HA function is developmentally specific, though its role in larvae is unknown. Although no MsClA receptors are expressed in the adult AL, it is possible that these receptors could be expressed in the LAC. However, as only adult Manduca sexta fly, these results provide evidence that MDHns may provide flight related information to the AL in adults. 
CHAPTER 2: Antennal lobe histamine across species is linked to behavioral ecology, and ventral nerve cord histamine interconnects body segments.

\section{INTRODUCTION}

Several insect species possess ascending histaminergic neurons in their ventral nerve cord, and those neurons bear a striking resemblance to the MDHns in Manduca sexta (Horner, 1996, Patschke \& Biker, 2011). In Manduca, the MDHns innervate the AL, as well as other sensory areas such as the AMMC. It was unknown however, whether AL innervation by the MDHns in Manduca was isolated to this species alone, or whether MDHn innervation of the AL is a phylogenetically conserved trait. Determining which species contain histamine neurons that project from the MsN into the ALs and linking the presence of this circuit to specific behavioral ecologies would provide evidence that the MDHns may relay specific types of information in specific contexts such as odor guided flight.

We performed histamine immunocytochemical labeling of the brains of several different arthropod species. These species ranged from being closely related to Manduca sexta (i.e. Bombyx mori), to less related (i.e. Drosophila melanogaster) to relatively unrelated (ticks Amblyomma americanum). We chose species to answer two fundamental questions about how individual neural circuits evolve, and give key insights to the function of the MDHns: 1) Do MDHns change their projection patterns between closely related species based on differing behavioral ecologies? and 2) How ancient are the MDHns, and how common is it for HA neurons to interconnect segments or ganglia? 


\section{SUMMARY}

Details of the methods, results, and conclusions are presented in Appendix B and Chapman et. al., 2017. The following is a description of the most important results that were produced by the author of this dissertation.

The MDHns in Manduca sexta are the exclusive source of HA in the AL (Bradley et. al., 2016). We therefore used a binary system (whether AL HA immunolabeling was present, or absent in closely related species) to determine if the MDHns were influencing olfactory processing in other species. We first looked in very closely related moths, the macrolepidopteran moths, a large group in which Manduca sexta belongs. I examined Manduca sexta, along with Idia aemula, the powdered snout moth, to determine that HA was present in the ALs of macrolepidopteran moths while other authors examined Bombyx mori.

We next turned our attention to the butterflies, which are very closely related to moths but are diurnal and fly very differently. Butterflies are more closely related to macrolepidopteran moths, than are microlepidopteran (basal) moths. I examined two species of butterflies Papilio appalachiensis as well as Limenitis archippus, while other authors examined Pieres rapae None of the butterfly species examined contained AL HA immunelabeling. Because macrolepidopteran moths and butterflies share a common ancestor, I also examined basal (microlepidopteran) moths to determine if MDHn AL innervation appeared in a common ancestor of the macrolepidopteran moths, or whether it was lost in butterflies. I examined two species of moths and other authors examined one species of caddisfly, Galleria melonela and Grapholita molesta, and Lemnephilidae sp. respectively. All had HA expression in their ALs suggesting that instead of MDHn AL innervation arising in macrolepidopteran moths, butterflies 
had lost the trait. All of the species examined thus far had MDHns in the thoracic region that were virtually anatomically identical.

In order to understand the function of thoracic HA cells further, I examined the CNS posterior to the brain in other species of arthropods. I examined Theatops californiensis and Amblyomma americanum a centipede and a tick respectively while other authors examined the fruit fly, milkweed bugs, Kenyan cockroach and beetle. The two species I examined are so distantly related to the moths we examined that we couldn’t determine whether MDHns innervated olfactory areas or not, but the general morphology of histamine immunolabeled neurons in these regions begins to differ from the MDHns. In particular, rather than a single pair of histaminergic neurons that ascend, the centipede showed several bilateral pairs of histamine neurons, some which ascended, and some which descended. The tick only has one centralized neuropil, but HA labeling was dense within all the motor and sensory regions. We were able to determine the location of the olfactory lobes, and HA was not present. Additionally, the relative position of the cell bodies was not consistent with the MDHns. It is apparent that HA neurons interconnect body segments as a general feature of arthropod neuroanatomy and may interconnect motor and sensory pathways. These findings provide evidence for and strengthen the argument that MDHns provide a CD to the olfactory system in moths and caddisflies. 


\section{CHAPTER 3: MDHns provide a CD to the olfactory system in Manduca sexta INTRODUCTION}

There are two general requirements to identify a novel CD circuit. First, it must be determined that the neurons/pathway is architecturally able to provide information about one or more motor commands to a sensory pathway. Next, it must be determined that sensory system performance to reafferent-like stimuli is dependent on the functionality of the circuit. Chapters 1 and 2 establish an architecture consistent with a CD. To address whether the MDHns function as a CD to the olfactory system, I first recorded from the MDHns and flight motor neurons while driving fictive flight to determine whether MDHn activity was correlated to wing motor output. The primary inputs tofre the MDHns are unknown. They could receive information from the CPG for flight, or walking, from sensory neurons from the wings and legs, or may be getting direct input from motor neurons. The flight generating circuitry is distributed across three areas, the pro-, meso-, and meta-thoracic neuromeres. Sensory afferents innervate these areas so in order to isolate motor activity influence on the MDHns, it was important to perform the recordings in the absence sensory input. Central pattern generators are isolated circuits, which on their own can produce pattern in the absence of sensory input with the application of specific drugs. To drive the CPG, I bath applied the drug chlordimeform $\left(10^{-5} \mathrm{M}\right)$ which is known to induce fictive flight (Vierk et. al., 2009).

Next, to determine the role of the MDHn circuit in affecting olfactory function, I quantified olfactory performance of moths in behavioral assays while blocking histamine receptor function in the AL and compared these animals to matched groups using a double-blind testing protocol (assisted by other authors). We used Pavlovian conditioning to reinforce feeding response in the presence of a conditioned odor. To simulate the reafferent stimuli, we pulsed 
odors at the mean wingbeat frequency after the injection of cimetidine (histamine receptor antagonist) and used a conditioned feeding response as an indication that the moth detected the conditioned odor. By testing across a dilution series, we can then determine if detection or discrimination thresholds are increased, indicating a loss of olfactory acuity.

\section{SUMMARY}

Details of the methods, results, and conclusions are presented in Appendix C and Chapman et. al., 2018. The following is a description of the most important results that were produced by the author of this dissertation.

I was able to obtain intracellular recordings of the MDHns while activating and monitoring the flight motor rhythm and determined that MDHn activity was correlated very closely with the flight motor rhythm during individual bouts of fictive flight. Because of the preparation, and bath application of chlordimeform (octopamine receptor agonist) fictive flight did not always occur in bouts, but rather many times the rhythm began, and never ceased. To determine whether MDHn activity was correlated over longer timescales, I smoothed data over the course of the recording to identify changes in activity that were correlated over longer timescales. I determined that within very short timescales $(<5 \mathrm{~ms})$ correlations between the flight motor rhythm and MDHns were not apparent. This suggests that MDHn activity is not a precise copy of the motor units themselves. However, when I smoothed the data over slightly longer timescales (>25ms) significant cross correlation emerged with wing motor output being offset or lagged by $100 \mathrm{~ms}$. This indicated that on a long timescale MDHn activity increases precede increases in wing motor output, and provides advanced information about imminent wing motor state to the AL. 
Next, we disrupted HA function in the AL by injecting cimetidine (a histamine receptor antagonist) into the AL after a Pavlovian based training paradigm. We examined both detection, and discrimination, two psychophysical measures that are intimately connected. We determined that after disrupting HA function in the AL, it took an order of magnitude higher odor concentration for moths to detect the odor as compared to the saline vehicle group. This suggests that HA function in the AL is important for olfactory acuity. After injecting animals, their discrimination threshold increased by two orders of magnitude. Detection is a prerequisite to discrimination, so it is reasonable to expect moths to discriminate at higher concentrations when HA function was disrupted.

MDHn activity is correlated with the flight motor rhythm on short (bouts of motor activity), and long (minutes) time scales, and disrupting HA function in the AL while simulating the reafferent stimulus disrupts the ability of moths to perform in olfactory based behavioral assays. These two findings represent the two criteria necessary to establish that the MDHns represent a flightolfactory corollary discharge circuit. 


\section{CONCLUSIONS}

\section{Summary of Results}

The primary goal of this dissertation was to describe a novel CD circuit that modulates primary olfactory network function using neuroanatomy, physiology, and behavioral pharmacology and comparative neuroanatomy. There were three components to this dissertation. The first section examined the extent of histamine labeling in the AL that was contributed by the MDHns, and determined that the MDHn circuit differed between larvae and adults. At the time, it was known that all of the histamine in the AL was attributed to neurons posterior in the VNC, however it was not known which of the neurons provided that input. It was previously postulated that the mesothoracic pair of HA neurons provided all of the HA to the AL (Homberg, 1991), however there are histaminergic neurons in the metathoracic and abdominal neuromeres of the pterothoracic ganglion; all of their axons ascend the neck connective and comingle with the MDHns. To determine which neurons provided HA to the AL, I lesioned the connection between the meso- and metathoracic neuromeres and confirmed that the HA labeling in the AL was intact. This suggests that only the MDHns provide HA to the AL. Next, because flying is a trait observable only in adult moths, we considered the hypothesis that if the MDHns were carrying flight related information to the AL, then the circuit would not be present in larval Manduca sexta. I performed histamine labeling and determined that histamine was still present in the LAC. Performing immune-labeling against the Manduca sexta histamine B receptor, and determined that while there was broad expression in the brain, there was no expression within the LAC. This was in striking contrast to the labeling of receptors in the adults, which demonstrated dense receptor labeling throughout the AL. Although the general architecture of the MDHns were intact, the total circuit (including receptor expression) was not complete. This could suggest that the MDHn projection to the AL is near/complete and in preparation for adult specific 
behaviors, such as flight but lacking HA receptor expression, the circuit is incomplete. During metamorphosis, the histamine B receptors are expressed to complete the circuit. Alternatively, histamine A receptors could be expressed in the LAC to complete the circuit, or HA in the LAC binds to other non-canonical receptors, however qPCR in adults revealed an absence of histamine A receptors in the adult antennal lobe. In one additional unpublished experiment, I performed histamine B receptor labeling in several pupal stages. Receptor expression can be seen as early as stage six pupa (Appendix D, Figure 2).

The second section of this dissertation determined that the MDHns olfactory innervation is an adaptation specific to nocturnal moths arguing that it contributes to behavioral challenges unique to species relying on acutely sensitive olfactory systems while flying. I performed immunocytochemistry across a broad range of species and determined that in all moths closely related to Manduca sexta, MDHns innervated the AL. This indicates that MDHns entering the AL is a common architectural feature. Next, I examined butterflies, as they share a recent common ancestor with the macroleipdopteran moths. I determined that the MDHns did not innervate the AL in any of the species of butterflies examined. This suggests that either the MDHn-AL circuit appeared in macrolepidopteran moths, or butterflies had lost this trait. Next, I examined several species of basal moths and one species of caddisfly, that share a more distant common ancestor with both macrolepidopteran moths and butterflies. The MDHns innervated the AL in all of the species observed. This supports the conclusion that butterflies must have lost the trait, which was retained in macrolepidopteran moths. Additionally, as HA in the AL in other taxa have been shown to be from other sources and in many other taxa HA is absent in the AL (Loesel \& Homberg, 1999), it is likely that branches of MDHns were exapted into the olfactory system of caddisflies and moths. Finally, to examine the function of histamine in the VNC, I 
chose increasingly distantly related species. I determined that in ancient arthropods additional pairs of HA neurons were present. Some pairs ascended, while others descended; HA neurons thematically interconnected body segments, and sensory areas of the brain. This suggests that the role of HA in the VNC may be to coordinate sensory motor function across different, possibly many body segments, about ongoing motor commands. Taken together these results provide evidence that the MDHns serve to provide motor information to the olfactory system in moths.

The third section of this dissertation was to provide physiological and behavioral evidence that the MDHns serve as a flight-to-olfactory CD circuit in moths. I recorded from the MDHns intracellularly while simultaneously recording from a motor output nerve. This allowed me to assess the correlation between MDHn firing, and motor output. I discovered that MDHn firing was correlated on short and long timescales, indicating the cells serve as a CD. However, the lack of a precise spiking relationship between the MDHn and the recorded motor output suggests this is not an efference copy per se. Finally, I performed behavior pharmacological studies and determined that disrupting AL HA activity increases detection and discrimination thresholds. Together these results imply that the MDHns function to inform the olfactory system of ongoing motor output.

\section{MDHn Olfactory Mechanisms.}

Wing beating causes a reafferent signal across the antennae (Lemon \& Getz, 1997, Tripathy et. al., 2010), and removal of the wings in Bombyx mori reduces the performance of pheromone induced tracking behavior (Obara, 1979). Furthermore, primary sensory neurons, and output neurons of the AL can track stimuli that simulate wing beating (Lemon \& Getz, 1997; Tripathy et al., 2010). It has also been shown that AL neurons had more distinct odor representations across odors in animals that were presented with pulsed stimuli, rather than a continuous stream 
of odor (Houot et. al., 2014). In some studies, the preparation required severing the VNC, and using an isolated head while performing intracellular PN recordings; these studies observed no PN entrainment to pulsed stimuli beyond $10 \mathrm{~Hz}$ (e.g. Christensen et. al., 1998). Multi-channel recordings conducted by my collaborators, where the VNC was cut, showed a progressive loss of ability to entrain to $20 \mathrm{~Hz}$ over a 30 min period (Chapman et al 2018; Appendix C). They also found that bath applying cimetidine which blocks HA receptor function, reduced the ability of projection neurons to track pulsed stimuli. Finally, they found that bath applying HA increased the ability of projection neurons to track pulsed stimuli (Appendix C). This indicates that HA is modulating the ability of the olfactory system to track the stimulus temporal structure of odorant stimuli. Since wing-beating in Manduca is very stereotypical and rhythmic and produces reafferent signals (Wilmott \& Ellington, 1997, Mishima, \& Kanzaki, 1998), the data presented in Appendix C collectively suggest that MDHn activity may serve to increase olfactory performance during flight.

The data presented in Appendix A show that there are 16 local interneurons in the AL that express inhibitory histamine B receptors, and that these local interneurons are primarily GABAergic. From these data we can argue that the mechanism of modulating pulse tracking is largely disinhibition. How then can the results of the multi-channel recordings be explained? Since the data were analyzed using spike counts, a disinhibition mechanism could help explain this phenomenon. The ability to track pulsed stimuli is a completely intrinsic property of the olfactory system (Christensen \& Hildebrand 1988). This property is produced through GABA mediated inhibition (Tripathy et. al., 2010). Given that MDHns likely synapse onto 16 GABAergic AL LNs and histamine B receptors are chloride channels, it is entirely feasible that these neurons indirectly regulate the gain of the output neurons through disinhibition of the AL 
network (increased firing of MDHns $\rightarrow$ decreased GABA release $\rightarrow$ more spikes in projection neurons, Appendix D Figure 1). It is also feasible that the local interneurons synapse onto other GABAergic neurons, shaping the PN response further. This mechanism can help explain the increased firing rate and temporal precision of PNs observed in the multi-channel recordings. However, to establish the mechanisms by which increases in MDHn activity enhance PN entrainment to temporally structured stimuli, requires identification and characterization of the remaining circuit elements between the $16 \mathrm{LNs}$ and the PNs that are affected, which will be challenging in Manduca sexta because of the limited molecular genetic tools available in the model. Nevertheless, more can be gleaned from this model and studies are underway to determine if an increased pulse tracking ability enhances odor identity coding in projection neurons.

\section{MDHn Inputs in CPG neuropil}

The intracellular recordings performed in Appendix C demonstrate that MDHn activity is correlated with flight motor output in the absence of sensory input due to the extreme nature of the surgery, which required ablation of all sensory input in order to perform these recordings. While a large portion of the volume of the MsG is devoted to the CPG, it is still possible that sensory input could also contribute to MDHn firing patterning. This could make sense, as the dendritic field of the MDHns are very broad, suggesting that MDHns receive information from many sources. One might expect that this CD circuit should display oscillatory activity to each wingbeat. In the absence of sensory input, the central (CPG) driving forces that activate MDHns would be the only observable activation. In the absence of sensory input, or reafference, CPGs have been shown to generate motor patterns that are much slower than the patterns elicited in intact animal behavior, and when sensory input is provided, CPGs physiology resembles 
behavior much more closely (Wallen \& Williams, 1983). Although it is highly speculative, sensory input from the wings could indirectly inhibit MDHns, causing an entirely different spiking pattern. The fact remains, however, that MDHn activity is at least partially dependent on central driving forces directly related to wing motor output. Several experiments are currently underway to describe the areas occupied by wing sensory neurons, and directly relate them to MDHn dendritic anatomy.

\section{MDHns co-opted to facilitate plume tracking}

The results described in Appendix B describe the variation of MDHn axonal arborization in several different species. Considering changes in general architecture between closely related species, and that this circuit appears to have first emerged in caddisflies and moths, this type of evolutionary change is called an exaptation. Exaptation is a process by which features of a biological system are co-opted, or otherwise used in different ways. It is apparent that the lineage of the MDHns can be traced solely by anatomy to very distantly related species, and that their basal architecture did not include the ALs. These neurons were therefore co-opted to serve an olfactory function in species that were nocturnal plume trackers. In butterflies (derived from moths), the co-opted circuit architecture was lost, and we propose that this may have occurred because butterflies do not rely as heavily on olfaction as they do vision as they are day flying, and that their wing biomechanics are very different than those of moths (more stochastic wingbeat). We have subsequently shown that a dayflying sphingid moth Hemaris sp., which is very closely related to Manduca sexta, has also lost this circuit, further strengthening the argument that this circuit emerges to facilitate difficult olfactory challenges for species that rely heavily on olfaction (Appendix D, Figure 3). However, since "flight biomechanics" of each species is nested within "day/night flying”, it could be possible that the changes we observe 
could be due to only the reliance on olfaction, or an interaction between that behavioral ecology, and flight biomechanics.

The data presented regarding very basal species (centipedes and ticks) demonstrate that histamine may play a far more general and fundamental role in coordinating sensory motor function across segments. Centipedes have dozens of legs across many segments. To walk and coordinate these segments, each segment must have information about what other segments of the body are doing. This could potentially explain the ascending and descending nature of histamine neurons in centipedes. The histamine neurons in ticks show dense arborization in neuropils that control all body segments as well as innervate areas that process sensory information. This is interesting because it conforms to the hypothesis that histamine neurons generally interconnect body segments and provide information about ongoing motor patterns.

\section{Future Directions}

Anatomical characterization of possible inputs to the MDHns in Manduca sexta are currently underway. It will be useful to understand which neurons synapse onto the MDHns, however current resources limit this approach in Manduca sexta. Complicating matters, MDHns not only arborize within the AL, but in many other brain structures that have been less well characterized in this model. In Drosophila melanogaster, the MDHns appear to have the same projection patterns as the MDHns in Manduca sexta, except for the projection into the AL (more similar to butterflies). In Drosophila, MDHns appear to project to well characterized sensory processing neuropils such as the AMMC. If we assume that the MDHns in Drosophila provide the same kind of CDC function as in Manduca, how can that same information be used to modulate/coordinate multiple sensory networks as they process self-generated or reafferent stimuli at the same time? With the vast number of genetic tools available in Drosophila 
melanogaster, it is now possible to generate neuron specific lines to probe the function of identified neurons in vivo. The projection pattern of the MDHns changed quite rapidly while butterflies and macrolepidopteran moths were emerging, so it is quite possible that the inputs to the MDHns in Drosophila are different than in Manduca, or that the MDHns do not represent a CD in Drosophila at all, or they might not even be homologous. Therefore, it will be important to first demonstrate CD functionality of the MDHns in Drosophila of non-olfactory sensory networks. There are also several structural differences between the dendritic patterns of the MDHns in Manduca vs Drosophila; the dendrites of Drosophila are constrained primarily to the midline while in Manduca the dendrites radiate further into the mesothoracic neuromere. These key differences may lead to predictions about how identified neurons in the brain may serve several different functional roles, and it is exceedingly important to understand how neurons expand their functionality to target multiple networks. 


\section{References:}

Andersson, M. N., Löfstedt, C., \& Newcomb, R. D. (2015). Insect olfaction and the evolution of receptor tuning. Frontiers in Ecology and Evolution, 3. https://doi.org/10.3389/fevo.2015.00053

Arnegard, M. E., \& Carlson, B. A. (2005). Electric organ discharge patterns during group hunting by a mormyrid fish. Proceedings of the Royal Society B: Biological Sciences, 272(1570), 1305-1314. https://doi.org/10.1098/rspb.2005.3101

Baker, T. C. (1986). Pheromone-modulated movements of flying moths, Mechanisms of Insect Olfaction. 46.

Bastian, J. (1995). Pyramidal-cell plasticity in weakly electric fish: a mechanism for attenuating responses to reafferent electrosensory inputs. Journal of Comparative Physiology A, 176(1), 63-78. https://doi.org/10.1007/BF00197753

Bell, C, C., (1989) Sensory Coding and Corollary Discharge Effects in Mormyrid Electric Fish. The Journal of Experimental Biology, 146, 229-253.

Bell, C. C., Caputi, A., Grant, K., \& Serrier, J. (1993). Storage of a sensory pattern by antiHebbian synaptic plasticity in an electric fish. Proceedings of the National Academy of Sciences, 90(10), 4650-4654. https://doi.org/10.1073/pnas.90.10.4650

Bellardita, C., \& Kiehn, O. (2015). Phenotypic Characterization of Speed-Associated Gait Changes in Mice Reveals Modular Organization of Locomotor Networks. Current Biology, 25(11), 1426-1436. https://doi.org/10.1016/j.cub.2015.04.005

Bradley, S. P., Chapman, P. D., Lizbinski, K. M., Daly, K. C., \& Dacks, A. M. (2016). A Flight Sensory-Motor to Olfactory Processing Circuit in the Moth Manduca sexta. Frontiers in Neural Circuits, 10. https://doi.org/10.3389/fncir.2016.00005

Carey, R. M., \& Wachowiak, M. (2011). Effect of Sniffing on the Temporal Structure of Mitral/Tufted Cell Output from the Olfactory Bulb. Journal of Neuroscience, 31(29), 10615-10626. https://doi.org/10.1523/JNEUROSCI.1805-11.2011

Casaday, G. B., \& Camhi, J. M. (1976). Metamorphosis of flight motor neurons in the mothManduca sexta. Journal of Comparative Physiology? A, 112(2), 143-158. https://doi.org/10.1007/BF00606534

Chapman, P. D., Bradley, S. P., Haught, E. J., Riggs, K. E., Haffar, M. M., Daly, K. C., \& Dacks, A. M. (2017). Co-option of a motor-to-sensory histaminergic circuit correlates with insect flight biomechanics. Proc. R. Soc. B, 284(1859), 20170339. https://doi.org/10.1098/rspb.2017.0339

Chapman, P. D., Burkland, R., Bradley, S. P., Houot, B., Bullman, V., Dacks, A. M., \& Daly, K. 
C. (2018). Flight motor networks modulate primary olfactory processing in the moth Manduca sexta. Proceedings of the National Academy of Sciences, 115(21), 5588-5593. https://doi.org/10.1073/pnas.1722379115

Charlton, R. E., Kanno, H., Collins, R. D., \& Cardé, R. T. (2008). Influence of pheromone concentration and ambient temperature on flight of the gypsy moth, Lymantria dispar (L), in a sustained-flight wind tunnel. Physiological Entomology, 18(4), 349-362. https://doi.org/10.1111/j.1365-3032.1993.tb00608.x

Christensen, T. A., \& Hildebrand, J. G. (1988). Frequency coding by central olfactory neurons in the sphinx moth Manduca sexta. Chemical Senses, 13(1), 123-130. https://doi.org/10.1093/chemse/13.1.123

Christensen, T. A., Waldrop, B. R., \& Hildebrand, J. G. (1998). Multitasking in the Olfactory System: Context-Dependent Responses to Odors Reveal Dual GABA-Regulated Coding Mechanisms in Single Olfactory Projection Neurons, 10.

Crapse, T. B., \& Sommer, M. A. (2009). Frontal Eye Field Neurons with Spatial Representations Predicted by Their Subcortical Input. Journal of Neuroscience, 29(16), 5308-5318. https://doi.org/10.1523/JNEUROSCI.4906-08.2009

Crapse, T. B., \& Sommer, M. A. (2012). Frontal Eye Field Neurons Assess Visual Stability Across Saccades. Journal of Neuroscience, 32(8), 2835-2845. https://doi.org/10.1523/JNEUROSCI.1320-11.2012

Crapse, Trinity B., \& Sommer, M. A. (2008a). Corollary discharge across the animal kingdom. Nature Reviews. Neuroscience, 9(8), 587-600. https://doi.org/10.1038/nrn2457

Crapse, Trinity B., \& Sommer, M. A. (2008b). Corollary discharge circuits in the primate brain. Current Opinion in Neurobiology, 18(6), 552-557. https://doi.org/10.1016/j.conb.2008.09.017

Cullen, K. E. (2004). Sensory signals during active versus passive movement. Current Opinion in Neurobiology, 14(6), 698-706. https://doi.org/10.1016/j.conb.2004.10.002

Dacks, A. M., Christensen, T. A., \& Hildebrand, J. G. (2006). Phylogeny of a serotoninimmunoreactive neuron in the primary olfactory center of the insect brain. Journal of Comparative Neurology, 498(6), 727-746. https://doi.org/10.1002/cne.21076

Daly, K. C., Christensen, T. A., Lei, H., Smith, B. H., \& Hildebrand, J. G. (2004). Learning modulates the ensemble representations for odors in primary olfactory networks. Proceedings of the National Academy of Sciences, 101(28), 10476-10481. https://doi.org/10.1073/pnas.0401902101

Daly, Kevin C., Bradley, S., Chapman, P. D., Staudacher, E. M., Tiede, R., \& Schachtner, J. (2016). Space Takes Time: Concentration Dependent Output Codes from Primary 
Olfactory Networks Rapidly Provide Additional Information at Defined Discrimination Thresholds. Frontiers in Cellular Neuroscience, 9.

https://doi.org/10.3389/fncel.2015.00515

Daly, Kevin C., Kalwar, F., Hatfield, M., Staudacher, E., \& Bradley, S. P. (2013). Odor Detection in Manduca sexta Is Optimized when Odor Stimuli Are Pulsed at a Frequency Matching the Wing Beat during Flight. PLOS ONE, 8(11), e81863. https://doi.org/10.1371/journal.pone.0081863

Fee, M. S., Mitra, P. P., \& Kleinfeld, D. (1997). Central Versus Peripheral Determinants of Patterned Spike Activity in Rat Vibrissa Cortex During Whisking. Journal of Neurophysiology, 78(2), 1144-1149. https://doi.org/10.1152/jn.1997.78.2.1144

Grillner, S., Wallén, P., McClellan, A., Sigvardt, K., Williams, T., \& Feldman, J. (1983). The neural generation of locomotion in the lamprey: an incomplete account. Symposia of the Society for Experimental Biology, 37, 285-303.

Grillner, Sten. (2003). The motor infrastructure: from ion channels to neuronal networks. Nature Reviews Neuroscience, 4(7), 573-586. https://doi.org/10.1038/nrn1137

Guthrie, B., Porter, J., \& Sparks, D. (1983). Corollary discharge provides accurate eye position information to the oculomotor system. Science, 221(4616), 1193-1195. https://doi.org/10.1126/science.6612334

Hammer, M., \& Menzel, R. (1998). Multiple Sites of Associative Odor Learning as Revealed by Local Brain Microinjections of Octopamine in Honeybees. Learning \& Memory, 5, 146156

Harris-Warrick, R. M., \& Marder, E. (1991). Modulation of Neural Networks for Behavior. Annual Review of Neuroscience, 14(1), 39-57. https://doi.org/10.1146/annurev.ne.14.030191.000351

Homberg, U., \& Hildebrand, J. G. (1991). Histamine-immunoreactive neurons in the midbrain and suboesophageal ganglion of the sphinx moth Manduca sexta. Journal of Comparative Neurology, 307(4), 647-657. https://doi.org/10.1002/cne.903070410

Hopkins, C. D. (1980). Evolution of electric communication channels of mormyrids. Behavioral Ecology and Sociobiology, 7(1), 1-13. https://doi.org/10.1007/BF00302513

Hörner, M., Helle, J., \& Schürmann, F.-W. (1996). The distribution of histamineimmunoreactive neurons in the ventral nerve cord of the cricket, Gryllus bimaculatus. Cell and Tissue Research, 286(3), 393-405. https://doi.org/10.1007/s004410050709

Houot, B., Burkland, R., Tripathy, S., \& Daly, K. C. (2014). Antennal lobe representations are optimized when olfactory stimuli are periodically structured to simulate natural wing beat effects. Frontiers in Cellular Neuroscience, 8. https://doi.org/10.3389/fncel.2014.00159 
Jefferis, G. S. X. E., Potter, C. J., Chan, A. M., Marin, E. C., Rohlfing, T., Maurer, C. R., \& Luo, L. (2007). Comprehensive Maps of Drosophila Higher Olfactory Centers: Spatially Segregated Fruit and Pheromone Representation. Cell, 128(6), 1187-1203. https://doi.org/10.1016/j.cell.2007.01.040

Kanzaki, R. (1998). Coordination of wing motion and walking suggests common control of zigzag motor program in a male silkworm moth. Journal of Comparative Physiology A, 182(3), 267-276. https://doi.org/10.1007/s003590050177

Kennedy, J. S. (2008). Zigzagging and casting as a programmed response to wind-borne odour: a review. Physiological Entomology, 8(2), 109-120. https://doi.org/10.1111/j.13653032.1983.tb00340.x

Khan, A. G., Sarangi, M., \& Bhalla, U. S. (2012). Rats track odour trails accurately using a multi-layered strategy with near-optimal sampling. Nature Communications, 3(1). https://doi.org/10.1038/ncomms1712

Kiehn, O. (2006). Locomotor Circuits in the Mammalian Spinal Cord. Annual Review of Neuroscience, 29(1), 279-306. https://doi.org/10.1146/annurev.neuro.29.051605.112910

Koehl, M. a. R. (2006). The Fluid Mechanics of Arthropod Sniffing in Turbulent Odor Plumes. Chemical Senses, 31(2), 93-105. https://doi.org/10.1093/chemse/bjj009

LeMasson, G., Marder, E., Abbott, L. (1993) Activity Dependent Regulation of Conductances in Model Neurons. Science, 259(5103), 1915-1917.

Lemon, W. C., \& Getz, W. M. (1997) Temporal Resolution of General Odor Plumes by Olfactory Sensory Neurons in American Cockroaches. The Journal of Experimental Biology, 200, 1809-1819.

Levine, R. B., \& Truman, J. W. (1985). Dendritic Reorganization of Abdominal Motoneurons during Metamorphosis of the Moth, Manduca sexta'. The Journal of Neuroscience, 5(9), 2424-2431.

Linster, C., \& Devore, S. (2012). Noradrenergic and cholinergic modulation of olfactory bulb sensory processing. Frontiers in Behavioral Neuroscience, 6. https://doi.org/10.3389/fnbeh.2012.00052

Loudon, C., \& Koehl, M. A. R. (2000). Sniffing by a Silkworm Moth. Jounal of Experimental Biology 203, 2977-2990.

Macrides, F., \& Chorover, S. L. (1972). Olfactory Bulb Units: Activity Correlated with Inhalation Cycles and Odor Quality. Science, 175(4017), 84-87. https://doi.org/10.1126/science.175.4017.84 
Marder, E., \& Calabrese, R. L. (1996). Principles of rhythmic motor pattern generation. Physiological Reviews, 76(3), 687-717. https://doi.org/10.1152/physrev.1996.76.3.687

Martin, J. P., Beyerlein, A., Dacks, A. M., Reisenman, C. E., Riffell, J. A., Lei, H., \& Hildebrand, J. G. (2011). The neurobiology of insect olfaction: Sensory processing in a comparative context. Progress in Neurobiology, 95(3), 427-447. https://doi.org/10.1016/j.pneurobio.2011.09.007

Martinez-Conde, S., Macknik, S. L., Troncoso, X. G., \& Dyar, T. A. (2006). Microsaccades Counteract Visual Fading during Fixation. Neuron, 49(2), 297-305. https://doi.org/10.1016/j.neuron.2005.11.033

Meek, J., Grant, K., \& Bell, C. (1999). Structural organization of the mormyrid electrosensory lateral line lobe. Journal of Experimental Biology, 202(10), 1291-1300.

Mishima, T., \& Kanzaki, R. (1998). Coordination of flipflopping neural signals and head turning during pheromone-mediated walking in a male silkworm moth Bombyx mori. Journal of Comparative Physiology A, 183(3), 273-282. https://doi.org/10.1007/s003590050255

Miura, K., Mainen, Z. F., \& Uchida, N. (2012). Odor Representations in Olfactory Cortex: Distributed Rate Coding and Decorrelated Population Activity. Neuron, 74(6), 10871098. https://doi.org/10.1016/j.neuron.2012.04.021

Mwilaria, E. K., Ghatak, C., \& Daly, K. C. (2008). Disruption of GABAA in the Insect Antennal Lobe Generally Increases Odor Detection and Discrimination Thresholds. Chemical Senses, 33(3), 267-281. https://doi.org/10.1093/chemse/bjm085

Nelson, A., Schneider, D. M., Takatoh, J., Sakurai, K., Wang, F., \& Mooney, R. (2013). A Circuit for Motor Cortical Modulation of Auditory Cortical Activity. Journal of Neuroscience, 33(36), 14342-14353. https://doi.org/10.1523/JNEUROSCI.2275-13.2013

Obara, Y. (1979). Bombyx mori Mationg Dance: an Essential in Locationg the Female. Applied Entomology and Zoology, 14(1), 130-132. https://doi.org/10.1303/aez.14.130

Olsen, S. R., \& Wilson, R. I. (2008). Lateral presynaptic inhibition mediates gain control in an olfactory circuit. Nature, 452(7190), 956-960. https://doi.org/10.1038/nature06864

PÄtschke, A., \& Bicker, G. (2011). Development of histamine-immunoreactivity in the Central nervous system of the two locust species Schistocerca gregaria and Locusta migratoria. Microscopy Research and Technique, 74(10), 946-956. https://doi.org/10.1002/jemt.20980

Phelan, P., Bacon, J. P., Davies, J. A., Stebbings, L. A., Todman, M. G., Avery, L., ... Wyman, R. J. (1998). Innexins: a family of invertebrate gap-junction proteins. Trends in Genetics : TIG, 14(9), 348-349. 
Porter, J., Craven, B., Khan, R. M., Chang, S.-J., Kang, I., Judkewitz, B., ... Sobel, N. (2007). Mechanisms of scent-tracking in humans. Nature Neuroscience, 10(1), 27-29. https://doi.org/10.1038/nn1819

Poulet, J. F. A. (2005). Corollary discharge inhibition and audition in the stridulating cricket. Journal of Comparative Physiology A, 191(11), 979-986. https://doi.org/10.1007/s00359$\underline{005-0027-\mathrm{z}}$

Poulet, James F. A., \& Hedwig, B. (2002). A corollary discharge maintains auditory sensitivity during sound production. Nature, 418(6900), 872-876. https://doi.org/10.1038/nature00919

Pytliak, M., Vargová, V., Mechírová, V., \& Felšöci. (2011). Serotonin Receptors - From Molecular Biology to Clinical Applications, Physiol. Res. 60, 15-25.

Richmond, B., \& Wurtz, R. (1980). Vision During Saccadic Eye Movements. II. A Corollary Discharge to Monkey Superior Colliculus. Journal of Neurophysiology, 43(4), 11561167. http://lsr-web.net/Assets/NEIPages/BobWurtz/pdfs/richmondwur80.pdf

Rytz, R., Croset, V., \& Benton, R. (2013). Ionotropic Receptors (IRs): Chemosensory ionotropic glutamate receptors in Drosophila and beyond. Insect Biochemistry and Molecular Biology, 43(9), 888-897. https://doi.org/10.1016/j.ibmb.2013.02.007

Sane, S. P. (2006). Induced airflow in flying insects II. Measurement of induced flow. Journal of Experimental Biology, 209(1), 43-56. https://doi.org/10.1242/jeb.01958

Schneider, D. M., Nelson, A., \& Mooney, R. (2014). A synaptic and circuit basis for corollary discharge in the auditory cortex. Nature, 513(7517), 189-194. https://doi.org/10.1038/nature13724

Schoenfeld, T. A., \& Cleland, T. A. (2005). The anatomical logic of smell. Trends in Neurosciences, 28(11), 620-627. https://doi.org/10.1016/j.tins.2005.09.005

Schroeder, C. E., Wilson, D. A., Radman, T., Scharfman, H., \& Lakatos, P. (2010). Dynamics of Active Sensing and Perceptual Selection. Current Opinion in Neurobiology, 20(2), 172176. https://doi.org/10.1016/j.conb.2010.02.010

Sizemore, T. R., \& Dacks, A. M. (2016). Serotonergic Modulation Differentially Targets Distinct Network Elements within the Antennal Lobe of Drosophila melanogaster. Scientific Reports, 6, 37119. https://doi.org/10.1038/srep37119

Skinner, F. K., Kopell, N., \& Marder, E. (1994). Mechanisms for oscillation and frequency control in reciprocally inhibitory model neural networks. Journal of Computational Neuroscience, 1(1-2), 69-87. https://doi.org/10.1007/BF00962719

Starich, T. A., Xu, J., Skerrett, I. M., Nicholson, B. J., \& Shaw, J. E. (2009). Interactions 
between innexins UNC-7 and UNC-9 mediate electrical synapse specificity in the Caenorhabditis elegans locomotory nervous system. Neural Development, 4, 16. https://doi.org/10.1186/1749-8104-4-16

Stocker, R. F. (2001). Drosophila as a focus in olfactory research: mapping of olfactory sensilla by fine structure, odor specificity, odorant receptor expression, and central connectivity. Microsc. Res. Tech, 284-296.

Straka, H., Simmers, J., \& Chagnaud, B. P. (2018). A New Perspective on Predictive Motor Signaling. Current Biology, 28(5), R232-R243. https://doi.org/10.1016/j.cub.2018.01.033

Suh, E., Bohbot, J., \& Zwiebel, L. J. (2014). Peripheral olfactory signaling in insects. Current Opinion in Insect Science, 6, 86-92. https://doi.org/10.1016/j.cois.2014.10.006

Tissot, M., \& Stocker, R. F. (2000). Metamorphosis in Drosophila and other insects: the fate of neurons throughout the stages. Progress in Neurobiology, 62(1), 89-111. https://doi.org/10.1016/S0301-0082(99)00069-6

Tripathy, S., Staudacher, E. M., Peters, O., Kalwar, F., Hatfield, M., \& Daly, K. (2010). Odors pulsed at wing beat frequencies are tracked by primary olfactory networks and enhance odor detection. Frontiers in Cellular Neuroscience, 4. https://doi.org/10.3389/neuro.03.001.2010

Tunstall, D. N., \& Pollack, G. S. (2005). Temporal and directional processing by an identified interneuron, ON1, compared in cricket species that sing with different tempos. Journal of Comparative Physiology A, 191(4), 363-372. https://doi.org/10.1007/s00359-004-0591-7

Veinante, P., \& Deschênes, M. (2003). Single-cell study of motor cortex projections to the barrel field in rats: Motor Cortex Projections to the Barrel Field. Journal of Comparative Neurology, 464(1), 98-103. https://doi.org/10.1002/cne.10769

Verhagen, J. V., Wesson, D. W., Netoff, T. I., White, J. A., \& Wachowiak, M. (2007). Sniffing controls an adaptive filter of sensory input to the olfactory bulb. Nature Neuroscience, 10(5), 631-639. https://doi.org/10.1038/nn1892

Vierk, R., Pflueger, H. J., \& Duch, C. (2009). Differential effects of octopamine and tyramine on the central pattern generator for Manduca flight. Journal of Comparative Physiology A, 195(3), 265-277. https://doi.org/10.1007/s00359-008-0404-5

Vierk, R., Duch, C., \& Pflüger, H.-J. (2010). Postembryonic development of centrally generated flight motor patterns in the hawkmoth, Manduca sexta. Journal of Comparative Physiology A, 196(1), 37-50. https://doi.org/10.1007/s00359-009-0490-z

Von Der Emde, G. (1999) Active Electrolocation of Objects in Weakly Electric Fish. The Journal of Experimental Biology, 202, 1205-1215. 
Waldrop, B., Christensen, T. A., \& Hildebrand, J. G. (1987). GABA-mediated synaptic inhibition of projection neurons in the antennal lobes of the sphinx moth, $<$ Emphasis Type="Italic" $>$ Manduca sexta $</$ Emphasis $>$. Journal of Comparative Physiology A, 161(1), 23-32. https://doi.org/10.1007/BF00609452

Walker, T. J. (1962). Factors Responsible for Intraspecific Variation in the Calling Songs of Crickets. Evolution, 16(4), 407-428. https://doi.org/10.1111/j.1558-5646.1962.tb03234.x

Wallén, P., \& Williams, T. L. (1984). Fictive locomotion in the lamprey spinal cord in vitro compared with swimming in the intact and spinal animal. The Journal of Physiology, 347(1), 225-239. https://doi.org/10.1113/jphysiol.1984.sp015063

Walsh, R. R. (1956). Single Cell Spike Activity in the Olfactory Bulb. American Journal of Physiology-Legacy Content, 186(2), 255-257. https://doi.org/10.1152/ajplegacy.1956.186.2.255

Wang, F., Nemes, A., Mendelsohn, M., \& Axel, R. (1998). Odorant Receptors Govern the Formation of a Precise Topographic Map. Cell, 93(1), 47-60. https://doi.org/10.1016/S0092-8674(00)81145-9

Willmott, A. P., \& Ellington, C. P. (1997). The Mechanics of Flight in the Hawkmoth Manduca sexta. Journal of Experimental Biology, 200, 2705-2722.

Wurtz, R. H., \& Albano, J. E. (1980). Visual-Motor Function of the Primate Superior Colliculus. Annual Review of Neuroscience, 3(1), 189-226. https://doi.org/10.1146/annurev.ne.03.030180.001201

Wurtz, R., \& Goldberg M. (1972) Activity of Superior Colliculus in Behaving Monkey, III Cells Discharging Before Eye Movements. Journal of Neurophysiology, 35(4), 575-586. http://lsr-web.net/Assets/NEIPages/BobWurtz/pdfs/wurtzgoldberg_III.pdf

Zhong, G., Diaz-Rios, M., \& Harris-Warrick, R. M. (2006). Intrinsic and Functional Differences among Commissural Interneurons during Fictive Locomotion and Serotonergic Modulation in the Neonatal Mouse. Journal of Neuroscience, 26(24), 6509-6517. https://doi.org/10.1523/JNEUROSCI.1410-06.2006

Zhou, M., Liang, F., Xiong, X. R., Li, L., Li, H., Xiao, Z., ... Zhang, L. I. (2014). Scaling down of balanced excitation and inhibition by active behavioral states in auditory cortex. Nature Neuroscience, 17(6), 841-850. https://doi.org/10.1038/nn.3701 


\title{
Appendix A
}

\section{A flight sensory-motor to olfactory processing circuit in the moth Manduca sexta}

\author{
Samual P. Bradley*, Phillip D. Chapman, Kristyn M. Lizbinski, Kevin C. Daly\#, Andrew M.
} Dacks ${ }^{\#}$

West Virginia University, Department of Biology, Morgantown, West Virginia United States of America

\begin{abstract}
Neural circuits projecting information from motor to sensory pathways are common across sensory domains. These circuits typically modify sensory function as a result of motor pattern activation; this is particularly so in cases where the resultant behavior affects the sensory experience or its processing. However, such circuits have not been observed projecting to an olfactory pathway in any species despite well characterized active sampling behaviors that produce reafferent mechanical stimuli, such as sniffing in mammals and wing beating in the moth Manduca sexta. In this study we characterize a circuit that connects a flight sensory-motor center to an olfactory center in Manduca. This circuit consists of a single pair of histamine immunoreactive (HA-ir) neurons that project from the mesothoracic ganglion to innervate a subset of ventral antennal lobe (AL) glomeruli. Furthermore, within the AL we show that the Manduca sexta histamine B receptor (MsHisClB) is exclusively expressed by a subset of GABAergic and peptidergic LNs, which broadly project to all olfactory glomeruli. Finally, the HA-ir cell pair is present in fifth stage instar larvae; however, the absence of MsHisClB-ir in the LAC indicates that the circuit is incomplete prior to metamorphosis and importantly prior to the expression of flight behavior. Although the functional consequences of this circuit remain unknown, these results provide the first detailed
\end{abstract}


description of a circuit that interconnects an olfactory system with motor centers driving flight behaviors including odor-guided flight.

\section{INTRODUCTION}

Animals exhibit stereotypical search behaviors in pursuit of potential food sources or mating partners. More specifically, some animals employ sampling strategies where rhythmic motor patterns optimize the interaction between stimuli and their affected sensory systems. Consequently, many of these motor systems project to and modulate how sensory systems process this information. For example, saccadic eye movements allow us to focus on objects despite having a fast adapting visual system (Martinez-Conde et al., 2006). Here the neural circuits driving these small movements also send a signal canceling the perception of a moving scene, therefore affording proper behavioral responses to other stimuli in the environment (Zaretsky and Rowell, 1979; Ross et al., 2001). Other motor to sensory circuits have been shown to amplify self-induced communication signals (Mohr et al., 2003), inhibit reflex responses (Chalfie et al., 1985) and are involved in sensory/motor planning (Sommer and Wurtz, 2002; Brainard and Doupe, 2000). While work in other sensory systems have made significant progress in characterizing motor to sensory circuits (Crapse and Sommer, 2014), it is not clear whether such circuits are present in the olfactory system.

When tracking odors, animals typically exhibit behaviors, such as sniffing, that periodically structure olfactory stimuli (Halpern, 1983). Each sniff cycle draws odor-laden air into the nasal cavity during inhalation and forces air out during exhalation, thus imposing a temporal structure on air/olfactory receptor interactions that persists in the absence of odor (Adrian, 1942; Kepecs et al., 2007). In this manner, sniffing couples reafferent mechanical stimuli with odor stimuli resulting in a temporally structured stimulus that improves physiological (Verhagen et al., 
2007), and presumably behavioral performance. In the moth Manduca sexta, wing beating causes high frequency oscillations in airflow over the antennae in a manner analogous to sniffing (Sane and Jacobson, 2006). These periodic signals have a potentially strong effect on odor-receptor interactions in moths (Loudon et al., 1994; Loudon and Koehl, 2000) and are effectively tracked by antennal and antennal lobe (AL) neurons (Tripathy et al., 2010). This implies that at least part of the temporal structure of encoding neuron activity is driven by time-dependent fluctuations in stimulus concentration (Christensen et al., 1998; Daly et al., 2011), driven by wing-beating. Simulating wing-beating effects on odor exposure by pulsing odor stimuli at wing beat frequencies increases separation of neural ensemble representations for different odors (Houot et al., 2014) and enhances behavioral performance in psychophysical assays of olfactory acuity (Tripathy et al., 2010; Daly et al., 2013). While AL neurons can track pulsed stimuli when the neck connective is intact (Houot et al., 2014), AL neurons are unable to do so when using isolated head preparations (Tripathy et al., 2010; Christensen et al., 1998). This suggests that the AL receives input from flight sensorimotor centers that affects the temporal fidelity with which the AL encodes odors (Christensen et al., 1998; Tripathy et al., 2010). However, relatively little is known about neural circuits connecting flight sensory-motor centers and the AL.

There is limited data describing input from flight sensory-motor centers to the ALs of Manduca. This circuit consists of a single pair of histamine (HA) immunoreactive neurons that project from the mesothoracic ganglion (MsG) and bilaterally innervate both ALs and the antennal mechanosensory and motor center (AMMC; Homberg, 1994). The purpose of this study was to provide a detailed morphological description of these mesothoracic to deutocerebral histaminergic neurons (MDHn) and to identify candidate post synaptic targets. Using immunohistochemistry, we found that the MDHns ramify in a subset of ventral glomeruli in the AL, the AL isthmus, and 
the coarse neuropil. A subset of GABAergic LNs along with one FMRFamide-ir and one allatotropin-ir (ATR-ir) local interneuron express the Manduca homologue of the histamine B receptor subtype (MsHisClB) and thus represent candidate postsynaptic targets of the MDHns. Furthermore, although the MDHns are present in larvae and survive metamorphosis there is no expression of the MsHisClB receptor in larval antennal center (LAC) neurons until after pupation has occurred, suggesting the MDHns only affect olfactory processing in adults. The MDHns therefore represent a novel circuit that provides a potential source of information from a flight sensory-motor integration system to the olfactory system.

\section{MATERIALS AND METHODS}

\section{Animals}

Animals were raised using a standard diet (Bell and Joachim, 1976) and rearing procedures (Tripathy et al., 2010). Adult moths were kept in brown paper bags and placed in an incubator (Percival Scientific Inc.; 166VLC8) where they were exposed to a 16/8 reverse light dark cycle set to $25^{\circ} \mathrm{C}$ and $75 \%$ humidity. Approximately 10 male or female moths aged 3-9 days were used for all experimental groups. For larval studies, stage 5 instar larvae were dissected with trachea removed. Ten larval nervous systems were used for developmental experiments.

\section{Immunohistochemistry}

Immunolabeling was performed as described previously (Dacks et al., 2010) on both sectioned and whole-mount brains depending upon the preparation. For HA immunolabeling, brains were placed in a 4\% N-3-dimethylaminopropyl-N'-ethylcarbodiimide (Sigma Aldrich, 03449) pre-fixative for $3-4$ hours at $4^{\circ} \mathrm{C}$, before being fixed overnight in $4 \%$ paraformaldehyde (Electron Microscope Sciences, 15710) in 1\% phosphate buffered saline (PBS; Sigma Aldrich, SLBC5890) at $4^{\circ} \mathrm{C}$. For the MsHisClB antibody, brains were placed in $4 \%$ paraformaldehyde 
(Electron Microscopy Sciences, 15710; $\mathrm{pH}$ 7.3-7.5) at $4^{\circ} \mathrm{C}$ overnight. Following fixation, brains were washed in PBS (pH 6.9). For sectioned tissue, adult brains and ganglia were embedded in 5\% agarose (Sigma Aldrich, SLBJ3744V) and sectioned between 50 and $250 \mu \mathrm{m}$ (depending on the antibody) using a Leica VT 1000S vibrating microtome. The tissue was washed in PBS with 0.5\% Triton ${ }^{\mathrm{TM}}-\mathrm{X} 100$ (PBST; Sigma Aldrich, 110M0009V), blocked for 1 hour with 2\% IgG-free bovine serum albumin (BSA; Jackson Laboratory, 001-000-162) and incubated in primary antibody in blocking solution with 5mM with sodium azide (PBSAT; Fisher Scientific, S2271). Brains were washed and blocked as above, then incubated in secondary antibody (1:1000 Alexa 488, 546, or 633 in PBSAT; Alexa fluor ${ }^{\circledR}$; Lifescience Technologies) overnight at room temperature except for experiments using MsHisClB and/or GABA in which tissue was incubated at $4^{\circ} \mathrm{C}$. SYTO 59 (a nuclear label; Invitrogen ${ }^{\mathrm{TM}}$; S11341) was used to outline the LAC. Tissue was washed several times in Tris Buffered Saline (TBS; Bio-Rad, 170-6435) and the tissue was incubated in 1:10,000 SYTO 59 in Tris-HCl (Fisher Scientific, BP153 for 60 minutes before mounting. All tissue was washed in PBST and PBS, then run through an ascending glycerol (Sigma Aldrich, BCBN3647V) series (40\%, 60\% and 80\%) and mounted in Vectashield ${ }^{\circledR}$ (Vector laboratories, ZA1222). For whole-mount preparations, tissue was run through an ascending ethanol (Sigma Aldrich, SHBF6704V) dilution series (30\%, 50\%, 70\%, 95\%, and 100\%) for 10 minutes each (after the PBS wash), a 1:1 ethanol methyl salicylate solution for 15 minutes, and finally mounted in 100\% methyl salicylate (Fisher Scientific, MFCD00002214). All primary antibody information (including dilutions used, manufacturer, host-species, immunogen and RRID) is included in Table 1.

\section{Antibody Manufacturing and Characterization}

Rabbit anti-histamine 
The HA antiserum was raised against synthetic HA conjugated via a carbodiimide linker to succinylated keyhole limpet hemocyanin. Control studies showed that the antibody had no cross reactivity with L-histidine or L-histidine containing peptides, and pre-adsorbing the antiserum with the HA conjugate eliminates labeling (Immunostar histochemical histamine antiserum specification sheet) as did an RNAi knock down of histidine decarboxylase in Drosophila (Melzig

et al., 1996). Finally, pre-adsorbing the HA antiserum against keyhole limpet hemocyanin alone did not eliminate HA labeling in Bombus impatiens (Dacks et al., 2010). Pre-adsorption controls in Manduca tissue were performed by incubating the rabbit anti-HA antiserum for 24hrs in blocking solution (1mg/ml BSA in PBSAT) with HA (Sigma Aldrich, H7250) at a ratio of 10:1 HA:antiserum. Non-pre-adsorbed controls in which rabbit anti-HA antibody was incubated in parallel under identical conditions resulted in immunolabeling (Fig. 1A) whereas preadsorbing the antibodyabolished all staining in Manduca AL tissue (Fig. 1B)..

\section{Mouse anti-bruchpilot}

Bruchpilot (Brp) is homologous to the protein ELKS/CAST in mammals and functions as a structural protein at presynaptic active zones (Wagh et al., 2006). The Brp antiserum was raised against Brp and western blots showed two bands for two isoforms of the Brp protein in Drosophila (Wagh et al., 2006). Brp labeling was absent in Brp mutants (Kittel et al., 2006) and has been shown to bind to amino acid sequence 1390-1740 (Fouquet et al., 2009). The Brp antiserum produced a single band at the predicted weight for the Manduca homologue of Brp in western blots using Manduca brain tissue (Lizbinski, et al., In Press). The purpose of using the anti-Brp antibody in this study was to highlight the boundaries of neuropil, rather than to make any conclusions about the distribution of the Manduca homolog of Brp.

\section{Mouse anti-GABA}


GABA antiserum was raised against GABA coupled to BSA with glutaraldehyde. Controls show that the antibody was highly specific to GABA and did not react with other amino acid BSA conjugates (Abcam data sheet). Pre-adsorption controls were performed by incubating the mouse anti-GABA antiserum for $24 \mathrm{hrs}$ in blocking solution $(1 \mathrm{mg} / \mathrm{ml}$ BSA in PBSAT) with GABA (Sigma Aldrich, cat \# A2129) at a ratio of 10:1 GABA:antiserum. Non-pre-adsorbed controls in which mouse anti-GABA antibody was incubated in parallel under identical conditions resulted in strong immunolabeling (Fig. 1C) whereas preadsorbing the antibody abolished all staining in Manduca AL tissue (Fig. 1D)..

\section{Rabbit anti-FMRFamide}

FMRFamide antiserum was provided by Dr. Eve Marder and was raised against synthetic RF-amide coupled to bovine thyroglobulin with glutaraldehyde (Marder et al., 1987). Preadsorbing the antiserum against synthetic FMRFamide eliminated labeling in larval Manduca nervous tissue (Witten and Truman, 1996).

\section{Rabbit anti-allatotropin}

Allatotropin (ATR) antiserum was provided by Dr. Jan Veenstra and raised against purified ATR coupled to thyroglobulin using glutaraldehyde (Veenstra and Hagedorn, 1993). ELISA did not show cross reactivity with 100 pmol corazonin, vasopressin, leucokinin IV, or proctolin, but did show significant immunoreacitivity to the truncated 6-13 analogue of Manduca ATR (Veenstra and Hagedorn, 1993). Preadsorbing the antiserum against ATR eliminated immunolabeling in Manduca tissue (Utz et al., 2007).

Rabbit anti-MsHisClB 
To determine the amino acid sequence of the Manduca homologue of the HA B-type receptor (MsHisClB), we used the Manduca genome (Agricultural Pest Genomics Resource Database: (www.agripestbase.org) to perform a forward protein BLAST analysis of the Drosophila melanogaster histamine B-type receptor (HisClB) amino acid sequence (ACA13298.1). The top match from the Manduca genome had an e-value of 0.0 (Msex2.04603RA). We then reverse blasted this sequence from the Manduca genome into the Drosophila genome in NCBI and the first 3 matches were Drosophila HisClB isoforms (NP_650116.2, NP_731632.1 and NP_001163591.1), all of which had e-values of 0.0. The next highest match from the Drosophila genome was the HisClA receptor (otherwise known as "ora transientless"; NP_524406.1) which is the other of the two histamine receptor types in Drosophila (Zheng et al. 2002) and had e-values of 3e-148 which is consistent with both histamine receptor types having high sequence homology (Zheng et al. 2002; Jones et al 2010). To ensure that there were not two predicted amino acid sequences from the Manduca genome with high sequence homology to the Drosophila HisClB receptor, we took the amino acid sequence from the Manduca genome with the second highest e-value for the Drosophila MsHisClB (Msex2.04216-RA; e-value = 1e-119) and ran a BLAST analysis of this sequence in the Drosophila genome. The BLAST analysis resulted in an e-value of 7.37e-158 for the Drosophila ora transientless indicating that the Manduca protein with the next closest sequence similarity to Drosophila HisClA was likely not the MsHisClB homologue. Figure $1 \mathrm{E}$ is a sequence alignment of the Manduca HisClB receptor (MsHisClB) with the sequences for known histamine B receptors from Drosophila melanogaster (ACA13298.1), Apis meliferia (ABG75740.1), and Nasonia vitripennis (ACZ51422.1) (Jones et al., 2010) using the EMBL-EBI Clustal omega tool (Sievers et al., 2011; http://www.ebi.ac.uk/Tools/msa/clustalo/). 
Custom affinity purified antibodies were generated in rabbit (Bethyl laboratories) using Cys-VNPDIELPQLD as the immunogenic sequence. The immunogenic sequence was highly conserved across D. melanogaster, A. mellifera and N. vitripennis (Fig. 1E). For western blots, adult brains were placed in Bolt ${ }^{\mathrm{TM}}$ LDS Sample Buffer (Life Technologies, B0007, Life Technologies) with protease inhibitor cocktail (Research Products International, P50900) and DNase I (Invitrogen, 18068-015) and kept on ice for homogenization with a pestle. Samples were heated in a water bath for 10 minutes at $95^{\circ} \mathrm{C}$. We used the Novex ${ }^{\circledR}$ Bolt ${ }^{\mathrm{TM}}$ Gel Electrophoresis System (Life Technologies) with Tris-Glycine SDS Running Buffer at 165V for 2.5 hours and Bolt $^{\mathrm{TM}}$ 4-12\% Bis-Tris Plus Precast Gels (BG04120BOX) to resolve proteins. We used the iBlot ${ }^{\circledR}$ Gel Transfer Device (Life Technologies, IB1001) program P0 (20 V for 1 min, 23 V for 4 min, 25 $\mathrm{V}$ for $2 \mathrm{~min}$ ) to transfer proteins to nitrocellulose membranes (nitrocellulose iBlot ${ }^{\circledR}$ Transfer Stacks, Life Technologies, IB3010-01). The WesternBreeze ${ }^{\circledR}$ Chromogenic Western Blot Immunodetection Kit (WB7105, anti-rabbit) protocol was used to detect proteins. Images of membranes were taken with FluorChem Q using Alpha View Analysis Software. The amino acid sequence of the MsHisClB receptor has a predicted molecular weight of 36kDa (ExPASy Bioinformatics Resource Portal: http://web.expasy.org/compute_pi/) and the western blot resulted in a single band at the predicted molecular weight of 36kDa (Fig. 1F). Histamine is the primary neurotransmitter of arthropod photoreceptors (Hardie, 1989; Stuart, 1999) and the HisClB receptor is expressed by glial cells in the lamina of Drosophila (Pantazis et al., 2008). Consistent with this, we observed a band of MsHisClB labeling in the lamina (Fig. 1G). Pre-adsorbing the MsHisClB antibody in a 10:1 antigenic peptide to antibody solution eliminated all labeling (Figure 1H). Preadsorption controls were run concurrently with samples incubated in antibody that had not been pre-absorbed with the antigenic peptide (Fig. 1G), but otherwise treated identically. 


\section{Direct fluorescent tagging of primary antibodies}

Both neuropeptide antibodies (anti-FMRFamide and anti-ATR) and the MsHisClB receptor antibody were produced in rabbit hosts. Therefore, to double label using the neuropeptides and the rabbit anti-MsHisClB antibodies we directly fluorescently tagged each primary antibody using the APEX antibody labeling kit (Life Technologies, A10468 488, A10475 for 647) (Woo et al., 2010). This method covalently bonds the IgG antibody to a fluorescent label, and therefore eliminates cross reactivity of secondary antibodies with primary antibodies raised in the same animal. To remove contaminants, the labeling tip was hydrated with $100 \mathrm{uL}$ of wash buffer to which 10-20 ug of IgG antibody is added and eluted with a syringe: $10 \mathrm{uL}$ of MsHisClB, and $1 \mathrm{uL}$ of both FMRFamide and ATR antibody respectively. This solution was then combined with reactive dye (either Alexa 488 or Alexa 647) containing 2uL of DMSO and $18 \mathrm{uL}$ of labeling buffer. This solution then incubated for 2 hours at room temperature. The solution was washed with $50 \mathrm{uL}$ of buffer and eluted through the tip. Finally, $40 \mathrm{uL}$ of elution buffer is eluted through the tip and mixed with $10 \mathrm{uL}$ of neutralization buffer to yield a final volume of $\sim 50 \mathrm{uL}$ of solution. This solution was then diluted in $350 \mathrm{uL}$ of PBSAT and tissue was incubated for 48 hours at $4^{\circ} \mathrm{C}$.

\section{Retrograde dye fills of AL PN output tracks}

Two to three day old moths were restrained with dental wax and the head capsule was opened. Once opened, dextran-Texas Red dye (ThermoFisher, D-1863) was injected into either the mushroom bodies or lateral horn (the two projection fields of AL PNs). Animals were kept alive for 2-3 days post injection and were fed sugar water to ensure that they survived. After 2-3 days, animals were sacrificed and ran through the HA staining protocol described above. 


\section{Ablation Studies}

To definitively demonstrate that the MDHns are the sole source of HA to the AL, lesion experiments were performed to ablate ascending HA-ir fibers from the MDHns or more posterior HA-ir neurons in the metathoracic and abdominal ganglia. At 1-3 days post-eclosion the connective between the sub-esophageal zone (SEZ) and the prothoracic ganglion was lesioned to destroy all ascending input to the brain from the thoracic and abdominal ganglia (including the MDHns; see dashed line in Fig. 2D) or the divide between the mesothoracic and metathoracic ganglia was cut to destroy all ascending cells posterior to the mesothoracic ganglia (MsG; including pairs of HA cells in the metathoracic ganglia and the first two abdominal ganglia; see dashed line between the MsG and the MtG in Fig. 2F). Moths were fed sugar water each day following the ablation to increase survival rates. After 8 days, the brains were dissected for immunolabeling for HA-ir and brp-ir. For the ablation of the connective between the prothoracic ganglion and SEZ we used 6 moths in which we cut the connective between the prothoracic ganglion and the SEZ and 6 sham operated moths. Successful ablation was verified by a lack of HA-ir in the remnants of the connective, while sham ablation (when the connective was not cut) was verified by the presence of HA-ir in the remnants of the connective. For the ablation of the boundary between the mesothoracic and metathoracic ganglia, successful ablation was verified by a lack of HA-ir fibers in the mesothoracic ganglion that originate from the more posterior ganglia. In 10 moths, 2 moths resulted in the successful elimination of the ascending fibers from the metathoracic ganglion, but this did not result in loss of HA-ir in the AL. 


\section{Confocal Microscopy}

Optical stacks were acquired using an Olympus Fluoview FV 1000 confocal microscope. All scans were taken with either a $20 \mathrm{X}$ or $40 \mathrm{X}$ oil lens. Confocal planes were stacked with optimized step sizes for the given objective (1.79 um for 20X and $0.54 \mathrm{um}$ for $40 \mathrm{X}$ ) in the Fluoview viewer software (FV10-ASW Version 04.00.02.09). All images were scanned at either 512x512 or 1024x1024 pixel resolution. Cell body counts and size measurements were performed in Fluoview. Corel Draw (Version 13.0.0.576) was used to organize figures. Vaa3D (Peng et al., 2010) was used to generate 3D reconstructions of confocal stacks that could be rotated to resolve the degree to which structures physically overlap.

\section{RESULTS}

\section{Two HA immunoreactive cells project from the MsG to the AL}

Although motor-to-sensory circuits have been extensively characterized in many sensory systems, there is a dearth of detailed descriptions of input from motor to olfactory centers. The purpose of this study was to extensively characterize the structure, candidate targets and development of a motor-to-olfactory circuit. In Manduca a pair of HA-ir cells (the MDHns) project from the MsG to the AL (Homberg, 1994). However, there is very little known about the fine morphological details of MDHns in either the MsG or the AL. Furthermore, nothing is known about the potential targets of the MDHns or their development through metamorphosis. Figure 2 shows the MDHns in the nervous system including the brain (Fig. 2A), entering the AL (Fig. 2B), entering the SEZ from the neck connective (Fig. 2C), in the neck connective (Fig. 2D), in the prothoracic ganglion (Fig. 2E), and in the MsG (Fig. 2F; n=54).

The large MDHn cell bodies ( $\sim 60 \mu \mathrm{m}$ in diameter) are located on the ventral surface of the MsG (Fig. 3A) near the intersection of the sagittal and coronal midlines, and extend large primary 
neurites to the dorsal MsG (Fig. 3A; n=30). In the dorsal MsG, the MDHns produce a radial planar sheet of processes, with occasional sparse innervation of the ventral MsG (Fig. 3B). Each MDHn extends a single axon ipsilaterally through the prothoracic ganglion and SEZ (Fig. 2E, 3A, 3B), and bilaterally arborizes in the ventral AL (Fig. 2A; 4A). To determine the extent to which the MDHns innervate the AL, we used the BRP antibody to delineate glomerular boundaries and immuno-labeled for HA. Varicose HA-ir processes extensively innervate a subset of ventral posterior glomeruli (Fig. 4A,B; n=21) and extend sparsely into the ventral posterior coarse neuropil of the AL. Reconstructing and rotating the confocal image stack confirms that the HA-ir processes both encapsulate and innervate the glomeruli (Fig. 4C,D).

In addition to the MDHns, HA-ir neurons in the metathoracic and first abdominal ganglia (Fig. 2F) extend processes to the brain via the cervicothoracic connectives. The processes of these HA-ir from other ganglia intertwine with those from the MDHn in the prothoracic ganglia (Fig. 2E), making it difficult to definitively ascribe the HA-ir processes in the AL as belonging exclusively to the MDHns. Furthermore, there are 20 pairs of HA-ir neurons in the SEZ and protocerebrum of Manduca (Homberg and Hildebrand, 1991). To demonstrate that the HA-ir processes in the AL originate from the MDHns, we performed two ablation experiments (Fig. 4E,F). In the first experiment, we cut the cervicothoracic connective between the prothoracic ganglion and brain in adult moths and kept the moths alive for 8 days. This protocol eliminates HA-ir processes arising from cells in the thoracic and abdominal ganglia (including the MDHns), but leaves the processes from other HA-ir neurons in the brain intact. Ablation of thoracic and abdominal sources of HA-ir was confirmed via elimination of HA-ir entering the ventral SEZ. Ablating the cervicothoracic connective eliminates all HA-ir in the AL (Fig. 4E) indicating that the HA-ir processes in the AL originate from the ventral nerve cord, posterior to the cut site. It is 
possible that cutting the cervicothoracic connectives indirectly affects other HA-ir neurons in the brain, which might contribute to AL HA-ir processes we observe. However, we find no evidence to support this notion. In the second ablation experiment, we lesioned the thoracic ganglia at the boundary between the metathoracic ganglion and MsG. This ablates all ascending HA-ir processes posterior to the MDHns (i.e. the HA-ir cells in the metathoracic and abdominal ganglia) but leaves MDHn processes intact. These experiments show that after ablating the cells posterior to the MDHns that there is still HA-ir in the AL (Fig. 4F). Together these experiments suggest that the MDHns are the exclusive source of the HA-ir processes in the AL.

\section{The MsHisCIB receptor is expressed in a subset of GABAergic LNs, one FMRFaminergic LN and one allatotropinergic $\mathbf{L N}$.}

To determine the candidate targets of the MDHns, antibodies were generated against the Manduca homolog of the HA B-type receptor (MsHisClB; Fig. 1 and see Methods). Insects possess two HA receptor types, HisClA and HisClB (Gisselman et al., 2002; Zheng et al., 2002), both of which are ligand-gated chloride channels (McClintock and Ache, 1989; Hardie, 1989). Each receptor is homomeric with two genes coding for the two subunits HisCl- $\alpha 1$ and HisCl- $\alpha 2$ (Gisselmann et al., 2001). These receptors are members of the large cys-bridge superfamily of ligand-gated ion channels comprised of four transmembrane domains (Gisselmann et al., 2001). The MsHisCIB antibody produces extensive labeling in the lamina of the optic lobes of Manduca where histaminergic photoreceptors terminate (Fig. 1G) which is consistent with HisClB receptor expression by glial cells in the lamina of Drosophila (Pantazis et al., 2008). Within the AL, MsHisClB-ir was observed in every glomerulus, which was surprising as the MDH neurons only innervate a set of ventral glomeruli. The MsHisClB antibody produces only a single band in western blots at the predicted height for the MsHisClB receptor (Fig. 1F; $\mathrm{n}=5$ ) and all labeling is 
eliminated by pre-adsorption with the immunogenic sequence (Fig. 1G,H; $\mathrm{n}=6$ ), making it unlikely that this antibody is labeling additional proteins. It is however, possible that the MsHisClB-ir reflects distribution of the MsHisClB receptor during transport throughout the cell as opposed to distribution of the receptor at functional synapses.

In the AL we observed 11 ( \pm 0.81 SEM, from 3 moths) and 9.3 ( \pm 0.43 SEM, from 3 moths) MsHisClB-ir cell bodies in males and females, respectively, in the lateral cell cluster (Fig. 5A). The sex differences observed may be due to neurons that project to the macroglomerular complex in males, as we see widespread labeling therein (Fig. 5A). We observed two classes of MsHisClB labeled cells differing in cell body size. In each AL there were 1-2 larger MsHisClB-ir cells (23.98 um \pm 0.73 SEM diameter; $\mathrm{n}=10$ ) with the remainder having smaller cell bodies (14.79 um \pm 0.52 SEM diameter; $\mathrm{n}=10$ ). LN cell bodies are found only in the lateral cell cluster and fall within in two populations based on cell body size being either $\sim 12$ ums or $\sim 20$ ums in diameter (Hoskins et al., 1986) whereas we calculate an average PN cell body size of 8.16 um ( \pm 0.16 SEM) from our retrogradely filled PNs, thus the size of MsHisClB-ir cell bodies is consistent with LNs. Furthermore, we do not observe any MsHisClB-ir processes within any of the AL output tracts (Fig. S1A) and there are no HA-ir processes innervating any of the AL output tracts (Fig. S1B). The MsHisClB-ir neurons collectively branch in every glomerulus (Fig. 5A; n=37), again consistent with the MsHisClB receptor being expressed by LNs, rather than PNs. To further functionally characterize these MsHisClB-ir cells, we co-labeled for several transmitters, including GABA (Hoskins et al., 1986), FMRFamide (Homberg et al., 1990), and ATR (Utz et al., 2006). All but one MsHisClB-ir labeled neuron was GABA-ir (Fig. 5B; n=19) with one cell co-labeled for MsHisClB and FMRFamide and one cell co-labeled for MsHisClB and ATR (Fig. 5E,H respectively; $n=5,10$, respectively). Together these results suggest that any influence of the 
MDHns on AL processing is exerted via a population of GABAergic and peptidergic LNs. The expression of the MsHisClB receptor by AL neurons and the MDHn being the sole source of HAir in the AL suggests that the MDH neurons provide some form of input to the AL. This does not, however, imply that the MDH neurons do not also provide input to circuitry within the MsG. MsHisClB receptor is also expressed within the MsG (S2), however both the MDHns and HA-ir neurons from the metathoracic and abdominal ganglion (Fig. 2F) innervate the MsG, suggesting that HA also plays a role in network function within the MsG.

\section{MDHns survive metamorphosis but the LAC lacks MsHisClB expression.}

There are many neurons that survive metamorphosis, often being repurposed to take on new tasks to match the dramatic changes in behavioral demands between the larval and adult life stage. In Manduca, motor neurons survive metamorphosis, but their morphology and biophysical properties are altered dramatically to allow them to take on life-stage specific tasks, for instance, transitioning from participating in walking motor programs as larvae to flying motor programs as adults (Duch and Levine 2000). Given that odor-guided flight is an adult specific behavior, we predicted that the MDHns would either not be present or the MsHisClB-ir would not be expressed in the LAC. Similar to adults (see Fig. 3A), fifth instar larvae have a pair of large HA-ir cells in the MsG that ascend to the brain (Fig. 6A). As in adults, the cell bodies are also located ventrally near the intersection of the sagittal and horizontal midlines of the MsG, with a single axon ipsilaterally projecting up each connective. Furthermore, the HA-ir processes also radiate in all directions in the dorsal MsG as in the adult. Because the LAC does not express BRP-ir, we used Syto-59 to label the nuclei of cell bodies that surround the LAC (Fig. 6B,C) as a means of highlighting the boundaries of this brain region. In the larval brain, HA-ir is most abundant in the tritocerebrum (Fig. 6B; dash line) just ventral and lateral to the larval LAC (small dotted line) with 
a small amount of HA-ir entering the LAC. This suggests that the MDHns are present and project to the olfactory system of larval Manduca. However, there are no MsHisClB-ir neurons within the LAC, despite the presence of MsHisClB-ir collaterals in the tritocerebrum (Fig. 6C). This suggests that while the MDHns provide sparse innervation of the LAC, they likely do not play a functional role in the larval olfactory system, at least via the MsHisClB receptor, although it is possible that the MsHisClA receptor is expressed there. What role this circuit would play in the larval olfactory system is not clear as the larva do not fly, but there could be information about

\section{DISCUSSION}

Animals use a variety of behavioral strategies to optimize internal representations of the external world, including repetitive motor patterns that alter stimulus structure. Nervous systems have concurrently evolved circuits that provide information to sensory systems about impending behaviors that will affect sensory input. Although this has been well-documented in many sensory systems, very little is known about neural circuits projecting from neural centers governing odorguided behaviors to olfactory networks. The goal of this study was to characterize a novel sensorymotor to olfactory circuit that projects from flight sensory-motor centers to the primary olfactory processing center in insects. We found that the MDH circuit provides the only source of HA to the AL and affects a small but diverse population of widely projecting LNs in adult Manduca (Fig. 7). Our data suggest that the MDHns provide histaminergic inhibitory input to the AL that could modify olfactory processing within the context of flight or other MsG mediated activity.

The MDHn processes project laterally across the MsG (Fig. 3A), yet are most dense in the dorsal MsG (Fig. 3B), suggesting that while they may integrate information from both sides of the animal, they are likely to interact with cells that are restricted to the dorsal aspect of the MsG. The MsG contains wing and leg motor neurons, sensory afferents, CPG components and modulatory 
neurons some of which occupy specific MsG regions. The dendritic fields of wing elevator and depressor motor neurons are located in the dorsal region of the MsG in Manduca (Rind, 1983) whereas most of the sensory afferents from the wings are localized in both the dorsal and ventral MsG in a closely related species of hawkmoth, Agrius convolvuli (Ando et al., 2011). In addition, there are a population of non-spiking, GABAergic local interneurons that project to the dorsal side of the MsG of the locust (Watson and Burrows 1987), and populations of octopaminergic (Stevenson et al. 1992), serotonergic and dopaminergic neurons (Claassen and Kammer, 1986) that project throughout the MsG. The extensive branching of the MDHns in the MsG suggests that these neurons interact with one or more components of the MsG. The potential cumulative effect of multiple inputs onto MDHns makes understanding the input to this neural circuit challenging. Single neurons releasing multiple neurotransmitters alone can have state dependent effects on network output (Nusbaum et al., 2001; Swensen and Marder, 2000). Furthermore, this complexity is compounded when considering the MDHns impact a heterogeneous population of AL LNs.

Arthropod HA receptors are ligand gated $\mathrm{Cl}^{-}$channels (McClintock and Ache, 1989; Hardie, 1989) sharing $~ 45 \%$ amino acid similarity to the alpha3 subunit of the human glycine receptor (Zheng et al., 2002), thus the effect of HA on MsHisClB expressing LNs is likely inhibitory in nature. Within the AL there are 300 LNs that belong to a diverse set of subtypes based on morphology, neurotransmitter content and physiological response properties (Chou et al., 2011; Reisenman et al., 2011). These LNs mediate diverse processing mechanisms such as lateral inhibition for gain control (Olsen and Wilson, 2007). In addition, these widely branching LNs activate metabotropic receptors whose effects occur on longer and more variable time scales than ionotropic receptors. Therefore the overall network effect of MDHn activity is variable in both the spatial and temporal domain making this circuit difficult to characterize. One potential mechanism 
would be suppression of GABA, FMRFamide and ATR release by select LNs within the AL. Theoretically, decreasing the influence of these predominantly inhibitory LNs could act to disinhibit the inhibitory AL local network, which could lead to a refinement of PN activity. While the role this refinement has on AL output activity is not clear, it could be in response to the rapid oscillatory nature of the stimulus experience which is driven in part by wing-beating (Sane and Jacobson, 2006). Finally, while invertebrate sensory-motor to sensory circuits typically function to filter reafferent stimuli, we suggest that it is unlikely that the MDHns function in this manner because non-olfactory responses persist in fully intact preparations (Tripathy et al., 2010). Therefore, it may be that MDHn activity indirectly refines PN spatiotemporal response patterns to modify the information output to higher order processing centers during flight. Indeed evidence suggests that the fine temporal structure of $\mathrm{AL} / \mathrm{OB}$ output patterns contain substantial information about odor identity (Rebello et al., 2014; Staudacher et al., 2009; Daly et al., 2004). However, future studies investigating both the activity patterns of MDHns during flight behavior and the consequences of HA release on AL response properties are necessary to confirm this hypothesis.

Many active sampling behaviors rapidly sample the sensory field providing discrete epochs of input to a sensory system; for example, micro-saccadic eye movements mentioned above. In addition, the details of temporally structured reafference may be dependent on the behavior of the animal. For instance, when exposed to a novel stimulus mice and rats increase their sniff frequencies (Wesson et al., 2008a; Kepecs et al., 2007) and sniff frequency modulation is dependent on the specifics of the behavioral task such as free exploration, detection, and discrimination (Wesson et al., 2008b). Insects also show stereotyped active sampling behaviors that are temporally structured. Bombyx mori require wing beating to track pheromone plumes 
despite their inability to fly (Obara, 1979) and male oriental fruit moths continue to fan their wings as they track a calling female even though their final approach is on foot (Baker and Carde, 1979).

From a whole nervous system perspective, it is perhaps not surprising that network-specific processing of information must be adjusted based on inputs from many disparate networks. It is becoming increasingly apparent that networks receive input from a large number of different sources and thus must integrate a variety of ongoing contexts. The mammalian Raphe nuclei provide widespread serotonergic input, yet they also receive input from many other brain areas (Dorocic et al., 2014; Liu et al, 2014; Weissbourd et al 2014). More specifically, the olfactory systems of animals receive a variety of inputs from other brain regions including serotonergic (Kent et al., 1987; McLean et al., 1987; Dacks et al., 2006), dopaminergic (Dacks et al., 2012), cholinergic (Macrides et al., 1981; Mandairon et al., 2006), octopaminergic (Dacks et al., 2005, Sinakevitch et al., 2005; Sinakevitch and Strausfeld, 2006; Dacks and Nighorn, 2011) and GABAergic (Nunez-para et al., 2013; Garcia-Llanes et al., 2010) cells all of which modify sensory processing within different, sometimes competing contexts. Our data support the hypothesis that olfactory processing in Manduca may also be adjusted within the context of ongoing activity in the MsG via the histaminergic MDHns.

Acknowledgements: We would like to thank Sarah Farris for technical advice and for editing the manuscript, Jackie Metheny for performing the Western Blot for the MsHisClB antibody.

\section{REFERENCES}

Adrian,ED. 1942. Olfactory reactions in the brain of the hedgehog. The Journal of Physiology 100:459-473. 
Ando N, Wang H, Shirai K, Kanzaki R. 2011. Central projections of the wing afferents in the hawkmoth, Agrius convolvuli. J insect phys 57:1518-1536.

Baker TC, Carde RT. 1979. Analysis of pheromone-mediated behaviors in male Grapholitha molesta, the oriental fruit moth (Lepidoptera: Tortricidae). Environ Entomol 8:956-968.

Bell CC. 1981. An efference copy which is modified by reafferent input. Science 214:450-453.

Bell RA, Joachim FG. 1976. Techniques for rearing laboratory colonies of tobacco hornworms and pink bollworms. Ann Entomol Soc Am 69:365-373.

Berg BG, Schachtner J, Homberg U. 2009. Gamma-aminobutyric acid immunostaining in the antennal lobe of the moth Heliothis virescens and its colocalization with neuropeptides. Cell Tissue Res 335:593-605.

Brainard MS, Doupe AJ. 2000. Interruption of a basal ganglia-forebrain circuit prevents plasticity of learned vocalizations. Nature 404:762-766.

Chalfie M, Sulston JE, White JG, Southgate E, Thomson JN, Brenner S. 1985. The neural circuit for touch sensitivity in Caenorhabditis elegans. J Neurosci 5:956-964.

Chou YH, Spletter ML, Yaksi E, Leong JC, Wilson RI, Luo L. 2010. Diversity and wiring variability of olfactory local interneurons in the Drosophila antennal lobe. Nature neuroscience. 13:439-449.

Christensen TA, Waldrop BR, Hildebrand JG. 1998. Multitasking in the olfactory system: context-dependent responses to odors reveal dual GABA-regulated coding mechanisms in single olfactory projection neurons. J Neurosci 18:5999-6008.

Claassen DE, Kammer AE. 1986. Effects of octopamine, dopamine, and serotonin on production of flight motor output by thoracic ganglia of Manduca sexta. J Neurobiol 17:1-14.

Clustering CC, Kittel RJ, Wichmann C, Rasse TM, Fouquet W, Schmidt M, Schmid A, Wagh D A, Pawlu C, Kellner RR, Willig KI, Hell SW, Buchner E, Heckmann M, Sigrist SJ. 2006. Bruchpilot promotes active zone assembly, Ca2+ channel clustering, and Vesicle Release. Science 312:1051-1054.

Crapse TB, Sommer MA. 2008. Corollary discharge across the animal kingdom. Nature Reviews Neuroscience 9:587-600. 
Dacks AM, Christensen TA, Agricola HJ, Wollweber L, Hildebrand JG. 2005. Octopamineimmunoreactive neurons in the brain and subesophageal ganglion of the hawkmoth Manduca sexta. J Comp Neurol. 488:255-68.

Dacks AM, Christensen TA, Hildebrand JG. 2006. Phylogeny of serotonin-immunoreactive neuron in the primary olfactory center of the insect brain. J Comp Neurol 498:727-746.

Dacks AM, Nighorn AJ. 2011. The organization of the antennal lobe correlates not only with phylogenetic relationship, but also life history: a Basal hymenopteran as exemplar. Chem Senses 36:209-20.

Dacks AM, Reisenman CE, Paulk AC, Nighorn AJ. 2010. Histamine-immunoreactive local neurons in the antennal lobes of the hymenoptera. J Comp Neurol 518:2917-2933.

Dacks AM, Riffell JA., Martin JP, Gage SL, Nighorn AJ. 2012. Olfactory modulation by dopamine in the context of aversive learning. J Neurophysiol 108:539-550.

Daly KC, Galan RF, Peters OJ, Staudacher EM. 2011. Detailed characterization of local field potential oscillations and their relationship to spike timing in the antennal lobe of the moth Manduca sexta. Front Neuroeng 4:1-22.

Daly KC, Kalwar F, Hatfield M, Staudacher EM, Bradley SP. 2013. Odor detection in Manduca sexta is optimized when odor stimuli are pulsed at a frequency matching the wing beat during flight. PLoS One 8:1-18.

Daly KC, Wright GA, Smith BH. 2004. Molecular features of odorants systematically influence slow temporal responses across clusters of coordinated antennal lobe units in the moth Manduca sexta. Journal of neurophysiology 92:236-254.

Dorocic IP, Fürth D, Xuan Y, Johansson Y, Pozzi L, Silberberg G, Carlén M, Meletis K. 2014. A Whole-Brain Atlas of Inputs to Serotonergic Neurons of the Dorsal and Median Raphe Nuclei. Neuron 83:663-678.

Duch C, Levine RB. 2000. Remodeling of membrane properties and dendritic architecture accompanies the postembryonic conversion of a slow into a fast motoneuron. J Neurosci 20:6950-6961.

Fouquet W, Owald D, Wichmann C, Mertel S, Depner H, Dyba M, Hallermann S, Kittel RJ, Eimer S, Sigrist SJ. 2009. Maturation of active zone assembly by Drosophila Bruchpilot. J Cell Biol 186:129-145. 
Gracia-Llanes FJ, Crespo C, Blasco-Ibáñez JM, Nacher J, Varea E, Rovira-Esteban L, MartínezGuijarro FJ. 2010. GABAergic basal forebrain afferents innervate selectively GABAergic targets in the main olfactory bulb. Neuroscience 170:913-922.

Halpern BP. 1983. Tasting and smelling as active, exploratory sensory processes. Am J Otolaryngol 4:246-249.

Hardie RC. 1989. A histamine-activated chloride channel involved in neurotransmission at a photoreceptor synapse. Nature 339:704-706.

Hernández PP, Olivari F a, Sarrazin AF, Sandoval PC, Allende ML. 2007. Regeneration in zebrafish lateral line neuromasts: expression of the neural progenitor cell marker sox2 and proliferation-dependent and-independent mechanisms of hair cell renewal. Dev Neurobiol 67:637-654.

Holst E, Mittelstaedt H. 1950. The principle of reafference: Interactions between the central nervous system and the peripheral organs. Die Naturwissenschaften 37:464-476.

Hoskins SG, Homberg U, Kingan TG, Christensen T a., Hildebrand JG. 1986. Immunocytochemistry of GABA in the antennal lobes of the sphinx moth Manduca sexta. Cell Tissue Res 244:243-252.

Houot B, Burkland R, Tripathy S, Daly KC. 2014. Antennal lobe representations are optimized when olfactory stimuli are periodically structured to simulate natural wing beat effects. Front Cell Neurosci 8:159.

Jones AK, Bera AN, Kees K, Sattelle DB. 2010. The cys-loop ligand-gated ion channel gene superfamily of the parasitoid wasp, Nasonia vitripennis. Heredity 3:247-259.

Kennedy JS, Ludlow AR, Sanders CJ. 1981. Guidance of flying male moths by wind-borne sex pheromone. Physiol Entomol 6:395-412.

Kent KS, Hoskins SG, Hildebrand JG. 1987. A novel serotonin-immunoreactive neuron in the antennal lobe of the sphinx moth Manduca sexta persists throughout postembryonic life. Dev Neurobiol 18:451-465.

Kepecs A, Uchida N, Mainen ZF. 2007. Rapid and precise control of sniffing during olfactory discrimination in rats. J Neurophysiol 98:205-213.

Liu Z, Zhou J, Li Y, Hu F, Lu Y, Ma M, Feng Q, Zhang JE, Wang D, Zeng J, Bao J, Kim JY, Chen ZF, El Mestikawy S, Luo M. 2014. Dorsal raphe neurons signal reward through 5-HT and glutamate. Neuron 81:1360-74. 
Lizbinski KM, Metheny JD, Bradley SP, Kesari A, Dacks AM. In Press. The Anatomical Basis for Modulatory Convergence in the Antennal Lobe of Manduca sexta. J Comp Neurol. In Press.

Loudon C, Best B, Koehl M. 1994. When does motion relative to neighboring surfaces alter the flow through arrays of hairs? J Exp Biol 193:233-54.

Loudon C, Koehl MA. 2000. Sniffing by a silkworm moth: wing fanning enhances air penetration through and pheromone interception by antennae. J Exp Biol 203:2977-2990.

Mandairon N, Ferretti CJ, Stack CM, Rubin DB, Cleland T a., Linster C. 2006. Cholinergic modulation in the olfactory bulb influences spontaneous olfactory discrimination in adult rats. Eur J Neurosci 24:3234-3244.

Martinez-Conde S, Macknik SL, Hubel DH. 2002. The function of bursts of spikes during visual fixation in the awake primate lateral geniculate nucleus and primary visual cortex. Proc Natl Acad Sci USA 99:13920-13925.

Martinez-Conde S, Macknik SL, Troncoso XG, Dyar TA. 2006. Microsaccades counteract visual fading during fixation. Neuron 49:297-305.

Martinez-conde S, Martinez-conde S, Macknik SL, Macknik SL, Hubel DH, Hubel DH. 2000. Microsaccadic eye movements and firing of single cells in the striate cortex of macaque monkeys. Nat Neurosci 3:409.

McClintock TS, Ache BW. 1989. Histamine directly gates a chloride channel in lobster olfactory receptor neurons. Proc Natl Acad Sci USA 86:8137-8141.

McLean JH, Shipley MT. 1987. Serotonergic afferents to the rat olfactory bulb: I. Origins and laminar specificity of serotonergic inputs in the adult rat. J Neurosci 7:3016-3028.

Melzig J, Buchner S, Wiebel F, Wolf R, Burg M, Pak WL, Buchner E. 1996. Genetic depletion of histamine from the nervous system of Drosophila eliminates specific visual and mechanosensory behavior. J Comp Physiol A 179:763-773.

Mohr C, Roberts PD, Bell CC. 2003. The mormyromast region of the mormyrid electrosensory lobe. II. Responses to input from central sources. J Neurophysiol 90:1211-1223.

Nunez-Parra A, Maurer RK, Krahe K, Smith RS, Araneda RC. 2013. Disruption of centrifugal inhibition to olfactory bulb granule cells impairs olfactory discrimination. PNAS 110:14777-82. 
Nusbaum MP, Blitz DM, Swensen AM, Wood D, Marder E. 2001. The roles of co-transmission in neural network modulation. Trends in neurosci 24:146-154.

Obara T. 1979. Bombyx mori mating dance: an essential in locating the female. Appl Entomol Zool 14:130-132.

Pantazis A, Sezaran A, Liu C-H, Nikolaev A, Rister J, Thum AS, Roeder T, Semenov E, Juusola M, Hardie RC. 2008. Distinct roles for two histamine receptors (hclA and hclB) at the Drosophila photoreceptor synapse. J Neurosci 28:7250-7259.

Peng H, Ruan Z, Long F, Simpson JH, Myers EW. (2010). V3D enables real-time 3D visualization and quantitative analysis of large-scale biological image data sets. Nature biotechnology. 28:348-353.

Porter J, Craven B, Khan RM, Chang S-J, Kang I, Judkewitz B, Volpe J, Settles G, Sobel N. 2007. Mechanisms of scent-tracking in humans. Nat Neurosci 10:27-29.

Poulet JF, Hedwig B. 2002. A corollary discharge maintains auditory sensitivity during sound production. Nature 418:872-876.

Rebello MR, McTavish TS, Willhite DC, Short SM, Shepherd GM, Verhagen JV. 2014. Perception of Odors Linked to Precise Timing in the Olfactory System. PLoS biology 12.

Reinagel P, Godwin D, Sherman SM, Koch C. 1999. Encoding of visual information by LGN bursts. J Neurophysiol 81:2558-2569.

Reisenman CE, Dacks AM, \& Hildebrand JG. 2011. Local interneuron diversity in the primary olfactory center of the moth Manduca sexta. Journal of Comparative Physiology A, 6:653665.

Rind CF. 1983. The organization of flight motoneurones in the moth, Manduca sexta. J Exp Biol 102:239-251.

Ross J, Concetta Morrone M, Goldberg ME, Burr DC. 2001. Changes in visual perception at the time of saccades. Trends in Neurosciences 24:113-121.

Rothermel M, Carey RM, Puche a, Shipley MT, Wachowiak M. 2014. Cholinergic inputs from basal forebrain add an excitatory bias to odor coding in the olfactory bulb. J Neurosci 34:4654-4664.

Sane SP, Jacobson NP. 2006. Induced airflow in flying insects II. Measurement of induced flow. J Exp Biol 209:43-56. 
Sievers F, Wilm A, Dineen DG, Gibson TJ, Karplus K, Li W, Lopez R, McWilliam H, Remmert M, Söding J, Thompson JD, Higgins D. 2011. Fast, scalable generation of high-quality protein multiple sequence alignments using Clustal Omega. Mol Syst Biol 7:1-6.

Sinakevitch I, Niwa M, Strausfeld NJ. 2005. Octopamine-like immunoreactivity in the honey bee and cockroach: comparable organization in the brain and subesophageal ganglion. J Comp Neurol. 488:233-54.

Sinakevitch I, Strausfeld NJ. 2006. Comparison of octopamine-like immunoreactivity in the brains of the fruit fly and blow fly. J Comp Neurol. 494:460-75.

Sommer MA, Wurtz RH. 2002. A pathway in primate brain for internal monitoring of movements. Science 296:1480-1482.

Staudacher EM, Huetteroth W, Schachtne, J, Daly KC. 2009. A 4-dimensional representation of antennal lobe output based on an ensemble of characterized projection neurons. Journal of neuroscience methods 180:208-223.

Stevenson PA, Pflüger HJ, Eckert M, Rapus J. 1992. Octopamine immunoreactive cell populations in the locust thoracic-abdominal nervous system. J Comp Neurol 315:382-397.

Stuart AE. 1999. From fruit flies to barnacles, histamine is the neurotransmitter of arthropod photoreceptors. Neuron 22:431-433.

Swensen AM, Marder E. 2000. Multiple peptides converge to activate the same voltagedependent current in a central pattern-generating circuit. J Neurosci 20: 6752-6759.

Tripathy SJ, Peters OJ, Staudacher EM, Kalwar FR, Hatfield MN, Daly KC. 2010. Odors pulsed at wing beat frequencies are tracked by primary olfactory networks and enhance odor detection. Front Cell Neurosci 4:1-14.

Utz S, Huetteroth W, Vömel M, Schactner J.2008. Mas-allatotropin in the developing antennal lobe of the sphinx moth Manduca sexta: distribution, time course, developmental regulation, and colocalization with other neuropeptides. Devel Neurobiology 68:123-142.

Veenstra JA, Hagedorn HH. 1993. Sensitive enzyme immunoassay for Manduca allatotropin and the existence of an allatotropin-immunoreacitve peptide in Periplaneta americana. Arc of insect biochem and phys 23:99-109.

Wagh D a., Rasse TM, Asan E, Hofbauer A, Schwenkert I, Dürrbeck H, Buchner S, Dabauvalle MC, Schmidt M, Qin G, Wichmann C, Kittel R, Sigrist SJ, Buchner E. 2006. Bruchpilot, a 
protein with homology to ELKS/CAST, is required for structural integrity and function of synaptic active zones in Drosophila. Neuron 49:833-844.

Watson AH, Burrows M. 1987. Immunoctochemical and pharmacological evidence for GABAergic spiking local interneurons in the locust. J Neurosci 7:1741-1751.

Weiss KR, Cohen JL, Kupfermann I. 1978. Modulatory control of buccal musculature by a serotonergic neuron (metacerebral cell) in Aplysia. J Neurophysiol 41:181-203.

Weissbourd B, Ren J, DeLoach KE, Guenthner CJ, Miyamichi K, Luo L. 2014. Presynaptic partners of dorsal raphe serotonergic and GABAergic neurons. Neuron 83:645-62.

Wesson DW, Carey RM, Verhagen J V., Wachowiak M. 2008a. Rapid encoding and perception of novel odors in the rat. PLoS Biol 6:717-729.

Wesson DW, Donahou TN, Johnson MO, Wachowiak M. 2008b. Sniffing behavior of mice during performance in odor-guided tasks. Chem Senses 33:581-596.

Witten JL, Truman JW. 1996. Developmental plasticity of neuropeptide expression in motoneurons of the moth, Manduca sexta: steroid hormone regulation. J Neurobio. 29:99114.

Woo SH, Stumpfova M, Jensen UB, Lumpkin EA, Owens, D M. 2010. Identification of epidermal progenitors for the Merkel cell lineage. Development. 23:3965-3971.

Zaretsky M, Rowell CHF. 1979. Saccadic suppression by corollary discharge in the locust. Nature. 280: 583-585.

Zheng Y, Hirschberg B, Yuan J, Wang AP, Hunt DC, Ludmerer SW, Schmatz DM, Cully DF. 2002. Identification of two novel Drosophila melanogaster histamine-gated chloride channel subunits expressed in the eye. J Biol Chem. 3:2000-2005.

\section{FIGURE LEGENDS}

\section{Figure 1.}

Characterization of the histamine (HA) GABA and Manduca sexta histamine B receptor (MsHisClB) antibodies. (A) HA labeling in control animals where the antibody was not pre- 
adsorbed. Arrow head highlights HA labeling that enters the ventral and medial AL (for all panels outlined with a dashed line). (B) HA labeling in the antennal lobe (AL) is abolished after the HA antibody was pre-adsorbed with a 10:1 HA to antibody solution.(C) GABA labeling remains in control animals where the antibody was not pre-adsorbed with GABA. (D) GABA labeling in the AL is abolished after the GABA antibody was pre-adsorbed with a 10:1 GABA to antibody solution. For each panel the same dorsal lateral axis is used. (E) Amino acid sequence alignment of the histamine B receptor subunits of Manduca sexta (MsHB; Msex2.04603-RA), Drosophila melanogaster (DmHB; ACA13298.1), Apis mellifera (AmHB; ABG75740.1) and Nasonia vitripennis (NvHB; ACZ51422.1). Asterisks indicate sequence identity across all 4 species. Bold font indicates the immunogenic peptide sequence from Manduca that was used to generate the MsHisClB antibody. (F) Western blot using MsHisClB receptor antibody on Manduca brain tissue resulted in a single band at the predicted molecular weight (36 kDa) of the MsHisClB protein. (G) Frontal section of optic lobe depicting MsHisClB-ir in the lamina. (H) Pre-adsorption with the immunogenic peptide sequence eliminates all labeling in the lamina. Scale bars $=100 \mu \mathrm{m}$.

\section{Figure 2.}

MDH neurons project from the mesothoracic ganglia to the AL of Manduca sexta. (A) Frontal view of HA-ir labeling in a whole mount brain preparation. Hatched line outlines the AL boundary. (B) Saggital view of a HA-ir process entering the AL (bracket). (C) Frontal view of HA-ir processes entering the SEZ from the cervicothoracic connective. Notice that 4 pairs enter the SEZ. (D) HA-ir processes in the cervicothoracic connective. Brackets highlight three HA-ir processes. (E) Horizontal view of the HA-ir processes in the prothoracic ganglia. Notice 4 pairs ascending from here as well. (F) Horizontonal view of HA-ir in the MsG, the metathoracic ganglia, and the first two abdominal ganglia. Each SEZment has a pair of HA-ir cell bodies located in the medial 
third of their respective ganglia. (G) Schematic of the Manduca nervous system highlighting the MDHns (green). Hatched boundary indicates the MsG. All scale bars $=100$ um. AL=antennal lobe; oe=esophageal foramen; SEZ=sub-esophageal zone; CTC=cervicothoracic connective; $\mathrm{PtG}=$ prothoracic ganglia; $\mathrm{MsG}=$ mesothoracic ganglia; $\mathrm{MtG}=$ metathoracic ganglia; ab1=abdominal ganglion 1 ; ab2=abdominal ganglion 2 .

\section{Figure 3.}

MDH neurons processes radiate laterally throughout the MsG, but are primarily restricted to the dorsal aspect. (A) Horizontal view of the MSG showing two cell bodies with each cell projecting out one side of the ganglia. (B) Sagittal section of the MsG shows two large HA-ir cells with cell bodies (white arrow head) situated ventrally and a radiating dendritic field dorsally with the axon (black arrow) projecting up the connective between the mesothoracic and prothoracic ganglia. White dotted line indicates the boundary between the mesothoracic and metathoracic ganglia. Arrow indicates MDHn cell body in each image. All scale bars $=100 \mu \mathrm{m}$.

\section{Figure 4.}

The MDH neurons provide the sole source of HA-ir input to the ALs. (A) Saggital section of the AL with HA-ir (green). Bruchpilot (Brp) (magenta) outlines glomeruli of the AL. Dotted line outlines the posterior boundary of the AL. Scale bar $=100 \mathrm{um}$. (B) High magnification view of inset from (A). Highly varicose HA-ir processes innervate 4-6 ventral posterior glomeruli. Scale bar $=50$ um. (C) Rotation of image (A) about the y-axis showing HA still overlapping with BRP labeling. (D) Rotation of image (A) about the x-axis again showing HA overlapping with BRP labeling, collectively confirming that HA ramifies glomeruli. (E) Frontal section showing that HAir is absent in the AL following ablation of the cervicothoracic connective. Scale bar $=100 \mathrm{um}$. (F) Sagittal view of HA-ir in the AL following ablation between the MsG and the metathoracic 
ganglia in which the lesioning of metathoric HA-ir neuron axons was confirmed. Asterisks indicates MDHn cell bodies. Scale bar $=50$ um.

\section{Figure 5.}

Within the AL the MsHisClB receptor is expressed by a subset of GABAergic LNs and one FMRFamidergic and one ATRergic LN. (A) MsHisClB (green) and GABA (magenta) co-labeling in the lateral cell cluster of the AL. MsHisClB-ir is expressed in all AL glomeruli. Scale bar 100 um. (B) GABA-ir and MsHisClB-ir expression in the lateral cell cluster. (C), (D). Inset from (B) highlights a single large MsHisClB-ir cell body that does not express GABA. (E) FMRFamide-ir (cyan) and MsHisClB-ir (green) expression in the lateral cell cluster. (F), (G) Inset from (E) highlights a single large cell body that expresses both MsHisClB-ir and FMRFamide-ir. (H) ATR-ir (orange) and MsHisClB-ir (green) expression in the lateral cell cluster. (I), (J) Inset from (H) highlights a single large cell body that expresses both MsHisClB-ir and FMRFamide-ir. All scale bars $=50$ um unless otherwise noted.

\section{Figure 6.}

The MDHns survive metamorphosis, but the MsHisClB receptor is not expressed in the larval antennal center (LAC). (A) Horizontal view of HA-ir in the 5th instar larval MsG shows highly similar cell morphology and radiation patterns of fine processes as in the adult MsG. (B) HA-ir in the larval brain (green) shows extensive branching in the tritocerebrum (dash-dot line), but very little innervation in the LAC (dashed line). Syto-59 (magenta) highlights the boundary of the tritocerebrum and LAC. (C) MsHisClB-ir (green) is present in the tritocerebrum, but not in the LAC. LAC and tritocerebrum highlighted with Syto-59 (magenta) as in (B). All scale bars $=100$ um. 


\section{Figure 7.}

Schematic of the proposed MDHn circuit. (A) Manduca with overlaid nervous system cartoon. (B) Schematic of the MDHn cells from the thoracic ganglia to the AL. Only one cell is shown in detail with processes radiating in the MsG, a small process in the prothoracic ganglion, projecting up the cervicothoracic connective, a branch to the AMMC, and bilateral projections to each AL. (C) MDHn projection entering the ventral AL (green) along with the proposed AL circuitry. For the sake of simplicity, only the processes from MsHisClB-ir expressing neurons (green outline) are shown. MsHisClB-ir GABAergic (pink with green outline) and peptidergic (cyan or orange with green outline for FMRFamide and allatotropin, respectively) LNs ramify each glomerulus. Other cell types are also present including PNs (open circles), GABAergic LNs (pink circles with black outlines), ATR LNs (orange circles with black outline), and FMRF LNs (blue circles with black outline). $\quad \mathrm{AL}=$ antennal lobe; oe=esophageal foramen; $\mathrm{SEZ}=$ sub-esophageal zone; CTC=cervicothoracic connective; $\mathrm{PtG}=$ prothoracic ganglia; $\mathrm{MsG}=$ mesothoracic ganglia; MtG=metathoracic ganglia; ab1=abdominal ganglion 1; ab2=abdominal ganglion 2 . 


\section{TABLES}

Table 1. Primary antibodies used in this study

\begin{tabular}{|c|c|c|c|c|c|}
\hline Antigen & Immunogen & $\begin{array}{l}\text { Manufacturer, } \\
\text { host, monoclonal } \\
\text { vs. polyclonal }\end{array}$ & $\begin{array}{l}\text { Catalog } \\
\#\end{array}$ & RRID & \begin{tabular}{|l} 
Dilution \\
used
\end{tabular} \\
\hline $\begin{array}{l}\text { Histamine } \\
\text { (HA) }\end{array}$ & $\begin{array}{l}\text { Synthetic histamine } \\
\text { coupled to } \\
\text { succinylated keyhole } \\
\text { limpet } \\
\text { hemocyanin with } \\
\text { carbodiimide linker }\end{array}$ & $\begin{array}{l}\text { Immunostar, } \\
\text { Rabbit, } \\
\text { polyclonal }\end{array}$ & 22939 & AB_572245 & $1: 500$ \\
\hline $\begin{array}{l}\text { Bruchpilot } \\
\text { (BRP) }\end{array}$ & $\begin{array}{l}\text { Bruchpilot peptide } \\
\text { sequence (1390- } \\
\text { 1740) from head } \\
\text { homogenate }\end{array}$ & $\begin{array}{l}\text { DSHB, Mouse, } \\
\text { monoclonal }\end{array}$ & Nc-82 & AB_2314866 & $1: 50$ \\
\hline $\begin{array}{l}\text { Manduca sexta } \\
\text { Histamine B } \\
\text { receptor } \\
\text { (MsHisClB) }\end{array}$ & $\begin{array}{l}\text { Histamine B } \\
\text { receptor peptide } \\
\text { sequence } \\
\text { (VNPDIELPQLD) }\end{array}$ & $\begin{array}{l}\text { Bethyl } \\
\text { Laboratory } \\
\text { (custom), Rabbit, } \\
\text { polyclonal }\end{array}$ & N/A & N/A & 1:5000 \\
\hline $\begin{array}{l}\gamma \text {-aminobutyric } \\
\text { acid (GABA) }\end{array}$ & $\begin{array}{l}\text { Purified GABA } \\
\text { conjugated to BSA }\end{array}$ & $\begin{array}{l}\text { Abcam, Mouse, } \\
\text { monoclonal }\end{array}$ & ab49675 & AB_880138 & $1: 500$ \\
\hline $\begin{array}{l}\text { Allatotropin } \\
\text { (ATR) }\end{array}$ & $\begin{array}{l}\text { Allatotropin coupled } \\
\text { to thyroglobulin with } \\
\text { glutaraldehyde }\end{array}$ & $\begin{array}{l}\text { Dr. Jan Veenstra, } \\
\text { Rabbit, } \\
\text { polyclonal }\end{array}$ & N/A & AB_2313973 & $1: 8^{*}$ \\
\hline $\begin{array}{l}\text { FMRF-amide } \\
\text { (FMRF) }\end{array}$ & $\begin{array}{l}\text { Synthetic FMRF- } \\
\text { Amide coupled to } \\
\text { bovine thyroglobulin } \\
\text { with gluteraldehyde }\end{array}$ & $\begin{array}{l}\text { Dr. Eve Marder, } \\
\text { Rabbit, } \\
\text { Polyclonal }\end{array}$ & N/A & AB_572232 & $1: 8^{*}$ \\
\hline
\end{tabular}

* See fluorescent tagging subsection of the methods for details. 


\section{FIGURES}

\section{Figure 1}

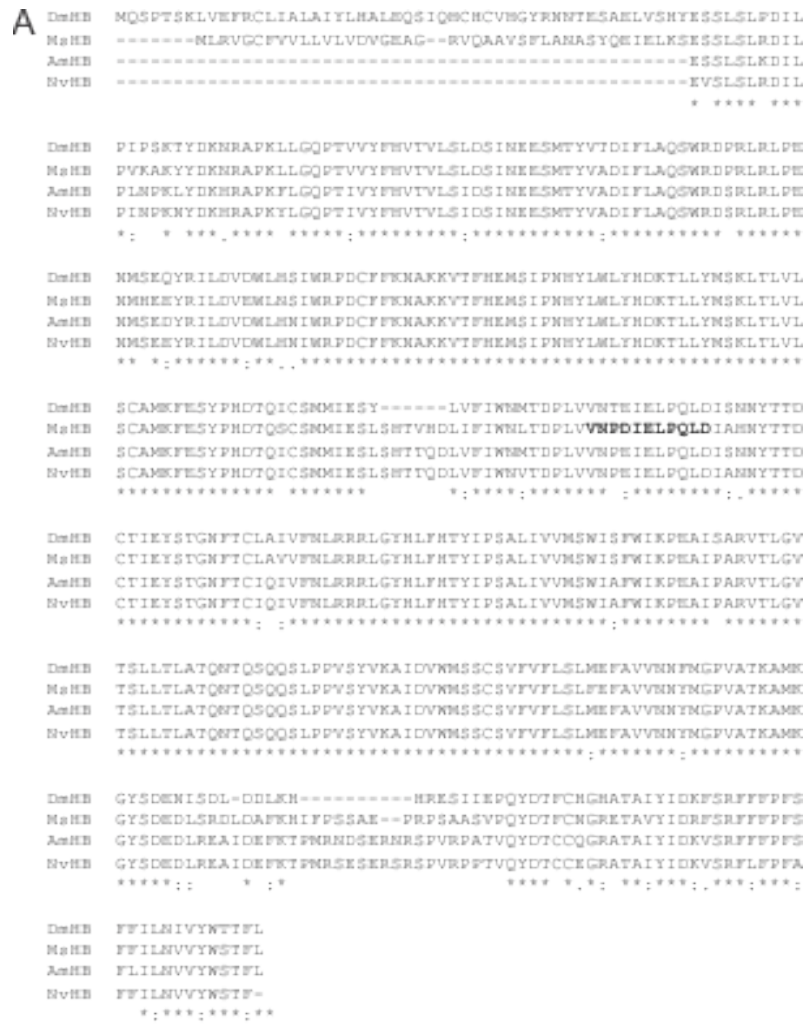

B

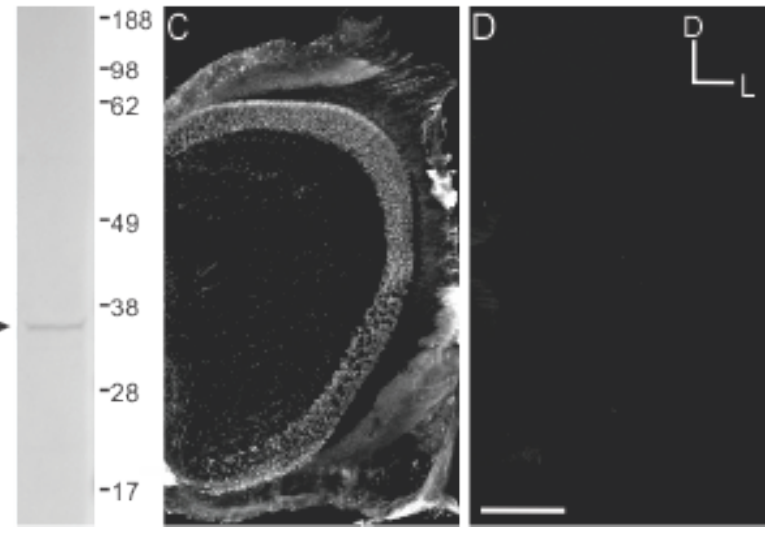


Figure 2

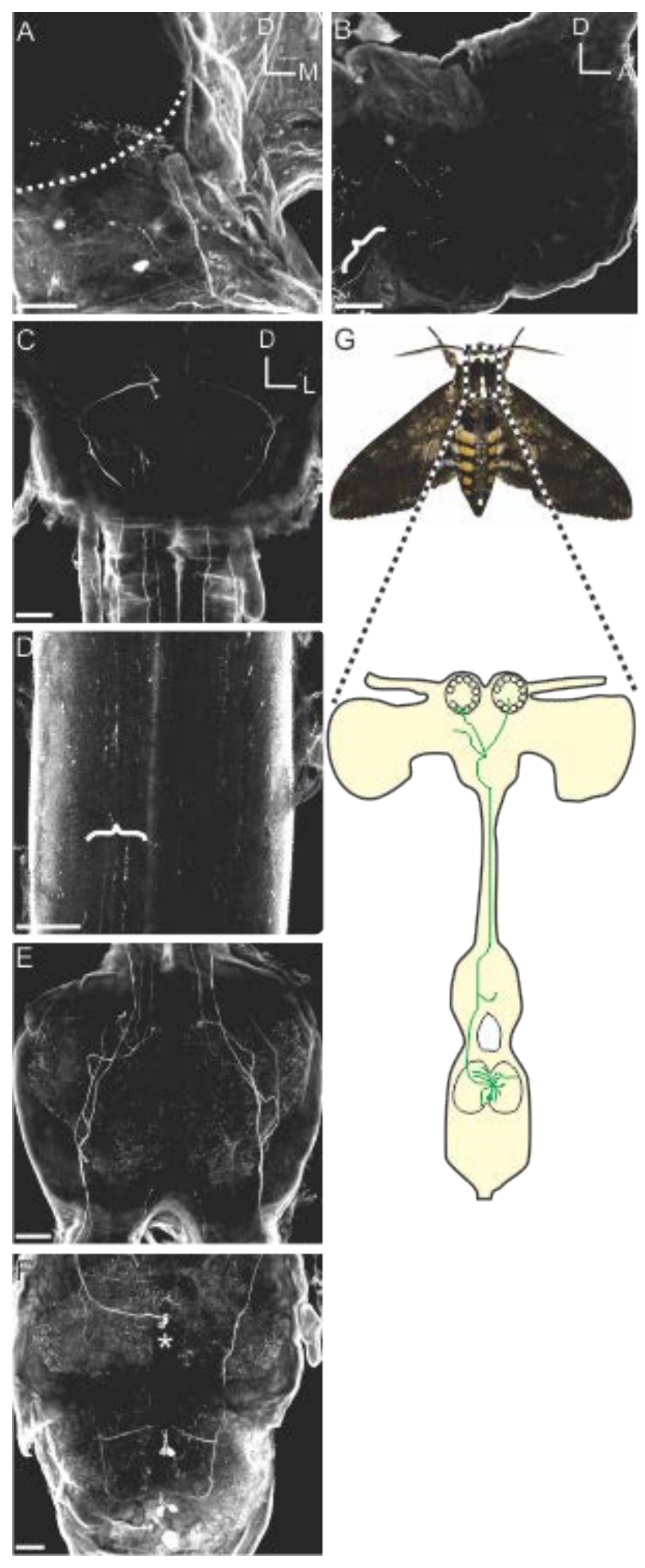


Figure 3
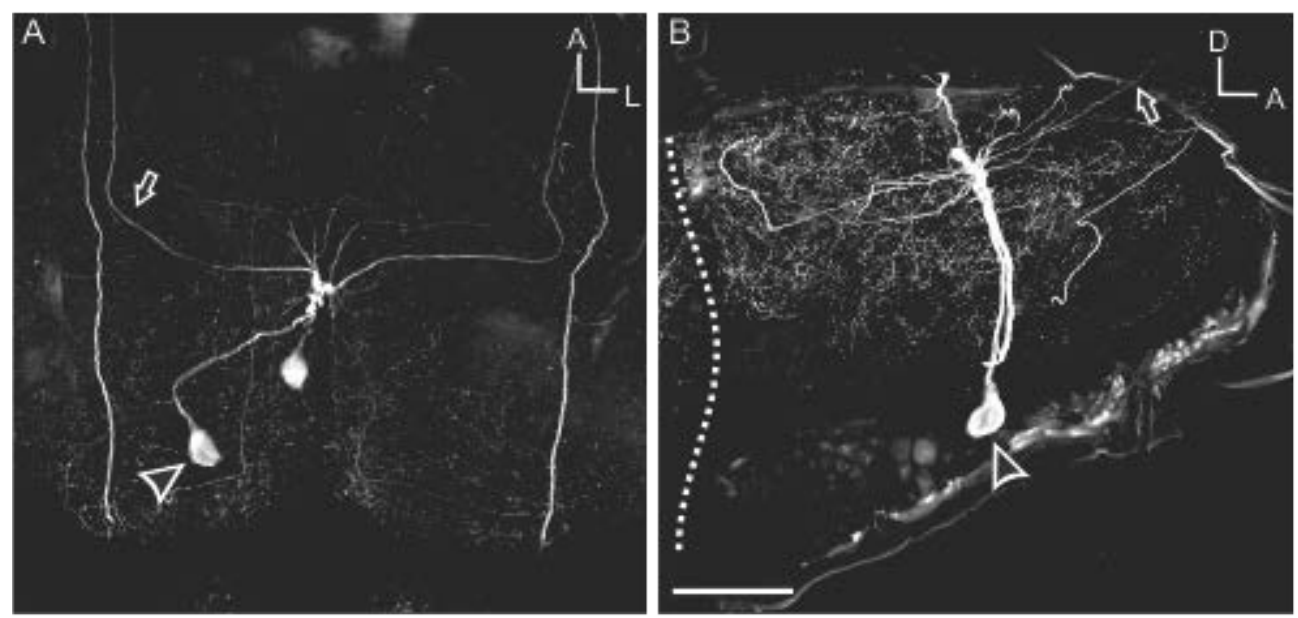
Figure 4

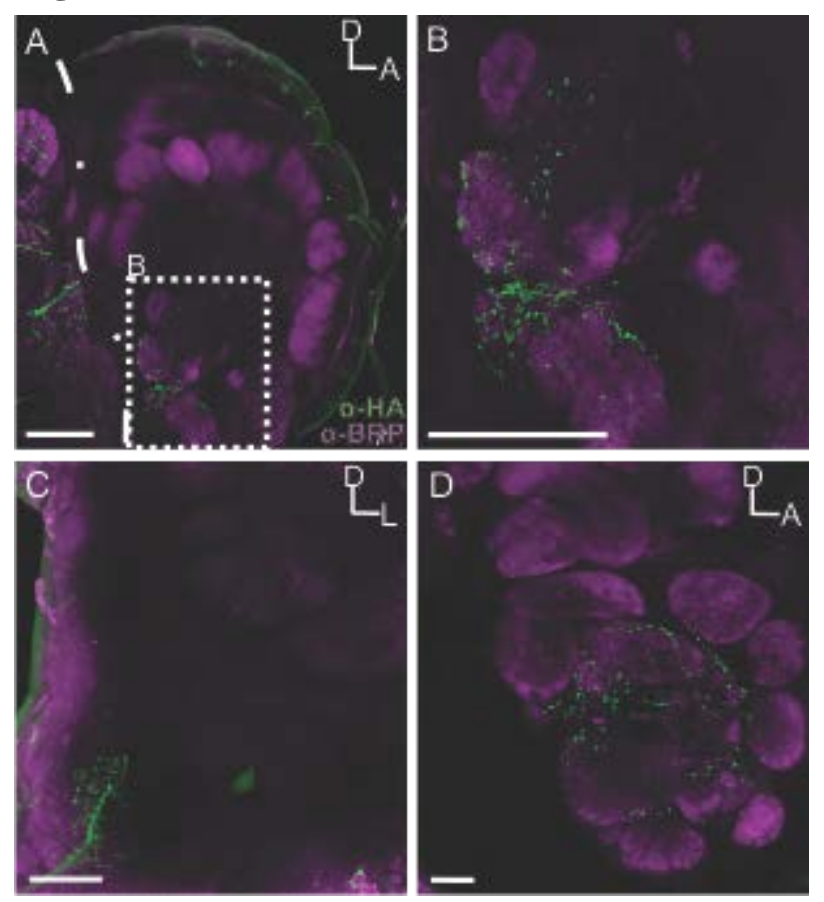


Figure 5

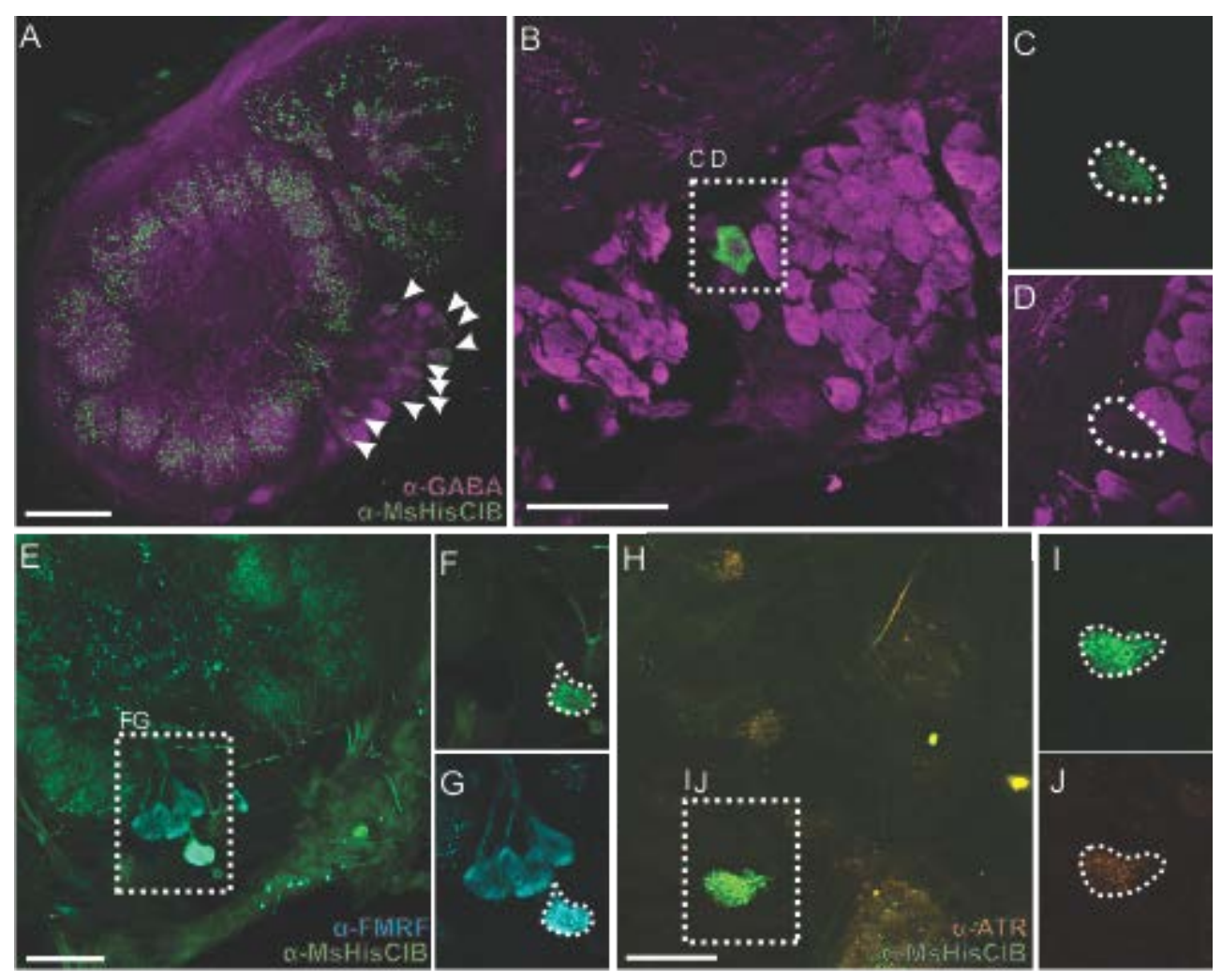


Figure 6

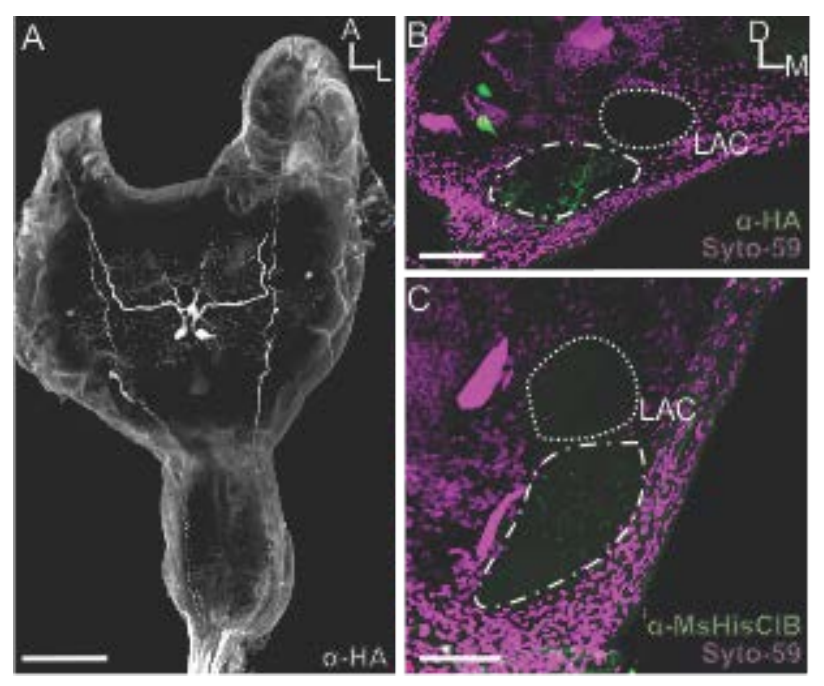


Figure 7

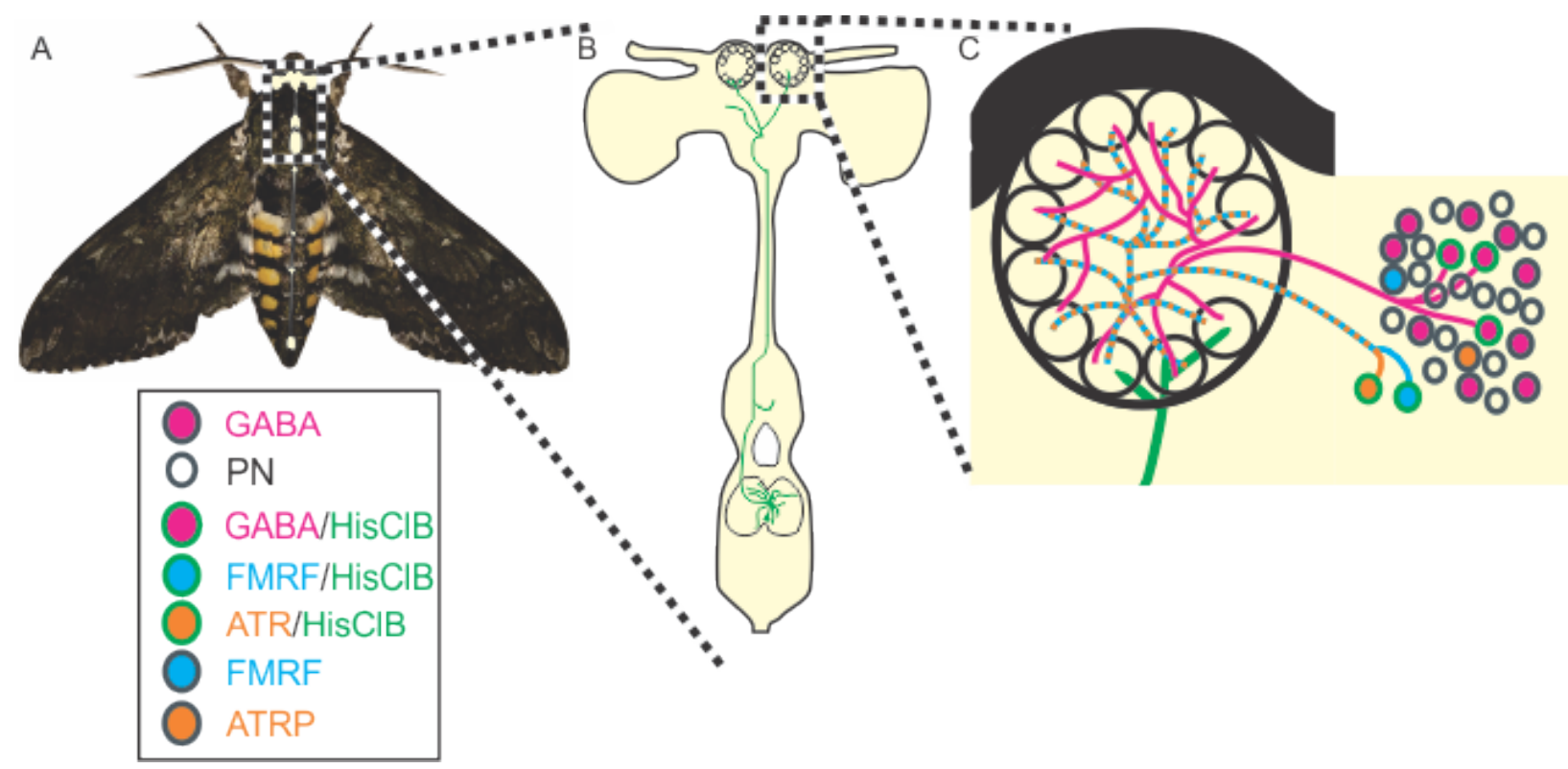




\title{
Appendix B \\ Co-option of a Motor-to-Sensory Histaminergic Circuit Correlates with Insect Flight Biomechanics.
}

\author{
Phillip D. Chapman, Samual P. Bradley, Erica J. Haught, Kassandra E. Riggs, Mouaz M. Haffar, Kevin \\ C. Daly, Andrew M. Dacks \\ Department of Biology, West Virginia University, Morgantown, West Virginia, 26506, USA.
}

\begin{abstract}
Nervous systems must adapt to shifts in behavioral ecology. One form of adaptation is neural exaptation, in which neural circuits are co-opted to perform additional novel functions. Here, we describe the co-option of a motor-to-somatosensory circuit into an olfactory network. Many moths beat their wings during odor-tracking, whether walking or flying, causing strong oscillations of airflow around the antennae, altering odor plume structure. This self-induced sensory stimulation could impose selective pressures that influence neural circuit evolution, specifically fostering the emergence of corollary discharge circuits. In Manduca sexta a pair of mesothoracic to deutocerebral histaminergic neurons (MDHns), project from the mesothoracic neuromere to both antennal lobes (ALs), the first olfactory neuropil. Consistent with a hypothetical role in providing the olfactory system with a corollary discharge, we demonstrate that the MDHns innervate the ALs of advanced and basal moths, but not butterflies, which differ in wing beat and flight pattern. The MDHns likely arose in crustaceans and in many arthropods innervate mechanosensory areas, but not the olfactory system. The MDHns therefore represent an example of architectural exaptation, in which neurons that provide motor output information to mechanosensory regions have been co-opted to provide information to the olfactory system in moths.
\end{abstract}




\section{INTRODUCTION}

Exaptation is a core feature in the development of new phenotypic traits, allowing pre-existing traits to be co-opted to take on new or additional roles. There are numerous examples of exaptations involving the co-option of genes [1], body appendages [2], and behaviors [3]. For instance, the co-option of the teleost gas bladder into lungs, and lobe fins into limbs supported the conquest of land by tetrapods [4]. Feathers are another commonly cited example of exaptation; originally thought to support thermoregulation, they were exapted to produce thrust during flight [5]. While there are several examples of exaptation in the nervous system in general [6], the cellular and neural circuit basis for nervous system exaptation are poorly understood. For example, primitive insect wings originated from tracheal gills present on all body segments [7], yet the specific changes that occurred within motor networks to allow flight motor control in present-day insects remain to be identified. However, as traits such as appendages are co-opted to take on additional functions the neural networks associated with these structures are likely also co-opted for use in this new function.

Often, adaptations in nervous system function manifest as changes in biophysical and synaptic properties, which have been extensively described in networks that produce rhythmic output such as central pattern generators $[8,9]$. In addition to changes in biophysical and synaptic physiology, exaptations can also involve changes in neural architecture, such that neurons can be co-opted to innervate neural networks to which they did not project in the ancestral state. Architectural changes have the potential to modify existing brain regions to perform new functions [6]. In theory, the exaptation of circuitry could provide an existing network with additional information to enhance processing. Although there is evidence for neural exaptation 
within the context of entire brain regions [10], very little is known about the potential for neural exaptation at the level of individual neurons. In this study, we used comparative neuroanatomy to describe an example of architectural neural exaptation at the level of a pair of identified neurons, the mesothoracic to deutocerebral histaminergic neurons (“MDHn”). We demonstrate that the MDHns form a motor-to-mechanosensory circuit throughout the arthropods and were potentially co-opted to serve additional olfactory function in moths. This trait was subsequently lost in butterflies in correlation with changes in flight biomechanics and sensory dominance from olfaction to vision for locating food sources. This suggests that co-option of neural circuits at the level of individual neurons can result as a byproduct of behavior-specific natural selection. Furthermore, the conservation of the MDHn morphology across the arthropods suggests that interganglionic communication between limb motor control and mechanosensory centers in the brain is a fundamental feature of sensory processing.

\section{METHODS}

\section{Animals}

Manduca sexta were raised and maintained on a standard artificial diet [11]. Bombyx mori were purchased from Mulberry farms (Fallbrook, CA), and raised on standard artificial diet. Idia aemula, Papilio appalachiensis and Limenitis archippus were collected in Morgantown, WV. Pieris rapae and Theatops californiensis were purchased from Carolina Biological Supply Co. (Burlington, NC). Grapholita molesta were provided by Dr. Mark Willis (Case Western Reserve University). Galleria mellonella, Gyna Lurida, and Tenebrio molitor were provided by Dr.

George Keeney (The Ohio State University). Caddisflies were provided by Kathy Kyle Stout (Wildscape Inc.). Drosophila melanogaster were raised at WVU. Amblyomma americanum were provided by Dr. Timothy Driscoll (WVU). At least 6 individuals were used for each species. 


\section{Immunocytochemistry}

Histamine labeling was performed as previously described [12]. Post-dissection, tissue was fixed in a 4\% solution of N-3-dimethylaminopropyl-N'-ethylcarbodiimide (Sigma-Aldrich, 03449) in 0.01M phosphate buffered saline (PBS, pH 6.9; Sigma-Aldrich, P-5368) at $4^{\circ} \mathrm{C}$ between 2-6 hours depending on tissue volume (e.g. 2 hours for D. melanogaster, 6 hours for M. sexta). Tissue was then fixed in 4\% paraformaldehyde (Electron Microscopy Sciences, 15710) in PBS overnight. Post-fixation, brains were washed in PBS. For sectioned tissue, brains were embedded in 5\% agarose (Sigma-Aldrich, SLBJ3744V) and sectioned between 100 and 150 $\mu \mathrm{m}$ using a Leica VT 1000S vibratome. The tissue was washed in PBS with 0.5\% Triton ${ }^{\mathrm{TM}}-\mathrm{X} 100$ (PBST; Sigma-Aldrich, 110M0009V), and blocked in 2\% bovine serum albumin (BSA; Jackson Laboratory, 001-000-162) for 1 hour. Brains were then incubated in 1:50 mouse anti-bruchpilot (Developmental Studies Hybridoma Bank, nc82) with 2\% BSA in PBST at $4^{\circ} \mathrm{C}$ for 5 days before adding 1:500 Rabbit anti-histamine, and incubating for another two days. The histamine antibody was raised against histamine conjugated to succinylated keyhole limpet hemocyanin via carbodiimide and this antibody shows no cross-reactivity keyhole limpet hemocyanin alone [12]. Preadsorption with histamine also eliminates labeling [13]. Finally, in D. melanogaster, histidine decarboxylase mutants lack histamine immunolabeling using this antibody [14]. Following primary antibody application, tissue was washed in PBST, then blocked (as above), and incubated in 1:1000 Alexa 488, or 546(Alexa Flour®; Thermo Fisher Scientific A-11008, A11030). Tissue was washed in PBST and PBS. For sectioned brains, tissue was run through an ascending glycerol (Sigma-Aldrich, BCBN3647V) series (40\%, 60\%, and 80\%) and mounted in Vectashield ${ }^{\circledR}$ (Vector laboratories, Za1222). For whole mounts, tissue was run through an ascending ethanol (Sigma-Aldrich, SHBF6704V) series (30\%, 50\%, 70\%, 95\%, and 100\%) for 10 minutes; tissue was placed in a 1:1 solution of ethanol and methyl salicylate for 15 minutes, 
then $100 \%$ methyl salicylate for 15 minutes, then mounted in Permount ${ }^{\circledR}$ (Fisher Scientific, SP15-500).

\section{Optical Imaging Acquisition and Analysis}

Fluorescent tissue was viewed with a laser scanning confocal microscope (Olympus FV1000) equipped with red/green HeNe, and argon lasers. Images were acquired using either a 20x or 40x magnification optical objective. Distance between confocal planes were optimized for the objective (1.79 um for 20X and 0.54 um for 40X) using Fluoview software (FV10-ASW Version 04.00.02.09). Pixel resolution was adjusted to compensate for the size of each specimen between 1024 x 1024 to 2048 x 2048 pixels. Images were only modified for contrast enhancement. All optical stacks were rendered with a maximum intensity projection across either the whole mount or sectioned tissue. Figures were organized in CorelDraw (Version X4).

\section{RESULTS}

In Manduca sexta, the pterothoracic ganglion is a fused structure that includes the prothoracic, mesothoracic, metathoracic and first two abdominal neuromeres. The MDHns branch extensively within the mesothoracic neuromere $(\mathrm{MsN})$ and project ascending axons to innervate the subesophageal zone (SEZ), antennal mechanosensory and motor center and antennal lobe (AL) [13, 15] (Fig., 1A). Excluding the optic lobes, there are 11 pairs of histaminergic neurons in the brain of $M$. sexta [15], however ablation experiments have demonstrated that the MDHns are the sole source of histamine in the AL [13]. Insects possess only two histamine receptors, both of which are histamine-gated chloride channels $[16,17]$. In the AL of $M$. sexta, the HisClB receptor is expressed by a subset of GABAergic local interneurons that innervate every glomerulus [13], and although HA-ir itself is constrained to several ventral glomeruli, this it is likely that the MDHns provide fast inhibitory input to a subset of neurons that themselves exert network-wide 
inhibition. However, while histaminergic neurons in the MsN of crickets [18], locusts [19] and Drosophila [14] project ascending axons into the AMMC (which also receives input from antennal mechanosensory neurons), they do not innervate the AL. This suggests that while the MDHns may be present in many insect taxa, they do not necessarily innervate the olfactory system, which may reflect differences in the impact of species-specific flight mechanics on odor plumes [20,21]. The olfactory system of $M$. sexta is able to track odors pulsed at the wing-beat frequency [22, 23], so we therefore hypothesized that MDHn innervation of the AL arose due to selective pressures associated with a need to process odors carried by flight-induced air flow oscillations during plume tracking. We used a comparative approach to determine when over evolutionary time the MDHns began to innervate the AL and if this trait was lost with the evolution of different flight biomechanics within the Lepidoptera.

\section{(a) MDHn Innervation of the AL is Specific to Caddisflies and Moths.}

To determine whether MDHn AL innervation was specific to M. sexta (Sphingidae), we examined the MDHns in Bombyx mori (Bombycidae), a closely related species with similar wing beating frequency and mechanics $[24,25]$. Both moths belong to the superfamily Bombycoidea and B. mori, although flightless, must beat their wings while walking to successfully track odor plumes [26]. The MDHns have a distinct, consistent morphology that, in combination with HAimmunolabeling allow their identification between species. In M. sexta, MDHn somata were located ventrally and send primary neurites dorsally where they project radially throughout the MsN (Fig. 1B). In addition, the MDHns project a single axon that ascends via the ventral nerve cord to the brain. HA-ir was present in the ALs of M. sexta in several ventral glomeruli (Fig. 1C). The MDHns in B. mori possessed nearly identical morphology with ventrally located cell bodies, dorsal radial MsN projections and axons that ascend to the brain (Fig 1D). Similar to $M$. 
sexta, HA-ir was present in the AL of B. mori in several ventral glomeruli (Fig. 1E). To determine the phylogenetic distribution of AL innervation by the MDHns in the Macrolepidoptera further, we examined Idia aemula (Erebidae), the powdered snout, which belongs to the superfamily Noctuoidea. The MsN of I. aemula contains histaminergic neurons with nearly identical morphology to the MDHns in M. sexta and B. mori, (Fig. 1F), including ascending projections to the brain and bilateral innervation of both ALs (Fig. 1G). Our results together indicate that histaminergic neurons that project from the MsN to the olfactory system are conserved within macrolepidopteran moths.

Butterflies also belong to the Macrolepidoptera, but primarily use vision to locate mates and food [27]. The flight patterns of butterflies are also much more heterogeneous than moths due to nonperiodic wing flapping, gliding, and turn unpredictability [28]. These characteristics lower predation risk [28], but would theoretically reduce plume tracking ability. Butterflies are relatively closely related to the Bombycoidea and thus make great candidates for studying the emergence of MDHn innervation of the AL. Due to these differences between butterfly and moth flight behavior, we hypothesized that diurnal, and visually guided butterflies would have no AL MDHn innervation. We examined the ALs and MsNs of representative species from three of the five total families of butterflies (Nymphalidae, Papilionidae, and Pieridae). In Pieris rapae (Pieridae), ventrally located MDHns in the MsN project ascending axons along the ventral nerve cord to the brain, and have a general architecture similar to M. sexta (Fig. 2A \& B). However, in P. rapae and Limenitis archippus (Nymphalidae) there were no HA-ir processes detected in the ALs (Fig 2C and D respectively). Finally, the MDHns of Papilio appalachiensis (Papilionidae) also branch radially throughout the MsN and project to the brain via the ventral nerve cord, but again HA-ir processes were absent within the AL (Fig 2E \& F). These results together suggest 
that MDHn innervation of the AL was either lost in butterflies or arose in the macrolepidopteran moths.

The Microlepidoptera are the most basal lepidopterans and are therefore ideally situated to determine if AL HA innervation by the MDHns had been lost in butterflies, or arose in the macroplepidopteran moths. To this end, we examined the MDHns of two microlepidopterans, Grapholita molesta (Tortricidae) and Galleria mellonella (Pyralidae), both of which walk and fan their wings during their final approach to an odor source [29, 30]. Similar to the macrolepidopteran moths, the MDHn axons of G. molesta ascend from the MsN (Fig. 3A) via the ventral nerve cord to innervate the ALs (Fig. 3B). This was also the case for G. mellonella (Pyralidae) (Fig. 3C \& D). We next examined the MDHns of one species of caddisfly (Limnephilidae) as Trichoptera is the sister taxon to the Lepidoptera. Although the wing kinematics of caddisflies has not been studied, caddisflies rely on sex pheromones as long distance communication cues [31], suggesting that they may be under similar behavioral and ecological constraints as moths. Similar to moths, the MDHns of caddisflies have ventrally located cell bodies that project ascending fibers to the brain (Figure 3E) that innervate the ALs (Fig. 3F). These results suggest that MDHn innervation of the ALs was present in a common ancestor of the Lepidoptera and caddisflies, but subsequently lost in the butterflies.

\section{(b) MDHns are Present Throughout Arthropods}

The olfactory systems of many arthropods species, including insects, are innervated by HA-ir processes from sources other than MDHns [12, 32-37], while the olfactory systems of other species lack HA-ir altogether [12, 14, 38, 39]. To determine when the characteristic morphology of the MDHns arose, we examined the MsN of several insect species and the second leg neuromeres of several more arthropod species (the equivalent neuromere to the mesothoracic 
neuromere in insects). Drosophila melanogaster (Drosophilidae) possess MDHns with the characteristic radial planar projections within the MsN and ascending axonal projections (Fig. 4A). However, while these ascending projections innervate the SEZ and AMMC, they do not enter the ALs (Figure 4B). In Tenebrio molitor (Coleoptera), Oncopeltus fasciatus (Hemiptera), and Gyna lurida (Blattodea), ventrally located cell bodies with ascending HA fibers were also observed in the MsN (Figure 4C, D \& E), as is also the case for the maxillulary cephalic neuromere of the copepod Calanus finmarchicus (Crustaceae; [34]) and in the thoracic ganglia of the lobster Homarus americanus (Crustaceae; [40]). In the centipede Theatops californiensis, at least two pairs of histaminergic neurons were located in the ganglion corresponding to the segment bearing the second pair of legs (Fig. 4F). One pair of midline cells possessed ventral cell bodies and ascending axons. The extent of branching of these cells within the ganglion was minimal, but the axons were located dorsally, consistent with all other species observed. Finally, in the tick Amblyomma americanum (Chelicerata; Ixodidae), dorsally and laterally located cell bodies were observed, and there were no ascending projections (Figure 4G), rather these cells projected diffusely in most neuromeres of the synganglion. In particular, we observed dense histaminergic innervation of the pedal, and cheliceral neuromeres, areas that process leg and mouthpart sensorimotor information [41]. This distribution of histaminergic neurons was similar to that observed in the synganglia of spiders [42]. It is unclear, however, whether these neurons are homologs of the MDHns as their cell bodies are dorsally located and reside along the lateral margin of the synganglion. Thus, MDHns appear to be widely distributed within the arthropods, and while homologous neurons are not apparent in ticks, histaminergic neurons that interconnect limb control and somatosensory regions appear to be a common feature of the arthropod nervous system. 


\section{DISCUSSION}

Using a comparative approach to study specific neural circuits provides insight into how circuits are co-opted to perform new functions within a relatively short evolutionary time. Here, we hypothesized that the presence of a circuit interconnecting the flight motor and olfactory systems would correlate with flight mechanics that impact the sensory field. In this study, we found that a morphologically distinct neuron that ascends from the MsN to innervate the AL arose after the last common ancestor of the Diptera and Lepidoptera (Fig. 5). This circuit was conserved across much of the Lepidoptera, however this trait was lost in diurnal butterflies which differ dramatically from nocturnal moths in their behavioral ecology (Fig. 5). Thus, the MDHns are the sole source of histamine to the olfactory system in moths and the loss of their presence in the ALs resulted in a complete lack of histamine at this olfactory processing stage in butterflies. Furthermore, paired, histaminergic neurons that ascend from motor centers in the ventral nerve cord to the brain appear to be conserved within the insects and crustaceans. However, in ticks (Fig. 4) and spiders [42] the palpal/pedipalpal neuropil receive dense innervation from HA-ir neurons with dorso-laterally located somata, suggesting that the MDHns (which have ventromedial somata) likely arose after the Chelicerates. Regardless of origin, across all arthropods appear to possess histaminergic neurons that interconnect ganglia representing different body segments.

Why would the olfactory systems of specific groups of insects receive input from flight motor centers, but not others? One potential explanation, is that differences in MDHn structure arose in response to the effects of wing beating on odor plume structure. In $M$. sexta, wing beating in tethered flight creates strong oscillatory flow of air over the antennae that is tightly coupled to the wing beat frequency [21]. Moths use odor plumes to locate mates, food, and oviposition sites. 
Furthermore, wing-beating biomechanics in B. mori while walking [24] and M. sexta while hovering during odor guided flight [25] are similar with respect to stable frequency and wing kinematics, suggesting that wing movement has similar impacts on odor plume structure and odor-antenna interactions. These wing beat-induced oscillations in airflow therefore create a periodic temporal structure that appears to be ecologically important. Butterflies, however, have strikingly different flight mechanics from moths. While moths have a consistent wing beat frequency and stroke during odor-guided flight [25, 43, 44], butterflies have a more stochastic wing beat, and flight path [28]. Indeed, many butterflies incorporate protean behavior into their flight patterns which ultimately creates a flight pattern with wingbeat frequencies that aren't as stable as in moths, which may be a means to avoid predation [28]. While the distribution of turning angles in moths is either bimodal or normal [45], the distribution in butterflies is uniform across all angles [46] and butterflies have been shown to prioritize flower color over scent [47]. Furthermore, although male and female butterflies produce pheromones, they are used as shortrange cues (1-2 meters) to determine mate quality after a potential mate has been located visually $[27,48]$, whereas male moths locate female moths via pheromones over distances of several tens of meters [49]. Although the path of the wing tip during each wing stroke is similar between $D$. melanogaster and moths [50], the wing beat frequency of D. melanogaster is $\sim 190-230 \mathrm{~Hz}$ [51], much higher than the $\sim 27-28 \mathrm{~Hz}$ wing beat frequency of $M$. sexta [21] and much higher than the upper limit of what antennal responses in D. melanogaster can track [52]. Furthermore, antennal responses across several insect species can track rapid odor concentration fluctuations [22, 53, 54], in some cases exceeding $100 \mathrm{~Hz}$ [52]. Local field potentials within the AL have also been shown to respond to fluctuations at least up to $\sim 70 \mathrm{~Hz}$ [22], well within the range of Lepidopteran wing beat frequencies. In addition, neural population responses from the AL of $M$. 
sexta track and represent olfactory stimuli optimally when odors are presented at the wingbeat frequency [23]. This finding also corresponds to enhanced olfactory acuity as measured behaviorally [55] supporting the conclusion that their olfactory system has adapted to encode information that is embedded within a temporal structure induced by their own active sampling behavior. The disturbances caused by the very high frequency wing-beating in D. melanogaster on the other hand, are unlikely to be tracked by the AL, although there is clear evidence that the mechano-acoustic signature of the wing beat is detected by the arista and processed in the AMMC [56, 57]. On the other hand, the lower frequency and relatively large amplitude disturbances in flow induced by wing beating in $M$. sexta, alter the structure of odor plumes in a manner that affects odor evoked activity in the $\mathrm{AL}[22,23]$. There are potentially two ways in which the MDHns could communicate information about motor output to the AL of M. sexta. It is possible that MDHn activity is controlled by the overall level of motor activity in the MsN, which would suggest that the MDHns simply inform the olfactory system that the moth is moving. The other possibility is that the MDHns provide a precise efference copy to the olfactory system, thus informing this sensory network of the timing of motor output that will disrupt the structure of the olfactory stimulus. Future experiments that determine the context for MDHn activation will shed insight on the role of the MDHns in olfactory coding.

Typically, across more moderate periods of evolutionary time, neural circuits change by dedicating more space and resources to processing stimuli that are most important for an ecological niche. For instance, a third of the male M. sexta AL is devoted to processing female sex pheromone [58], the size of the mushroom body calyces is tightly correlated with ant and bee worker caste [59] and cortical expansion in star-nosed moles, hedgehogs, and moles reflect species-specific changes in ecological niches and sensory appendages [60]. While many 
examples exist of the expansion and reduction of brain areas over time, very few examples exist of the invasion of new brain regions by identified neurons that are conserved across a broad range of species. Rather than an expansion within the context of a pre-existing function, the innervation of the ALs by the MDHns represent an example of co-option of a circuit into an additional network. The appearance, and subsequent loss of MDHn innervation of the ALs within the Lepidoptera suggests that individual neurons can be co-opted into existing neural networks in a relatively short period of evolutionary time.

We observed ascending histaminergic neurons that innervated mechanosensory regions for head appendages in the brains of arthropods that span $\sim 250$ million years of evolution. In $D$. melanogaster, as well as all moths and butterflies, MDHns innervate the AMMC, and even in ticks, which may lack MDHn homologs, there was dense histaminergic innervation of the dorsal anterior portion of the synganglion which receives sensory input from the mouthparts [41]. The conservation of this trait suggests that information about limb motor output is a critical component of mechanosensory network activity. The presence of interganglionic histaminergic neurons in the AMMC could also reflect the co-option of head appendages themselves from a locomotory function, to mechanosensory, and then olfactory function [61, 62]. Our data suggest that behavioral and morphological specializations in moths resulted in the co-option of this circuit that provides input to a mechanosensory network in the ancestral state to also provide additional input to the olfactory system.

Acknowledgments: We would like to thank John Boback, Mark Willis, George Keeney, Kathy Kyle Stout and Timothy Driscoll for providing various arthropod species. We would also like to thank Kristyn Lizbinski, Tyler Sizemore, Kaylynn Coates, and Kate Allen for comments on earlier drafts. 
Author Contributions: PC, SB, MH, EH, KR and AD collected data. PC, SB, KD and AD designed the project. All authors contributed to writing the paper.

Funding: This work was funded by NIH 1 R03 DC013997-01 to AMD and USAFOSR FA955017-1-0117 to KCD and AMD, as well as WVU Center for Neuroscience Summer Undergraduate Research Internships (NIGMS 5P30 GM103503) to MMH, EJH and KER.

\section{FIGURE LEGENDS}

\section{Figure 1}

MDHns in Macrolepidopteran Moths Innervate the ALs. A: Schematic of MDHns (green) in Manduca sexta. Each MDHn innervates the SEZ and AMMC before projecting to both ALs. Depth: B: Whole mount Manduca sexta pterothoracic ganglion immunolabeled for HA. MDHns are the most anterior pair of histaminergic neurons (arrow heads). $166.6 \mu \mathrm{m} \mathrm{C}$ : Frontal section of Manduca sexta AL immunolabeled for HA (green). Bruchpilot immunolabeling delineates neuropil (magenta). Depth: $52.36 \mu \mathrm{m}$ D: Sagittal section of Bombyx mori MsN immunolabeled for HA. Depth: $133 \mu \mathrm{m}$ E: Sagittal section of Bombyx mori AL immunolabeled for HA (green). Bruchpilot immunolabeling delineates neuropil (magenta). Depth: $58.8 \mu \mathrm{m}$ F: Whole mount sagittal view of Idia aemula pterothoracic ganglion. Depth: $164.64 \mu \mathrm{m}$ G. Sagittal section of Idia aemula AL immunolabeled for HA (green). Bruchpilot immunolabeling delineates neuropil (magenta). Bruchpilot (magenta) is used to delineate neuropil. HA-ir (green). Depth: $124 \mu \mathrm{m}$ Scale bars $=100 \mu \mathrm{m}$. Arrows $=$ cell bodies; Arrow heads $=$ ascending axons; Hatched white lines in $\mathrm{E}$ and $\mathrm{G}$ delineates the boundary of the AL. 


\section{Figure 2}

MDHns do not Innervate ALs in Butterflies. A: Full CNS montage of HA-ir in Pieris rapae. Depth: $239.86 \mu \mathrm{m}$ B: Whole mount sagittal view of Pieris rapae MsN. Depth: $157.36 \mu \mathrm{m}$ C: Pieris rapae AL showing absence of HA-ir (green). Bruchpilot immunolabeling delineates neuropil (magenta). Depth: $29.68 \mu \mathrm{m}$ D: Whole mount frontal view of Limenitis archippus of brain showing no AL HA-ir. HA-ir can be seen directly posterior of the left AL in D (Depth: $39.38 \mu \mathrm{m}$ ) however optical stacks restricted to the depth of tissue including only the AL (Depth: $21.48 \mu \mathrm{m})$ demonstrate that these HA-ir processes do not enter the AL. E: Horizontal view of MsN of Papilio appalachiensis. Depth: 170.05 um F: Horizontal section of Papilio appalachiensis brain showing no HA-ir (green) in the AL. Bruchpilot (magenta) delineates neuropil. Depth: $25.76 \mu \mathrm{m}$. Scale bars $=100 \mu \mathrm{m}$. Arrows $=$ cell bodies; Arrow heads $=$ ascending axons; Hatched white lines in C, D and F delineates the boundary of the AL.

\section{Figure 3}

The MDHns in Microlepidoptera and Trichoptera innervate the ALs. A: Whole mount horizontal view of Galleria mellonella MsN. Depth: $123.3 \mu \mathrm{m}$ B: Whole mount frontal view of Galleria mellonella brain showing HA-ir (green) in the AL. Bruchpilot (magenta) delineates neuropil. Depth: $46.77 \mu \mathrm{m}$ C: Whole mount horizontal view of Grapholita molesta MsN. Depth: 147.11

$\mu \mathrm{m}$ D: Whole mount frontal view of Grapholita molesta brain. Depth: $40.8 \mu \mathrm{m} \mathrm{E}$ : Whole mount horizontal view of caddisfly (Limnephilidae) MsN. Depth: $103.82 \mu \mathrm{m}$ F: Whole mount frontal view of caddisfly (Limnephilidae) brain showing HA-ir (green) processes within the AL (brackets). Bruchpilot (magenta) delineates neuropil. Depth: $144.99 \mu \mathrm{m}$. Scale bars $=100 \mu \mathrm{m}$. Arrows $=$ cell bodies; Arrow heads $=$ ascending axons; Hatched white lines in B, D and F delineates the boundary of the AL. 


\section{Figure 4}

MDHns are Present in the Majority of Arthropods. A: Whole mount horizontal view of the ventral nervous system of Drosophila melanogaster. Depth: $132 \mu \mathrm{m}$ B: Whole mount frontal view of the brain of Drosophila melanogaster. No HA-ir is observed in the ALs (insets). Bruchpilot (magenta) delineates neuropil. Depth: $132 \mu \mathrm{m}$ C: Whole mount horizontal view of the MsN of Tenebrio molitor immunolabeled for HA. Depth: $156 \mu \mathrm{m}$ D: Whole mount horizontal view of thoracic ganglia of Oncopeltus fasciatus immunolabeled for HA. Depth: $211.22 \mu \mathrm{m}$ E: Whole mount horizontal view of the MsN of Gyna lurida immunolabeled for HA. Depth: $140 \mu \mathrm{m}$ F: Whole mount horizontal view of the first post-cephalic ganglion in Theatops californiensis immunolabeled for HA. Depth: $97.29 \mu \mathrm{m} \mathrm{G}$ : Whole mount horizontal view of the synganglion in Amblyomma americanum. Depth: $119 \mu \mathrm{m}$ Scale bars $=100 \mu \mathrm{m}$. Arrows $=$ cell bodies; Arrow heads = ascending axons; Hatched white lines in B delineates the boundary of the AL.

\section{Figure 5}

Schematic representation of the proposed evolutionary history of the MDHns. In this representation, the MDHns originally projected from the mesothoracic neuromere (MsN; blue) to the sub-esophageal zone and antennal mechanosensory and motor center (AMMC/SEZ; lavender). In the last common ancestor of the Lepidoptera and Trichoptera, the MDHns were coopted (1; Dashed MDHn branches) to innervate the antennal lobes (ALs; magenta). The innervation of the ALs was lost in the butterflies (2), but maintained in macrolepidoteran moths. 


\section{REFRENCES}

[1] True, J.R. \& Carroll, S.B. 2002 Gene co-option in physiological and morphological evolution. Annu Rev Cell Dev Bi 18, 53-80. (doi:10.1146/annurev.cellbio.18.020402.140619).

[2] Shubin, N., Tabin, C. \& Carroll, S. 2009 Deep homology and the origins of evolutionary novelty. Nature 457, 818-823. (doi:10.1038/nature07891).

[3] Borgia, G. \& Coleman, S.W. 2000 Co-option of male courtship signals from aggressive display in bowerbirds. Proc Biol Sci 267, 1735-1740. (doi:10.1098/rspb.2000.1203).

[4] Ahlberg, P.E. \& Clack, J.A. 2006 Palaeontology: a firm step from water to land. Nature 440, 747-749. (doi:10.1038/440747a).

[5] Ostrom, J.H. 1974 Archaeopteryx and Origin of Flight. Q Rev Biol 49, 27-47. (doi:Doi 10.1086/407902).

[6] Anderson, M.L. 2010 Neural reuse: A fundamental organizational principle of the brain. Behavioral and Brain Sciences 33, 245-+. (doi:10.1017/S0140525x10000853).

[7] Dumont, J.P.C. \& Robertson, R.M. 1986 Neuronal Circuits - an Evolutionary Perspective. Science 233, 849-853. (doi:DOI 10.1126/science.233.4766.849).

[8] Dickinson, P.S. 2006 Neuromodulation of central pattern generators in invertebrates and vertebrates. Curr Opin Neurobiol 16, 604-614. (doi:10.1016/j.conb.2006.10.007).

[9] Katz, P.S. \& Harris-Warrick, R.M. 1999 The evolution of neuronal circuits underlying species-specific behavior. Curr Opin Neurobiol 9, 628-633. (doi:S0959-4388(99)00012-4 [pii] 10.1016/S0959-4388(99)00012-4).

[10] Anderson, M.L. 2007 Evolution of cognitive function via redeployment of brain areas. Neuroscientist 13, 13-21. (doi:10.1177/1073858406294706).

[11] Bell, R.A. \& Joachim, F.G. 1976 Techniques for Rearing Laboratory Colonies of Tobacco Hornworms and Pink Bollworms Lepidoptera-Sphingidae-Gelechiidae. Ann Entomol Soc Am 69, 365-373.

[12] Dacks, A.M., Reisenman, C.E., Paulk, A.C. \& Nighorn, A.J. 2010 Histamineimmunoreactive local neurons in the antennal lobes of the hymenoptera. J Comp Neurol 518, 2917-2933. (doi:10.1002/cne.22371). 
[13] Bradley, S.P., Chapman, P.D., Lizbinski, K.M., Daly, K.C. \& Dacks, A.M. 2016 A Flight Sensory-Motor to Olfactory Processing Circuit in the Moth Manduca sexta. Front Neural Circuits 10, 5. (doi:10.3389/fncir.2016.00005).

[14] Melzig, J., Buchner, S., Wiebel, F., Wolf, R., Burg, M., Pak, W.L. \& Buchner, E. 1996 Genetic depletion of histamine from the nervous system of Drosophila eliminates specific visual and mechanosensory behavior. Journal of Comparative Physiology a-Sensory Neural and Behavioral Physiology 179, 763-773.

[15] Homberg, U. \& Hildebrand, J.G. 1991 Histamine-immunoreactive neurons in the midbrain and suboesophageal ganglion of sphinx moth Manduca sexta. J Comp Neurol 307, 647-657. (doi:10.1002/cne.903070410).

[16] Gisselmann, G., Pusch, H., Hovemann, B.T. \& Hatt, H. 2002 Two cDNAs coding for histamine-gated ion channels in D. melanogaster. Nat Neurosci 5, 11-12. (doi:10.1038/nn787).

[17] Zheng, Y., Hirschberg, B., Yuan, J., Wang, A.P., Hunt, D.C., Ludmerer, S.W., Schmatz, D.M. \& Cully, D.F. 2002 Identification of two novel Drosophila melanogaster histamine-gated chloride channel subunits expressed in the eye. J Biol Chem 277, 2000-2005.

(doi:10.1074/jbc.M107635200).

[18] Horner, M., Helle, J. \& Schurmann, F.W. 1996 The distribution of histamineimmunoreactive neurons in the ventral nerve cord of the cricket, Gryllus bimaculatus. Cell and Tissue Research 286, 393-405. (doi:DOI 10.1007/s004410050709).

[19] Patschke, A. \& Bicker, G. 2011 Development of histamine-immunoreactivity in the Central nervous system of the two locust species Schistocerca gregaria and Locusta migratoria. Microsc Res Tech 74, 946-956. (doi:10.1002/jemt.20980).

[20] Gomez-Marin, A., Duistermars, B.J., Frye, M.A. \& Louis, M. 2010 Mechanisms of odortracking: multiple sensors for enhanced perception and behavior. Front Cell Neurosci 4, 6. (doi:10.3389/fncel.2010.00006).

[21] Sane, S.P. \& Jacobson, N.P. 2006 Induced airflow in flying insects II. Measurement of induced flow. J Exp Biol 209, 43-56. (doi:209/1/43 [pii] 10.1242/jeb.01958). 
[22] Tripathy, S.J., Peters, O.J., Staudacher, E.M., Kalwar, F.R., Hatfield, M.N. \& Daly, K.C. 2010 Odors Pulsed at Wing Beat Frequencies are Tracked by Primary Olfactory Networks and Enhance Odor Detection. Front Cell Neurosci 4, 1. (doi:10.3389/neuro.03.001.2010).

[23] Houot, B., Burkland, R., Tripathy, S. \& Daly, K.C. 2014 Antennal lobe representations are optimized when olfactory stimuli are periodically structured to simulate natural wing beat effects. Front Cell Neurosci 8, 159. (doi:10.3389/fncel.2014.00159).

[24] Mishima, T. \& Kanzaki, R. 1998 Coordination of flipflopping neural signals and head turning during pheromone-mediated walking in a male silkworm moth Bombyx mori. Journal of Comparative Physiology a-Sensory Neural and Behavioral Physiology 183, 273-282. (doi:DOI 10.1007/s003590050255).

[25] Willmott, A.P. \& Ellington, C.P. 1997 The mechanics of flight in the hawkmoth Manduca sexta. I. Kinematics of hovering and forward flight. J Exp Biol 200, 2705-2722.

[26] Obara, Y. 1979 Bombyx-Mori Mating Dance - Essential in Locating the Female. Appl Entomol Zool 14, 130-132.

[27] Scott, J.A. 1974 Mate-Locating Behavior of Butterflies. Am Midl Nat 91, 103-117. (doi:Doi 10.2307/2424514).

[28] Srygley, R.B. \& Chai, P. 1990 Flight Morphology of Neotropical Butterflies - Palatability and Distribution of Mass to the Thorax and Abdomen. Oecologia 84, 491-499.

[29] Giner, M., Balcells, M. \& Avilla, J. 2012 Insecticidal action of five allyl esters on eggs and larvae of three tortricid fruit pests: laboratory tests. B Insectol 65, 63-70.

[30] Roller, H., Biemann, K., Bjerke, J.S., Norgard, D.W. \& Mcshan, W.H. 1968 Sex Pheromones of Pyralid Moths .I. Isolation and Identification of Sex-Attractant of Galleria Mellonella L (Greater Waxmoth). Acta Entomol Bohemos 65, 208-\&.

[31] Wood, J.R. \& Resh, V.H. 1984 Demonstration of sex pheromones in caddisflies (Trichoptera). J Chem Ecol 10, 171-175. (doi:10.1007/BF00987654).

[32] Bornhauser, B.C. \& Meyer, E.P. 1997 Histamine-like immunoreactivity in the visual system and brain of an orthopteran and a hymenopteran insect. Cell Tissue Res 287, 211-221.

[33] Gebhardt, S. \& Homberg, U. 2004 Immunocytochemistry of histamine in the brain of the locust Schistocerca gregaria. Cell Tissue Res 317, 195-205. (doi:10.1007/s00441-003-0841-y). 
[34] Hartline, D.K. \& Christie, A.E. 2010 Immunohistochemical mapping of histamine, dopamine, and serotonin in the central nervous system of the copepod Calanus finmarchicus (Crustacea; Maxillopoda; Copepoda). Cell Tissue Res 341, 49-71. (doi:10.1007/s00441-0100974-8).

[35] Ignell, R. 2001 Monoamines and neuropeptides in antennal lobe interneurons of the desert locust, Schistocerca gregana: an immunocytochemical study. Cell Tissue Res 306, 143-156.

[36] Loesel, R. \& Homberg, U. 1999 Histamine-immunoreactive neurons in the brain of the cockroach Leucophaea maderae. Brain Res 842, 408-418. (doi:S0006-8993(99)01864-8 [pii]).

[37] Callaway, J.C. \& Stuart, A.E. 1999 The distribution of histamine and serotonin in the barnacle's nervous system. Microsc Res Tech 44, 94-104. (doi:10.1002/(SICI)10970029(19990115/01)44:2/3<94::AID-JEMT4>3.0.CO;2-F).

[38] Liu, W.W. \& Wilson, R.I. 2013 Transient and specific inactivation of Drosophila neurons in vivo using a native ligand-gated ion channel. Curr Biol 23, 1202-1208.

(doi:10.1016/j.cub.2013.05.016).

[39] Dacks, A.M. \& Nighorn, A.J. 2011 The organization of the antennal lobe correlates not only with phylogenetic relationship, but also life history: a Basal hymenopteran as exemplar. Chem Senses 36, 209-220. (doi:bjq121 [pii]

10.1093/chemse/bjq121).

[40] Mulloney, B. \& Hall, W.M. 1991 Neurons with Histamine-Like Immunoreactivity in the Segmental and Stomatogastric Nervous Systems of the Crayfish Pacifastacus-Leniusculus and the Lobster Homarus-Americanus. Cell and Tissue Research 266, 197-207. (doi:Doi 10.1007/Bf00678725).

[41] Hummel, N.A., Li, A.Y. \& Witt, C.M. 2007 Serotonin-like immunoreactivity in the central nervous system of two ixodid tick species. Exp Appl Acarol 43, 265-278. (doi:10.1007/s10493007-9120-z).

[42] Schmid, A. \& Becherer, C. 1999 Distribution of histamine in the CNS of different spiders. Microsc Res Tech 44, 81-93. (doi:10.1002/(SICI)1097-0029(19990115/01)44:2/3<81::AIDJEMT3>3.0.CO;2-O).

[43] Liu, H., Ellington, C. \& Kawachi, K. 1998 A computational fluid dynamic study of hawkmoth hovering. J Exp Biol 201 (Pt 4), 461-477. 
[44] Usherwood, J.R. \& Ellington, C.P. 2002 The aerodynamics of revolving wings I. Model hawkmoth wings. J Exp Biol 205, 1547-1564.

[45] Kuenen, L.P.S. \& Carde, R.T. 1994 Strategies for Recontacting a Lost Pheromone Plume Casting and Upwind Flight in the Male Gypsy-Moth. Physiol Entomol 19, 15-29. (doi:DOI 10.1111/j.1365-3032.1994.tb01069.x).

[46] Root, R.B. \& Kareiva, P.M. 1984 The Search for Resources by Cabbage Butterflies (PierisRapae) - Ecological Consequences and Adaptive Significance of Markovian Movements in a Patchy Environment. Ecology 65, 147-165. (doi:Doi 10.2307/1939467).

[47] Omura, H. \& Honda, K. 2005 Priority of color over scent during flower visitation by adult Vanessa indica butterflies. Oecologia 142, 588-596. (doi:10.1007/s00442-004-1761-6).

[48] Andersson, J., Borg-Karlson, A.K., Vongvanich, N. \& Wiklund, C. 2007 Male sex pheromone release and female mate choice in a butterfly. Journal of Experimental Biology 210, 964-970. (doi:10.1242/jeb.02726).

[49] Elkinton, J.S., Schal, C., Ono, T. \& Carde, R.T. 1987 Pheromone Puff Trajectory and Upwind Flight of Male Gypsy Moths in a Forest. Physiol Entomol 12, 399-406. (doi:DOI 10.1111/j.1365-3032.1987.tb00766.x).

[50] Zanker, J.M. 1988 How Does Lateral Abdomen Deflection Contribute to Flight Control of Drosophila-Melanogaster. Journal of Comparative Physiology a-Sensory Neural and Behavioral Physiology 162, 581-588. (doi:Doi 10.1007/Bf01342633).

[51] Lehmann, F.O. \& Dickinson, M.H. 1997 The changes in power requirements and muscle efficiency during elevated force production in the fruit fly Drosophila melanogaster. $J$ Exp Biol 200, 1133-1143.

[52] Szyszka, P., Gerkin, R.C., Galizia, C.G. \& Smith, B.H. 2014 High-speed odor transduction and pulse tracking by insect olfactory receptor neurons. P Natl Acad Sci USA 111, 16925-16930. (doi:10.1073/pnas.1412051111).

[53] Lemon, W. \& Getz, W. 1997 Temporal resolution of general odor pulses by olfactory sensory neurons in American cockroaches. J Exp Biol 200, 1809-1819.

[54] Bau, J., Justus, K.A. \& Carde, R.T. 2002 Antennal resolution of pulsed pheromone plumes in three moth species. J Insect Physiol 48, 433-442. 
[55] Daly, K.C., Kalwar, F., Hatfield, M., Staudacher, E. \& Bradley, S.P. 2013 Odor detection in Manduca sexta is optimized when odor stimuli are pulsed at a frequency matching the wing beat during flight. PLoS One 8, e81863. (doi:10.1371/journal.pone.0081863).

[56] Lai, J.S., Lo, S.J., Dickson, B.J. \& Chiang, A.S. 2012 Auditory circuit in the Drosophila brain. Proc Natl Acad Sci U S A 109, 2607-2612. (doi:10.1073/pnas.1117307109).

[57] Tootoonian, S., Coen, P., Kawai, R. \& Murthy, M. 2012 Neural representations of courtship song in the Drosophila brain. J Neurosci 32, 787-798. (doi:10.1523/JNEUROSCI.5104-11.2012).

[58] Rospars, J.P. \& Hildebrand, J.G. 2000 Sexually dimorphic and isomorphic glomeruli in the antennal lobes of the sphinx moth Manduca sexta. Chem Senses 25, 119-129.

[59] Ehmer, B. \& Gronenberg, W. 2004 Mushroom body volumes and visual interneurons in ants: comparison between sexes and castes. J Comp Neurol 469, 198-213.

(doi:10.1002/cne.11014).

[60] Catania, K.C. 2000 Cortical organization in insectivora: the parallel evolution of the sensory periphery and the brain. Brain Behav Evol 55, 311-321. (doi:6666).

[61] Hansson, B.S. \& Stensmyr, M.C. 2011 Evolution of insect olfaction. Neuron 72, 698-711. (doi:10.1016/j.neuron.2011.11.003).

[62] Jockusch, E.L., Williams, T.A. \& Nagy, L.M. 2004 The evolution of patterning of serially homologous appendages in insects. Dev Genes Evol 214, 324-338. (doi:10.1007/s00427-0040412-6). 


\section{FIGURES}

Figure 1

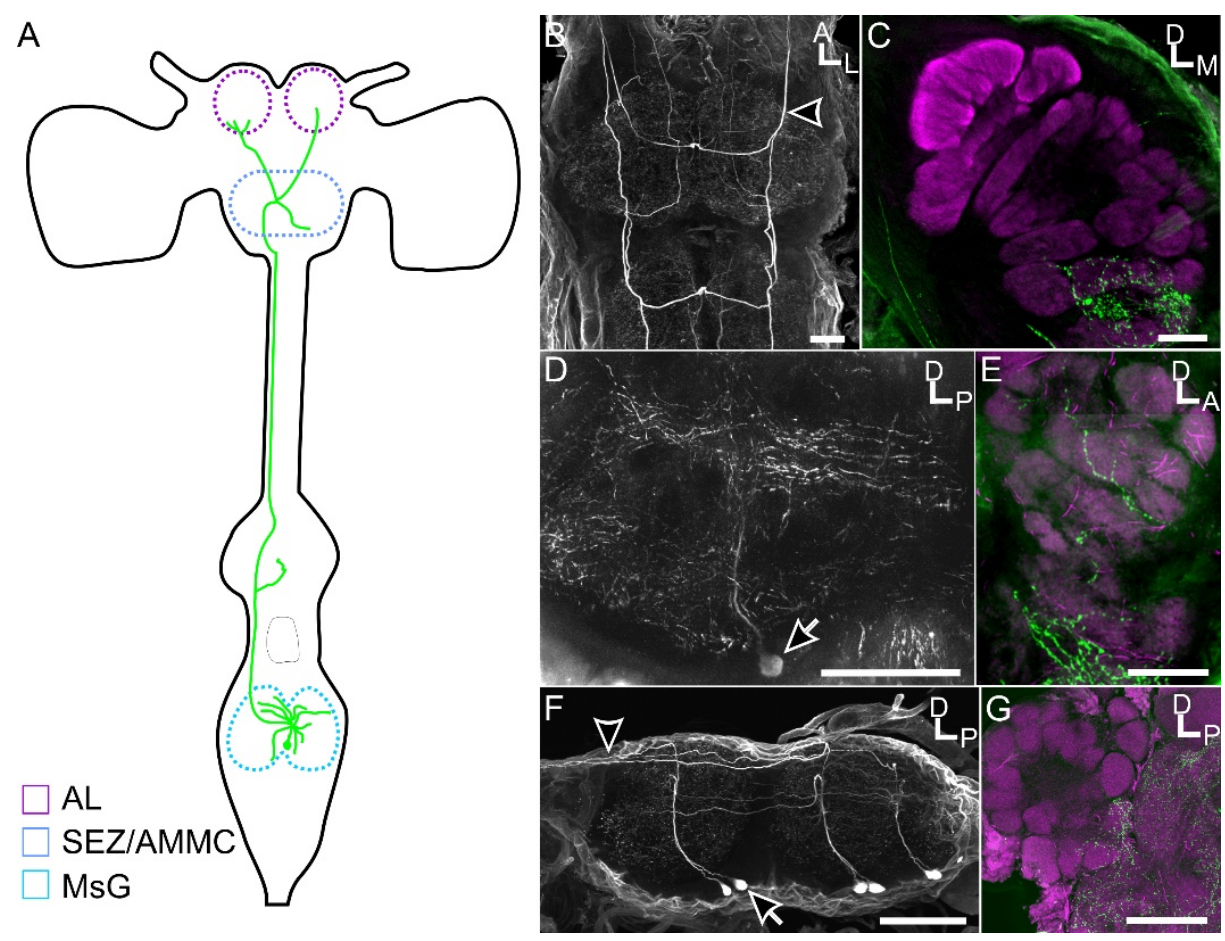


Figure 2

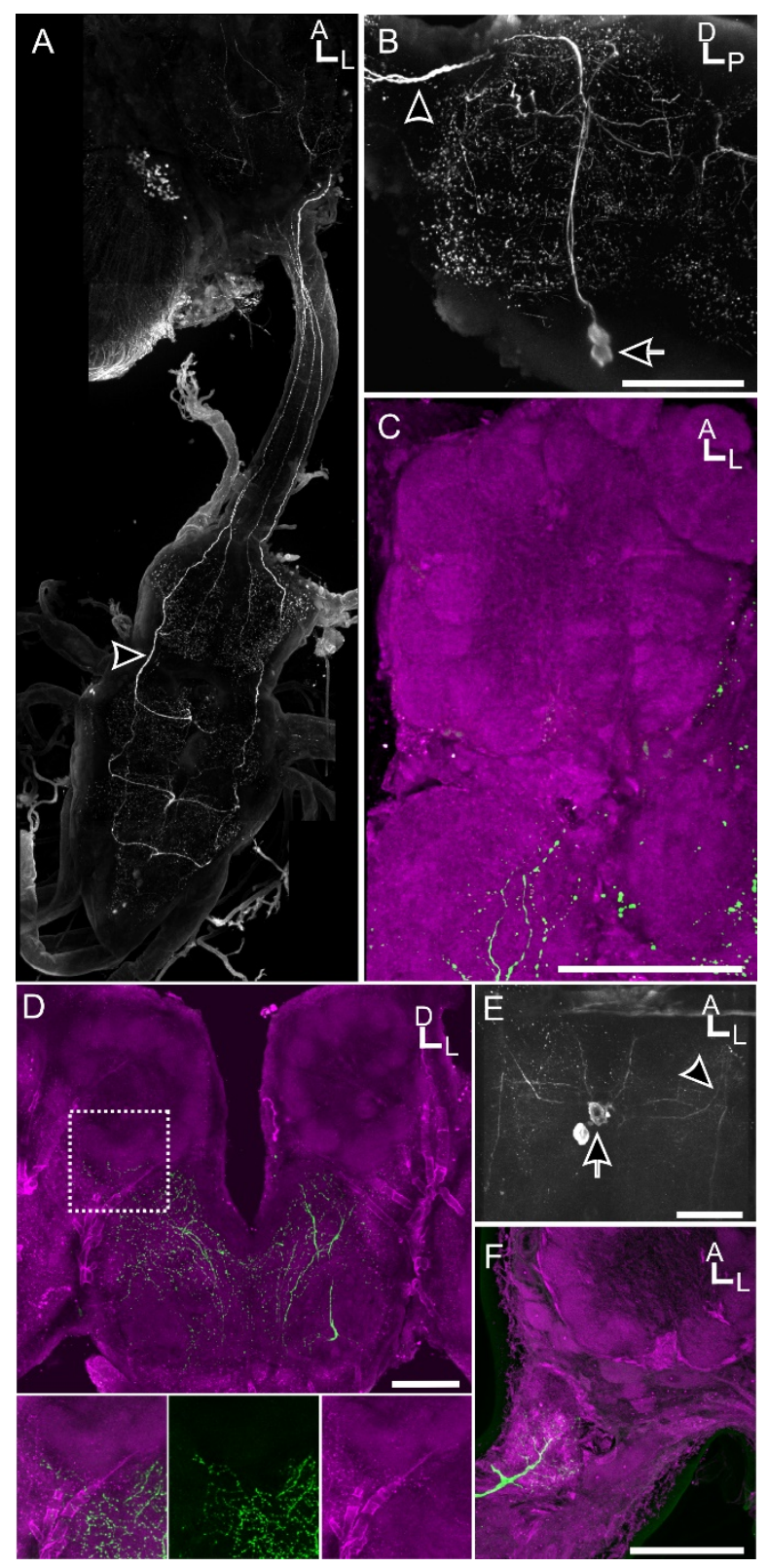


Figure 3

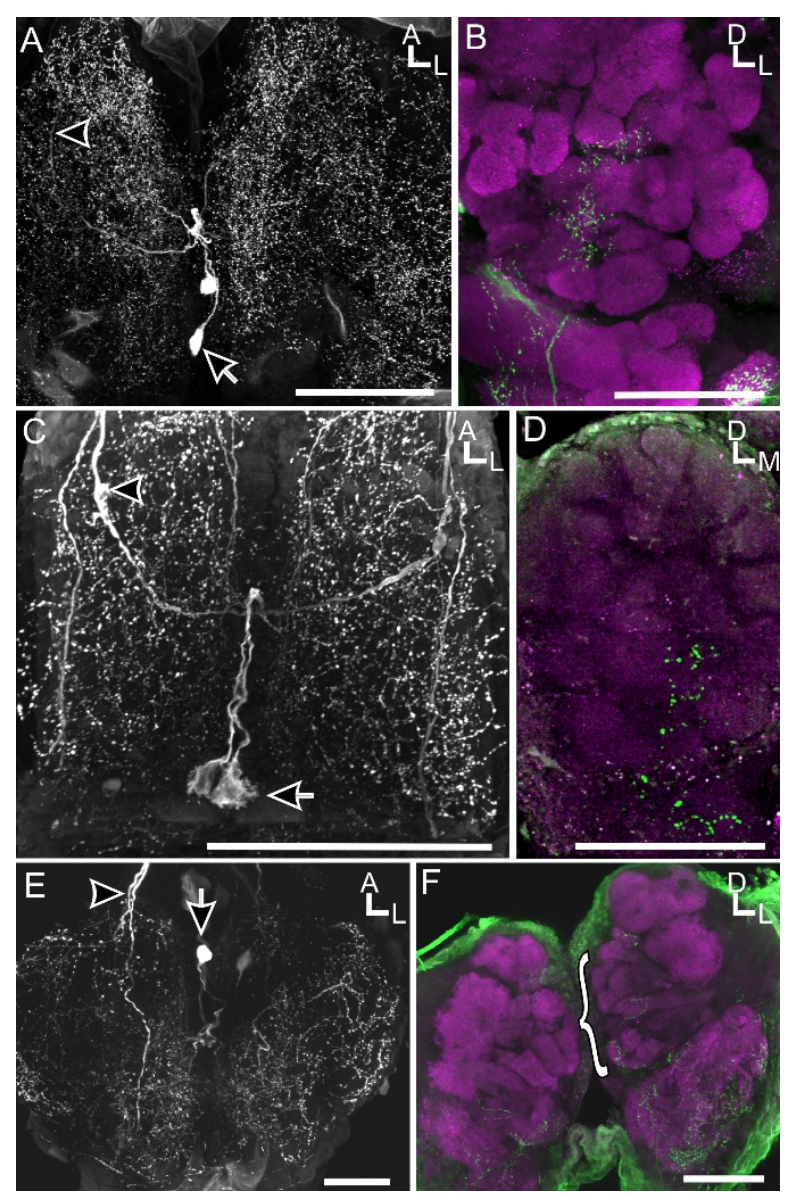


Figure 4

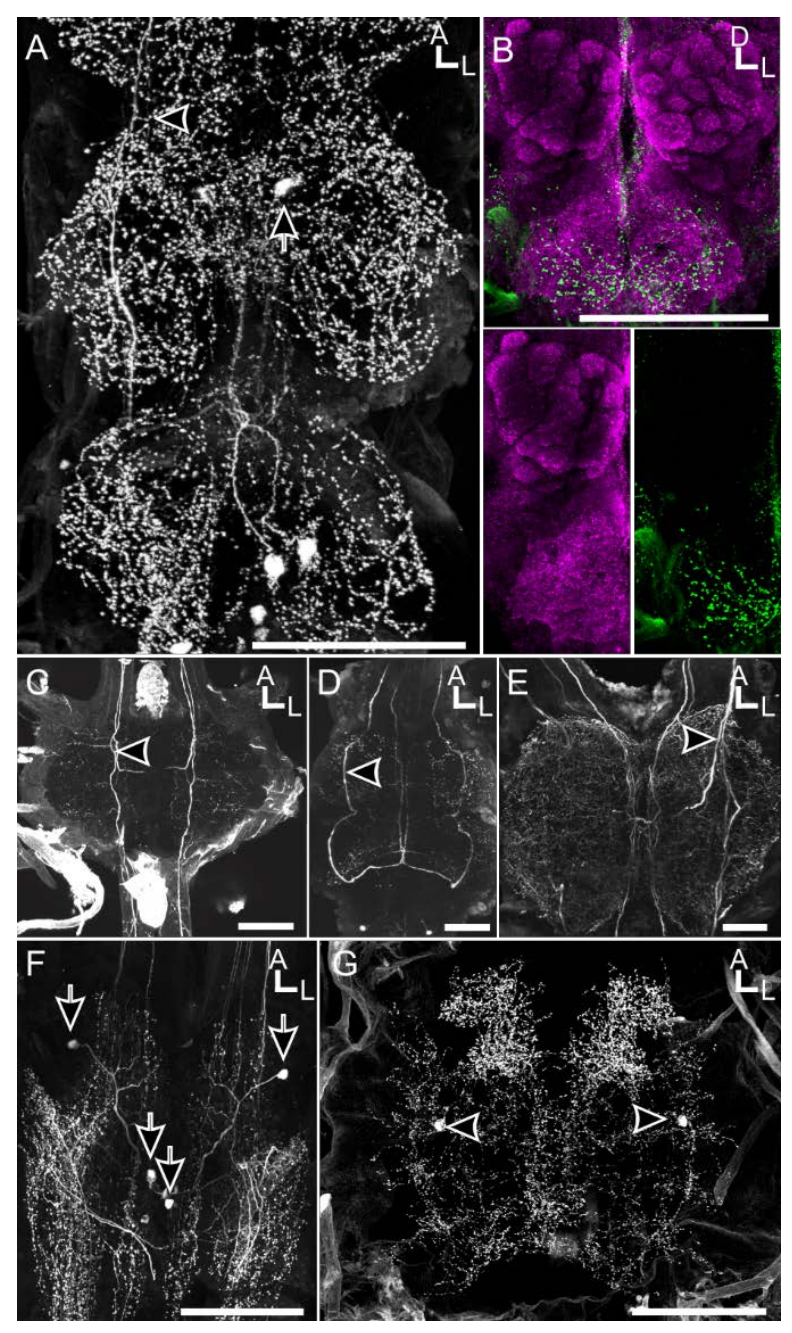


Figure 5

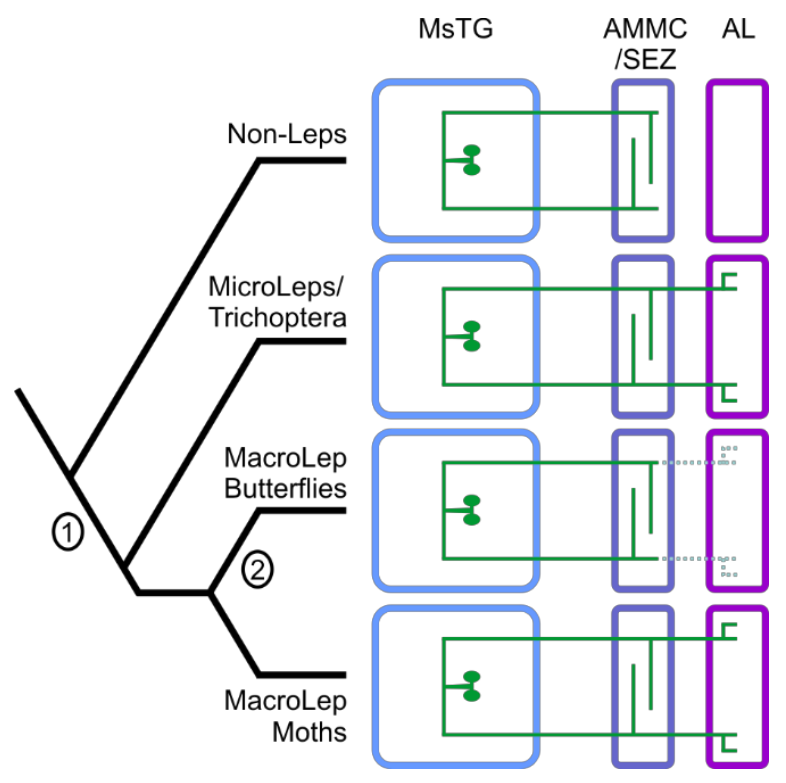




\title{
Appendix C
}

Flight Motor Networks Modulate Primary Olfactory Processing in the Moth Manduca sexta.

\author{
Phillip D. Chapman ${ }^{1}$, Rex Burkland ${ }^{1}$, Samual P. Bradley, Benjamin Houot ${ }^{2}$, Victoria Bullman, \\ Andrew M. Dacks, Kevin C. Daly \\ West Virginia University, Morgantown, WV, United States \\ ${ }^{1}$ These authors contributed equally to this work. \\ ${ }^{2}$ Division of Chemical Ecology, Department of Plant Protection Biology Swedish University of \\ Agricultural Sciences, Box 102, S-230 53 Alnarp Sweden
}

\begin{abstract}
Nervous systems must distinguish sensory signals derived from an animal's own movements (reafference) from environmentally derived sources (exafference). To accomplish this, motor networks producing reafference transmit motor information, via a corollary discharge circuit (CDC), to affected sensory networks, modulating sensory function during behavior. While CDCs have been described in most sensory modalities, none have been observed projecting to an olfactory pathway. In moths, two histaminergic neurons (MDHns) project from flight sensorimotor centers in the mesothoracic neuromere to the antennal lobe (AL) where they provide the sole source of histamine (HA), but whether they represent a CDC is unknown. We demonstrate that MDHn spiking activity is positively correlated with wing motor output and increased prior to bouts of motor activity, suggesting that MDHns communicate global locomotor state, rather than providing a precisely timed motor copy. Within the AL, HA application sharpened entrainment of PN responses to odor stimuli embedded within simulated
\end{abstract}


wing beat induced flows, whereas MDHn axotomy or AL HA receptor (HA-r) blockade reduced entrainment. This finding is consistent with higher order CDCs, as the MDHns enhanced rather than filtered entrainment of AL PNs. Finally, HA-r blockade increased odor detection and discrimination thresholds in behavior assays. These results establish MDHns as a CDC that modulates AL temporal resolution, enhancing odor-guided behavior. MDHns thus appear to represent a novel higher order CDC to an insect olfactory pathway, this CDC's unique nature highlights the importance of motor-to-sensory signaling as a context-specific mechanism that fine tunes sensory function.

Acknowledgements: We thank Mark Willis for fruitful discussions during the course of this research and Sadie Bergeron and Gary Marsat for comments on this manuscript. This research was supported by NIH DC009417 to KCD and AFOSR FA9550-17-1-0117 to KCD and AMD.

Significance: Across vertebrates and invertebrates, corollary discharge circuits (CDCs) project to and inform sensory networks about an animals' movements, which directly impact sensory processing. Failure of CDCs likely underlie sensory hallucinations in schizophrenia, Parkinson's disease and dyspnea, highlighting the fundamental importance of CDCs for successfully interpreting sensory cues to adaptively interact with the external world. Ultimately, understanding the role of CDCs in integrating sensory motor function will be vital to understand these diseases, but mechanistically little is known about how CDCs function. CDCs have been identified in most sensory domains except olfaction. Our findings indicate that a histaminergic CDC enhances the ability of the olfactory system to more precisely encode stimulus temporal structure, resulting in enhanced olfactory acuity. 


\section{INTRODUCTION}

As animals locomote, their motor actions can directly affect sensory function, causing selfinduced, or "reafferent”, sensory neural responses. Unchecked, reafference can interfere with or otherwise influence the experience of externally derived or “exafferent”, sensory cues.

Furthermore, behaviors causing reafference can be an integral component of active sensory sampling strategies. For instance, saccadic eye movements continually shift the retinal image in a ballistic fashion to interrogate the visual environment and yet visual experience is perceived as stable. This visual stabilization likely occurs because the superior colliculus sends information about eye movement commands to the frontal eye field of the cortex[1]. Such motor-to-sensory pathways are referred to as corollary discharge circuits (CDCs), which are a class of forward circuits that specifically provide information about motor activity to sensory systems, allowing them to account for behavior-induced effects on sensory function. CDCs can provide precisely timed facsimiles of motor commands (i.e., an efference copy) to modulatory-like signals that represent current or pending changes in behavioral state [2]. While all CDCs provide motor information to sensory systems, they can be further classified based on their functional consequences on sensory processing. CDCs that filter out reafferent inputs or inhibit sensorydriven reflexes [e.g. 3, 4] are classified as lower order CDCs, while those that predict, stabilize, facilitate sensory signal analysis, or sensory motor learning [e.g. 5, 6] can be classified as higher order CDCs[2]. Given their fundamental role in sensory-motor interactions, evidence of CDCs have been observed in vision[2, 5-7], hearing [4, 8, 9] and the sensing of body posture[10, 11], and their failure likely underlies sensory hallucinations in schizophrenia[12], Parkinson’s disease[13] and dyspnea[14]. Indeed, CDCs have been characterized to some degree in nearly every sensory domain except olfaction, and to date no higher order CDC has been described in any invertebrate nervous system. 
Like eye saccades in vertebrates, active olfactory sampling behaviors such as sniffing, antennal and tongue flicking, and wing beating are periodic[15]. These active sampling behaviors increase air flow and turbulence around the olfactory epithelium, inducing a mechanosensory component to olfactory neural responses observable even in the absence of odor[16-19]. In the hawkmoth Manduca sexta and other related insects, wing beating, in addition to casting back and forth through odor plumes, are an important component of active odor sampling behavior[20-22]. Wing beating can generate substantial oscillatory airflow over the antennae[23] and vibrates the antennae at the frequency of the beating wing during flight[24]. This implies that during odorguided flight, olfactory sensory neurons on the antennae are periodically exposed to odorant molecules in higher velocity flows induced by wing beating, presumably enhancing odorreceptor interactions[21]. Far from hindering moths, periodic odor stimulation is readily tracked by both local interneurons (LNs) and projection neurons (PNs) of the antennal lobe (AL; the primary olfactory network) up to but not beyond $\sim 28 \mathrm{~Hz}$, the maximum wing beat frequency of this species [25]. Pulsed delivery of odors elicits more distinctive AL odor representations relative to continuous odor stimulation[18], and appears to be required for several moth species to track and locate odor sources[20, 26, 27]. In theory, the ability to track odors presented in the wing beat frequency range could arise from purely feedforward mechanisms[28]. However, AL neural tracking of stimuli presented across the wing beat frequency range $(0-28 \mathrm{~Hz})$ requires neural connectivity between flight motor circuits in the thoracic neuromeres and the AL[25], suggesting that motor centers may directly influence the temporal resolution of the olfactory system. The only known connection between the flight motor pattern generating centers and the olfactory system in M. sexta is a single pair of mesothoracic to deutocerebral histaminergic (HA) neurons (MDHns); these cells represent the exclusive source of HA in the AL[29, 30]. Within 
each AL of M. sexta, 16 predominantly GABAergic LNs express the HA-B receptor (MsHisClBr) and collectively these LNs ramify all AL glomeruli whereas the HA-A receptor was not observed[30]. In arthropods, there are only two known HA receptors, both of which are fast inhibitory ionotropic $\mathrm{Cl}^{-}$channels[31-33], suggesting that MDHns disinhibit the AL network when active.

Adult M. sexta primarily fly to locomote and use their legs to grasp objects that they land upon, this suggests that MDHn function primarily relates to flight behavior. Consistent with this, the MsHisClBr is not expressed within the larval antennal center[30], despite the MDHns being present and projecting to these centers across all larval stages. This implies that that this circuit only becomes functional in adults and takes on a flight related role. In most insects, the MDHns project to the sub esophageal zone and antennal mechanosensory and motor center (AMMC). However, in nocturnally active plume tracking insects like caddisflies[34] and moths, the MDHns innervate the AL as well[35]. Interestingly, this circuit appears to have been lost in closely related butterflies[35], which are diurnal and differ from moths in their flight mechanics and relative reliance on visual, rather than olfactory cues. The MDHns are therefore excellent candidates for a CDC between flight sensory motor centers in the ventral nerve cord and the olfactory system in the moth brain, however neither their function during flight nor their functional role in olfactory processing and odor-guided behavior is known.

Here we demonstrate that the MDHns function as a higher order, flight-to-olfactory CDC. We show that MDHn spiking activity is positively correlated to the ongoing level of wing motor output and increased MDHn spike rate precedes bouts of motor output. Furthermore, increasing AL HA enhances entrainment to olfactory stimuli presented within the wing-beat frequency range, while disrupting AL HA-r function or removing MDHn input reduces entrainment. 
Finally, disruption of AL HA-r function decreases olfactory acuity in behavioral detection and discrimination threshold assays. Collectively, these results lead to the conclusion that during flight, the MDHns which likely disinhibit the AL network, upregulate AL entrainment to the stimulus temporal structure thereby enhancing olfactory acuity in behavioral assays. MDHns therefore do not filter the effects of wing beat induced sensory reafference from the neural response as would be the case in a lower order CDC. Rather, the MDHns upregulate the ability of the olfactory system to entrain to the temporal features of the odor stimulus and enhance the ability of moths to both detect and discriminate between odors. Thus, these results appear to represent a novel higher order motor-to-olfactory CDC.

\section{RESULTS}

\section{MDHn activity is positively correlated with forewing motor output.}

The MDHns arborize throughout the dorsal aspect of the mesothoracic neuromere, which along with the metathoracic neuromere, house flight central pattern generating circuitry, including wing sensory input[36-38]. To characterize the relationship between the MDHns and wing motor output, we developed an approach that leaves the entire central nervous system intact, exposing the mesothoracic neuromere where all sensory motor nerves emanating from the thoracic neuromeres were sectioned for stability; this also allowed us to make intracellular recordings from individual MDHns while simultaneously recording forewing depressor and elevator motor neuron output from the trunk IIN1b fiber using a suction electrode[39] (Fig. 1A). Intracellular electrode guidance to MDHns was visually blind, but spike shape and a tonic firing pattern guided selection of specific cells for recording. Each recorded cell was dye filled, and HA-immunolabeling was used to confirm that an MDHn was recorded (Fig 1B). 
All recorded MDHns ( $n=5$ ) produced highly stereotyped spike waveforms and were tonically active even in the absence of motor output (Fig 1C). In 4 of the 5 animals we were able to the hold intracellular recording long enough to induce wing motor output via bath application of chlordimeform $\left(10^{-5} \mathrm{M}\right)$ an effective and selective octopamine agonist known to reliably induce fictive flight in insects, including M. sexta[36]. In all cases MDHn tonic spike frequency was positively correlated with the presence and strength of wing motor output (Fig. 1C-G). This correlation could indicate that the MDHns receive input from motor circuitry or that chlordimeform directly affects the MDHns in parallel with motor circuitry. However, increases in MDHn firing rate were coupled to individual brief bouts of wing motor output (Fig. 1C), suggesting that MDHn activity was coupled to motor output per se and not necessarily chlordimeform application. This also suggests that MDHns were driven by network components that produce and regulate the initiation and cessation of wing motor output. In cases where wing motor output increased or otherwise remained tonically active on a time scale of minutes, MDH activity increased in coordination with gradual increases in motor output (Fig. 1D). Mean normalized spike rate of both MDHn and IIN1b were positively correlated across all recordings (Fig. 1E) and manually segmenting recordings into epochs of wing motor output versus “quiescence” (SI Methods) demonstrated a significant increase in MDHn spike rate during wing motor output (Fig. 1F). Thus, the activity of MDHns represents a corollary of wing motor output. MDHn activity could provide two types of information about wing motor output. MDHn spiking activity could be a precise efference copy of wing motor function (indicative of a lower-order $\mathrm{CDC}$ ), or rather than encoding precise wing movement, MDHn spiking activity could reflect the current behavioral state of the flight motor network (observed in higher order CDCs). Crosscorrelation analysis revealed no temporally precise spiking relationships between the recorded 
motor output fiber and MDHn (Fig. 1G). Rather, MDHn activity preceded bouts of motor activity by approximately $100 \mathrm{~ms}$ and the correlation between MDHn and IIN1b spiking was only evident when data was smoothed across 25 ms or more (Fig. 1G), indicating that MDHn spiking activity and flight motor output were correlated on a slower timescale. Thus, while MDHn and wing motor output appear to be driven by an at least partially overlapping circuitry, the MDHns do not represent a precise efference copy per se. This is further supported by the observation that in all MDHn recordings, there was persistent tonic spiking in the absence of motor output. Thus, MDHns appear to encode changes in behavioral state.

\section{Antennal lobe neural entrainment to stimulus temporal structure is modulated by histamine.}

MHDns increase their spiking activity during wing motor output, thus it stands to reason that HA release in the AL increases as well. We next asked whether HA release from the MDHns, which are the exclusive source of HA in the AL of M. sexta[30], affects neural responses to temporally patterned odor stimulation that simulates the periodic flow effects induced by wing beating[23]. We therefore used extracellular tetrodes to record simultaneously from multiple individual AL neural units[40] while stimulating the antenna with a single odorant (either 2hexanone or 2-octanone). Odor was presented in blocks of five $500 \mathrm{~ms}$ long $20 \mathrm{~Hz}$ pulse trains using a 50\% duty cycle (i.e. $25 \mathrm{~ms}$ on and $25 \mathrm{~ms}$ off) and 10 sec between each train of a block. This was repeated every two minutes for $30 \mathrm{~min}$. After the first block, the moth received one of the three treatments (Fig. 2A). On average 18-22\% of AL neural units within each group entrained to odor pulse trains. Based on their spiking characteristics, these units can be putatively classified as PNs[41]. First, to disrupt HA function, we bath applied the HA-r antagonist cimetidine (500 $\mu \mathrm{M}$; Fig. 2A). In many units that were initially able to entrain to $20 \mathrm{~Hz}$ pulsed stimuli, cimetidine application decreased their ability to entrain to stimulus temporal structure. 
For example, the unit depicted in Figure 2B, initially responded reliably to all ten pulses of the pulse train across all 5 repeats as indicated by 10 prominent peaks in the inset histogram. After cimetidine application, the same unit failed to reliably entrain to the stimulus; it failed to respond to the first two pulses then consistently responded to three, perhaps 4 subsequent pulses. To evaluate the ability of units to entrain to the $20 \mathrm{~Hz}$ pulse trains, we calculated power spectral densities for each unit in response to each stimulus block, then calculated the integrated power from $18-22 \mathrm{~Hz}$ [25]. Cimetidine application significantly decreased the mean integrated power across units over time indicating that, relative to time matched controls, the ability of units to entrain to pulsed odor had degraded within 6 minutes of application (Fig. 2C). If blocking HA-r function reduces the ability of AL neurons to entrain to pulsed stimuli, it stands to reason that removing input from the sole source of HA in the AL (the MDHns[30]) should have the same effect. Therefore, our second approach was to sever the neck connective in a second group of moths, thus axotomizing the two MDHn axons therein (Fig. 2A). As with cimetidine application, we observed that in moths where the neck connectives were cut, units that were initially able to reliably track pulsed odor were less able to track over time relative to time-matched sham surgery controls (e.g. Fig. 2D). Across the population this manifest as a significant reduction in integrated power around the pulsing frequency within 16 min (Fig. 2E). It is important to note that entrainment across the population was not completely lost in either case. Rather, there was a loss of responses to individual pulses of a train (Fig. 2B inset red box) and/or the relative degradation in ability of the cell to produce discrete bursts to individual pulses separated by interstitials with no spiking (see Fig. 2D, before vs after). Finally, if disrupting the MDH circuit degrades the temporal fidelity of odor encoding, bath application of HA should have the opposite effect. Therefore, in a final group of moths HA $(50 \mu \mathrm{M})$ was bath applied during pulsed odor 
stimulation (Fig. 2A). Within 4 minutes of initiating HA application, the ability of individual units within the ensemble to entrain to the stimulus temporal structure increased and in some instances, units that did not initially entrain to odor pulses were recruited into the population of entrained units (e.g. Fig. 2F). Across the population, we observed a significant increase in mean integrated power at the pulsing frequency relative to controls (Fig. 2G). This HA-induced increase in power only occurs at the pulse frequency and does so as the overall population spiking response to the pulse trains increases as well (SI Fig. 1). These results collectively indicate that MDHn release of HA within the AL enhances entrainment to the stimulus temporal structure as opposed to filtering out the reafference. This again supports the notion that this circuit be classified as a higher order CDC[2].

\section{Olfactory acuity is histamine dependent.}

The capacity for the olfactory system to guide behavior is fundamentally dependent on its ability to detect and identify (i.e. discriminate) important odors. Simulating wing beat induced flows enhances both separation of neural representations of different odors[18] and olfactory acuity in behavioral assays[25, 42]. Therefore, we predict that because this CDC enhances odor processing it will likewise enhance behavioral measures of odor detection and discrimination. Two behavioral assays were used to determine if HA circuit function contributes to the detection and discrimination of odors (see SI Methods and Materials). Both assays were based on a wellestablished Pavlovian olfactory learning approach[43-48] where moths were first conditioned (for detection assays) or differentially conditioned (for discrimination assays) to respond to target odors. Twenty-four hours post conditioning, moths were randomly assigned into drug or control injection treatments and tested in a blind format. Based on initial control experiments (See SI Fig. 2), an effective dose of $\sim 1 \mathrm{nl}$ of $50 \mu \mathrm{M}$ cimetidine was injected into each AL. Fifteen 
minutes following injection, moths were challenged with a blank stimulus then a series of increasing concentrations of the conditioned odor to determine the concentration at which they detected the odor as measured by a significant increase in conditioned feeding response relative to the response to blanks. Both groups acquired the conditioned response (Fig 3A). However, tests subsequent to injection indicated that cimetidine injected moths displayed an order of magnitude higher detection threshold relative to controls (Fig. 3B). This was replicated using a different HA-r antagonist, ranitidine (see SI Materials and Methods, SI Results and SI Fig. 3). Collectively, these results suggest that HA within the AL enhances olfactory sensitivity. As detection is a prerequisite for identification[44, 47], it stands to reason that increased detection thresholds would also impact the moths ability to identify target odors. Here we observed that discrimination thresholds also increased when HA-r function was blocked. Moths in both drug treated, and control groups learned to differentially respond to the CS+ and CSodors (Fig. 3C). Again, 24h after conditioning, moths were injected with either cimetidine or the saline vehicle, this time in a double-blind format. We then tested with both the CS+ and CSodors across a dilution series of increasing concentration to determine the odor discrimination threshold, the lowest odor concentration at which moths responded significantly more to the CS+ relative to the CS- (i.e. a "conditioned differential response”; see SI methods). The discrimination threshold for saline injected moths occurred at an odor concentration of 0.1 $\mu \mathrm{g} / 2 \mu \mathrm{l}$, but when injected with cimetidine, a significant differential response was observed at $10.0 \mu \mathrm{g} / 2 \mu \mathrm{l}$. Thus, disruption of HA-r function decreases both the ability to detect (Fig. 3B) and identify (Fig. 3D) odors. 


\section{DISCUSSION}

Nervous systems must coordinate sensory with motor network function to adjust sensory processing based on planned and ongoing motor activities. CDCs are one class of neural circuits that provide information about motor output to sensory pathways to optimize sensory processing within the context of specific behaviors. CDCs can be broadly classified into two categories, “lower-order" and "higher-order”, defined based on the functional consequence they have on their target sensory pathway[2]. Lower-order CDCs directly inhibit the reafference with precisely timed spikes that gate sensory signals[4]. Higher-order CDCs on the other hand, can activate hundreds of milliseconds prior to the onset of a behavior and can modulate the state of a sensory network to accommodate imminent changes in behavior[9]. Furthermore, higher order CDCs do not block or filter the reafferent sensory input, rather they exploit the reafferent input to facilitate sensory processing[2]. Several studies in insects have characterized different neural circuit mechanisms that coordinate modulation of sensory processing with changes in behavioral state, such as flight or walking triggered release of octopamine to modulate processing of visual flow [49-51]. Our results indicate that the MDHns are a higher-order CDC that functions to disinhibit the AL in advance of imminent motor actions of the wings, enhancing the ability of the AL to entrain to the stimulus temporal structure. MDHn firing rate increases just prior to and during wing motor output, but is not synchronous with IIN1b motor neuron spiking, suggesting that the MDHns do not provide precise information about the timing of motor output (i.e. an efference copy), but rather they appear to represent the broad behavioral state of flight.

The input signals that drive MDHn activity remain unknown though the list of candidates is relatively small and includes sensory afferents from the wings, legs and thorax; central neurons that mediate motor patterns; and the motor neurons themselves. Sensory afferents are unlikely to 
drive MDHns as our approach was to cut all thoracic sensory afferent (and motor) fibers; this occurred $\sim 45$ min prior to recording. Furthermore, in M. sexta, MDHn local processes within the mesothoracic neuromere are restricted to its dorsomedial aspect[30], while sensory afferents in a closely related moth species predominately innervate its ventrolateral aspect[38]. However, we cannot rule out the possibility that sensory input to the pterothoracic ganglia normally contributes to MDHn activity in intact animals. Additionally, MDHn activity precedes wing motor output, making it unlikely that motor output drives their activity either. Thus, our anatomical and physiological data suggest that these cells are centrally (as opposed to peripherally) driven.

The ability of the olfactory system to track odor timing is highly dependent on LNs that control a variety of network-wide coding features including the transient nature of PN responses[52, 53]. LNs therefore represent an elegant target for CDCs to regulate a sensory network. Pulse tracking is only weakly present in antennal field recordings in M. sexta but dominates AL local field potentials and spiking in at least some PNs. Furthermore, pulse tracking is both odor- and GABA- dependent, which implies lateral interactions clarify this periodic signal[25]. Thus, while GABA mediates pulse tracking in PNs, our current results suggest that the MDHns modulate this ability, and that LNs are the most likely target. Indeed, arthropods express just two HA-rs, both of which are ionotropic $\mathrm{Cl}^{-}$channels[31-33] and the $\mathrm{AL}$ of $M$. sexta, the MsHisClB receptor is expressed exclusively by 16 GABAergic AL LNs which broadly ramify the entire AL[30]. This implies that during flight, increased MDHn activity inhibits this subpopulation of inhibitory LNs. While the postsynaptic targets of these 16 LNs are unknown, the consequence of HA signaling is enhancement of the AL network to encode the temporal structure of olfactory stimuli at the level of PN output. This in turn enhances detection and identification at the level of sensory 
perception. Given that mammalian sniffing behavior produces the same physical flow effects as wing beating, it stands to reason that an analogous system might facilitate olfaction in mammals, though we cannot rule out the possibility that this CDC might also function to generally increase frequency response to the relatively more rapid stimulus temporal structure encountered during upwind flight.

If the MDHns sharpen AL entrainment to pulsed stimuli, how might this result in enhanced behavioral performance in the psychophysical assays of olfactory sensitivity and acuity? Primary olfactory networks are spontaneously active and noisy. Superimposed upon olfactory network dynamics are weak mechanosensory-driven oscillatory dynamics produced by active sampling behaviors like sniffing $[16,17]$ and wing beating $[23,24]$. While AL neurons can be entrained to pulses of clean air[18, 25], moths do not respond to these clean air pulse trains in behavioral assays (relative to the same duration continuous clean air stimulus), and thus oscillating mechanosensory responses from the AL are behaviorally subthreshold. However, pulsed odor stimuli are more easily detected in behavioral detection threshold assays than continuous stimuli[25, 42], suggesting that antennal and AL mechanosensory responses which are timecoupled and summate with odor-evoked activity, may facilitate stronger odor responses. Our results suggest that the MDHns fine tune AL entrainment to oscillating airflow while the moth is in flight and actively seeking odor sources, rather than canceling out these weak mechanosensory oscillations as would be the case for a lower-order CDC.

Taken together, we demonstrate that the MDHns represent an olfactory CDC that enhances olfactory processing presumably during flight. The MDHns interconnect flight motor-centers and the olfactory system, are active during wing motor output which results in enhanced the temporal fidelity of AL neurons and odor-guided behavior of moths. Thus, the MDHns meet the criteria of 
a CDC. Furthermore, the MDHns appear to function as a "higher-order" CDC to the AL as their activity sharpens temporal entrainment to the stimulus. Thus, the MDHns likely influence the ability of the AL network to track odor timing and facilitate assembly of a salient "olfactory image”. Given that odor-guided behavior in M. sexta is performed primarily during flight and the MDHns originate in a flight sensory and motor pattern generating center, we propose that the MDHns optimize olfactory function within the context of odor-guided flight. Finally, given their ubiquity across insects[35] and their projections into multiple additional sensory processing centers, we have only begun to understand the multimodal nature of MDHns role in coordinating wing motor actions with sensory processing.

\section{MATERIALS AND METHODS}

SI Materials and Methods detail all experimental procedures. Briefly, intracellular recordings of MDHns were made in "CNS intact" preparations that exposes the pterothoracic ganglion and lesions only nerves emanating from the pro, meso and metathoracic neuromeres to eliminate muscle contraction near the recording site. Multiunit studies of AL neural spiking responses to pulsatile stimuli were performed using a fully intact preparation described in[48]. Putative PNs are identified on spiking characteristics[41]. Equal ratios of males and females were used for all behavior pharmacology experiments. All behavioral pharmacological methods and psychophysical assays have been previously detailed[44, 46, 47]. 


\section{FIGURE LEGENDS}

\section{Figure 1:}

$\mathrm{MDH}$ activity is correlated with flight motor patterns. (A) Schematic of key components of the moth CNS including the antennal lobes (AL), subesophageal zone (SEZ) and antennal mechanosensory and motor center (AMMC) and the pterothoracic ganglion (PTG) which includes the fused mesothoracic and metathoracic neuromeres. Also highlighted is our experimental approach, which included the simultaneous intracellular recording of an MDHn (blue) and suction electrode recording of the IIN1b nerve fiber (red) while wing motor output is driven from the flight central pattern generator $(\mathcal{S})$ via bath applied chlordimeform $(50 \mu \mathrm{M})$. (B) HA immunolabeling (green) of the MDHns with the intracellularly recorded MDHn filled with Alexa 568 (magenta). Inset below zoom of two distinct cell bodies labeled. Left: both laser channels. Center: Alexa 568 channel showing a single filled cell body and primary neurite. Right: HA channel showing the two cell bodies and primary neurites of the MDHn pair. Complete spatial overlap confirms the recording was of an MDHn. $\left(C_{i}\right)$ Superimposition of the smoothed instantaneous spike rate of the recorded MDHn (blue) and the raw extracellular recording of the IIN1b fiber (red). Inset dashed rectangle highlights the time sample shown in $\left(C_{i i}\right)$ which shows the raw spike trains for both traces. Note that the MDH spike rate always increases just prior to and during bouts of wing motor output. (D) Plot of z-score normalized spike rate for MDH (blue) and IIN1b (red) across 10 min of continuous recording demonstrating that as IIN1b activity increases over time, so too does MDH spike rate $(r=0.71)$. (E) Scatterplot of z-score normalized spike rate of $\mathrm{MDH}$ and IIN1b. Inset linear regression ( $\mathrm{n}=4$ recordings/738 points; $\left.\mathrm{R}^{2}=0.09, r=0.30\right) .(F)$ Mean spike rate from epochs where the IIN1b was quiet versus producing wing motor output from the recording highlighted in C. Inset error bars represent the standard error. Inset statistical comparisons between states indicates 
corresponding significant increase in both IIN1b and MDH (Welch's t-test; $\mathrm{n}=8$ recording segments; $\mathrm{p}<0.05$ ). (G) Crosscorrelation between MDH and IIN1b firing rates using Gaussian smoothing windows ranging in width from 2 ms to $1000 \mathrm{~ms}$. Note that for smoothing widows within typical spike integration times (2-5 ms) there is no correlation between measures.

\section{Figure 2:}

HA enhances entrainment of AL PNs to rapidly pulsed odor. (A) To evaluate the effect of MDHn HA release on the ability of AL PNs to entrain to pulsed stimuli, we performed three experiments, each in separate groups of animals. For all experiments, multi-channel electrodes were placed into the AL and multi-unit recordings were made while the ipsilateral antenna was stimulated with a block of five $500 \mathrm{~ms}$ long stimulation at $20 \mathrm{~Hz}$ pulse trains every two minutes for a total of 15 presentations. After the first block of pulse trains animals were challenged with an experimental treatment. (Left) In the first experiment, to disrupt HA-r function we bath applied $50 \mu \mathrm{M}$ cimetidine (CIM) in saline vehicle continuously over the course of the experiment. (Middle) In the second experiment of animals, to remove intrinsic HA input from the MDHn's the neck connective was cut thereby axotomizing the MDHns. (Right) In the third experiment of animals, direct bath application of HA $(50 \mu \mathrm{M})$ in saline vehicle was used to simulate increased MDHn output during flight. Exemplar peristimulus rasters and histograms for the baseline responses (before) and during/after cimetidine $(B)$, neck connective cut $(D)$ and HA (F) treatments. Mean integrated power from 18-22 Hz by time across all recorded neurons that entrained to the pulsed odor at some point during cimetidine $(C)$, neck connective cut $(E)$ and HA $(G)$ treatments. Error bars represent the standard error. Results plotted as a function of time since treatment. Power was normalized by dividing mean power from each block by the mean baseline (pre-treatment block) power. Inset arrows indicated the first block where there was a 
significant difference in power between experimental and control treatments (Welch's t-test for two samples with unequal variance; $\mathrm{p}<0.05$ ). Inset regressions are second order polynomials. Inset red rectangle $(B)$ highlights the loss of responses to the first two pulses as a consequence of cimetidine relative to pre-treatment.

\section{Figure 3:}

HA-r blockade disrupts behavioral measures of olfactory acuity. (A) Acquisition of the conditioned feeding response to a single odor (2-hexanone) as a function of conditioning trial for groups of moths in the detection threshold assay. Twenty-four hours later, one group of moths was bilaterally injected with either $50 \mu \mathrm{M}$ cimetidine (CIM) in saline vehicle or the saline vehicle without drug (Saline) in a blind manner then tested. (B) Conditioned feeding response as a function of odor concentration for the CIM and Saline groups. Inset open and filled arrowheads indicate detection threshold concentrations, for the Saline and CIM groups respectively, as defined by the lowest concentration odor yielding a significant increase in response relative to the blank (1-tailed paired t-test; $\mathrm{n}=60 ; \mathrm{p}<0.001$. (C) Acquisition of the differential conditioned feeding response to the CS+ and CS- stimuli for CIM and saline injected groups. Moths were first differentially conditioned to one of the two odorants (2-hexanone or 2-octanone). Both odors were used as the CS+ and CS- in separate but equally sized groups to counterbalance odordependent effects; for display, data was pooled by CS+ and CS-. (D) Discrimination index ((CS)-(CS+)) displayed by concentration for the CIM and Saline injected groups. Inset open and filled arrowheads indicate discrimination threshold, the concentration at which there was a significant differential response to the CS+ and CS- odors using 1-tailed paired t-tests (saline 
controls: $\mathrm{p}=0.03 ; \mathrm{n}=46$; CIM injected: $\mathrm{p}=0.05 ; \mathrm{n}=43$ ). All inset regression lines are $3^{\text {rd }}$ order polynomials and all error bars represent the standard error. 


\section{REFERENCES}

1. Sommer MA, Wurtz RH (2008) Visual perception and corollary discharge. Perception. (Sage Journals), pp 408-418.

2. Crapse TB, Sommer M a (2008) Corollary discharge across the animal kingdom. Nat Rev Neurosci 9:587-600.

3. Roy JE (2004) Dissociating self-generated from passively applied head motion: neural mechanisms in the vestibular nuclei. $J$ Neurosci 24:2102-2111.

4. Poulet JF a, Hedwig B (2002) A corollary discharge maintains auditory sensitivity during sound production. Nature 418:872-876.

5. Sommer MA, Wurtz RH (2006) Influence of the thalamus on spatial visual processing in frontal cortex. Nature 444:374-377.

6. Cavanaugh J, Berman RA, Joiner WM, Wurtz RH (2016) Saccadic corollary discharge underlies stable visual perception. J Neurosci 36:31-42.

7. Rath-Wilson K, Guitton D (2015) Oculomotor control after hemidecortication: A single hemisphere encodes corollary discharges for bilateral saccades. Cortex 63:232-249.

8. Poulet JFA, Hedwig B (2006) The cellular basis of a corollary discharge. Science 311:518-22.

9. Schneider DM, Nelson A, Mooney R (2014) A synaptic and circuit basis for corollary discharge in the auditory cortex. Nature 513:189-194.

10. Montgomery JC, Bodznick D (1994) An adaptive filter that cancels self-induced noise in the electrosensory and lateral line mechanosensory systems of fish. Neurosci Lett 174:145-148. 
11. Moore JD, Deschênes M, Furuta T, et al (2013) Hierarchy of orofacial rhythms revealed through whisking and breathing. Nature 497:205-10.

12. Ford JM, Mathalon DH, Roach BJ, et al (2013) Neurophysiological evidence of corollary discharge function during vocalization in psychotic patients and their nonpsychotic first-degree relatives. Schizophr Bull 39:1272-1280.

13. Brown P (2003) Oscillatory nature of human basal ganglia activity: Relationship to the pathophysiology of parkinson’s disease. Mov Disord 18:357-363.

14. Meek PM, Schwartzstein RM, Adams L, et al (1999) Dyspnea: mechanisms, assessment, and management: a consensus statement. Am J Respir Crit Care Med 159:321-340.

15. Halpern BP (1983) Tasting and smelling as active, exploratory sensory processes. Am $J$ Otolaryngol Neck Med Surg 4:246-249.

16. Walsh RR (1956) Single cell spike activity in the olfactory bulb. Am J Physiol 186:255257.

17. Macrides F, Chorover SL (1972) Olfactory bulb units: activity correlated with inhalation cycles and odor quality. Science (80- ) 175:84-87.

18. Houot B, Burkland R, Tripathy S, Daly KC (2014) Antennal lobe representations are optimized when olfactory stimuli are periodically structured to simulate natural wing beat effects. Front Cell Neurosci 8:159.

19. Connelly T, Yu Y, Grosmaitre X, et al (2014) G protein-coupled odorant receptors underlie mechanosensitivity in mammalian olfactory sensory neurons. Proc Natl Acad Sci U S A 112:1-6. 
20. Obara Y (1979) Bombyx mori mationg dance: An essential in locationg the female. Appl Entomol Zool 14:130-132.

21. Loudon C, Koehl M a (2000) Sniffing by a silkworm moth: wing fanning enhances air penetration through and pheromone interception by antennae. J Exp Biol 203:2977-2990.

22. Bau J, Justus KA, Cardé RT (2002) Antennal resolution of pulsed pheromone plumes in three moth species. J Insect Physiol 48:433-442.

23. Sane SP, Jacobson NP (2006) Induced airflow in flying insects II. Measurement of induced flow. J Exp Biol 209:43-56.

24. Sane SP, Dieudonné A, Willis MA, Daniel TL (2007) Antennal mechanosensors mediate flight control in moths. Science 315:863-866.

25. Tripathy S, Peters O, Staudacher E, et al (2010) Odors pulsed at wing beat frequencies are tracked by primary olfactory networks and enhance odor detectio. Front Cell Neurosci 4:114.

26. Baker TC, Willis MA, Haynes KF, Phelan PL (1985) A pulsed cloud of sex pheromone elicits upwind flight in male moths. Physiol Entomol 10:257-265.

27. Willis MA, Baker TC (1984) Effects of intermittent and continuous pheromone stimulation on the flight behaviour of the oriental fruit moth, Grapholita molesta. Physiol Entomol 9:341-358.

28. Szyszka P, Gerkin RC, Galizia CG, Smith BH (2014) High-speed odor transduction and pulse tracking by insect olfactory receptor neurons. Proc Natl Acad Sci U S A 111:16925-30.

29. Homberg U (1994) Distribution of neurotransmitters in the insect brain. Prog in Zoo 
volume 40 (Gustav Fischer Verlag), pp 1-88.

30. Bradley SP, Chapman PD, Lizbinski KM, et al (2016) A flight sensory-motor to olfactory processing circuit in the moth Manduca sexta. Front Neural Circuits 10:5.

31. Hardie RC (1988) Effects of antagonists on putative histamine receptors in the first visual neuropile of the housefly (Musca domestica). J Exp Biol 138:221-241.

32. Hardie RC (1989) A histamine-activated chloride channel involved in neurotransmission at a photoreceptor synapse. Nature 339:704-706.

33. Roeder T (2003) Metabotropic histamine receptors - Nothing for invertebrates? Eur J Pharmacol 466:85-90.

34. Lofstedt C, Hansson BS, Petersson E, et al (1994) Pheromonal secretions from glands on the 5th abdominal sternite of hydropsychid and rhyacophilid caddisflies (Trichoptera). J Chem Ecol 20:153-170.

35. Chapman PD, Bradley SP, Haught EJ, et al (2017) Co-option of a motor-to-sensory histaminergic circuit correlates with insect flight biomechanics. Proc R Soc B Biol Sci 284: 20170339.

36. Kinnamon SC, Klaassen LW, Kammer AE, Claassen D (1984) Octopamine and chlordimeform enhance sensory responsiveness and production of the flight motor pattern in developing and adult moths. J Neurobiol 15:283-293.

37. Vierk R, Pflueger HJ, Duch C (2009) Differential effects of octopamine and tyramine on the central pattern generator for Manduca flight. J Comp Physiol A Neuroethol Sensory, Neural, Behav Physiol 195:265-277. 
38. Ando N, Wang H, Shirai K, et al (2011) Central projections of the wing afferents in the hawkmoth, Agrius convolvuli. J Insect Physiol 57:1518-1536.

39. Eaton JL (1974) Nervous system of the head and thorax of the adult tobacco hornworm, Manduca sexta (Lepidoptera: Sphingidae). Int J Insect Morphol Embryol 3:47-66.

40. Daly KC (2004) Molecular features of odorants systematically influence slow temporal responses across clusters of coordinated antennal lobe units in the moth Manduca sexta. $J$ Neurophysiol 92:236-254.

41. Lei H, Reisenman CE, Wilson CH, et al (2011) Spiking patterns and their functional implications in the antennal lobe of the tobacco hornworm Manduca sexta. PLoS One 6(8): e23382.

42. Daly KC, Kalwar F, Hatfield M, et al (2013) Odor detection in Manduca sexta is optimized when odor stimuli are pulsed at a frequency matching the wing beat during flight. PLoS One 8:1-18.

43. Daly KC, Smith BH (2000) Associative olfactory learning in the moth Manduca sexta. $J$ Exp Biol 203:2025-2038.

44. Daly KC, Carrell LA, Mwilaria E (2008) Characterizing psychophysical measures of discrimination thresholds and the effects of concentration on discrimination learning in the moth Manduca sexta. Chem Senses 33:95-106.

45. Daly KC, Bradley S, Chapman PD, et al (2015) Space takes time: concentration dependent output codes from primary olfactory networks rapidly provide additional information at defined discrimination thresholds. Front Cell Neurosci 9:515. 
46. Daly KC, Carrell L a, Mwilaria E (2007) Detection versus perception: physiological and behavioral analysis of olfactory sensitivity in the moth (Manduca sexta). Behav Neurosci 121:794-807.

47. Mwilaria EK, Ghatak C, Daly KC (2008) Disruption of GABAA in the insect antennal lobe generally increases odor detection and discrimination thresholds. Chem Senses 33:267-281.

48. Daly KC, Christensen T a, Lei H, et al (2004) Learning modulates the ensemble representations for odors in primary olfactory networks. Proc Natl Acad Sci U S A 101:1047610481.

49. Van Breugel F, Dickinson MH (2014) Plume-tracking behavior of flying drosophila emerges from a set of distinct sensory-motor reflexes. Curr Biol 24:274-286.

50. Suver MP, Mamiya A, Dickinson MH (2012) Octopamine neurons mediate flightinduced modulation of visual processing in drosophila. Curr Biol 22:2294-2302.

51. Luders J, Kurtz R (2015) Octopaminergic modulation of temporal frequency tuning of a fly visual motion-sensitive neuron depends on adaptation level. Front Integr Neurosci 9: 00036.

52. Christensen T a, Waldrop BR, Hildebrand JG (1998) Multitasking in the olfactory system: context-dependent responses to odors reveal dual GABA-regulated coding mechanisms in single olfactory projection neurons. J Neurosci 18:5999-6008.

53. Christensen T a, Waldrop BR, Harrow ID, Hildebrand JG (1993) Local Interneurons and Information-Processing in the Olfactory Glomeruli of the Moth Manduca-Sexta. J Comp Physiol a-Sensory Neural Behav Physiol 173:385-399. 


\section{FIGURES}

Figure 1
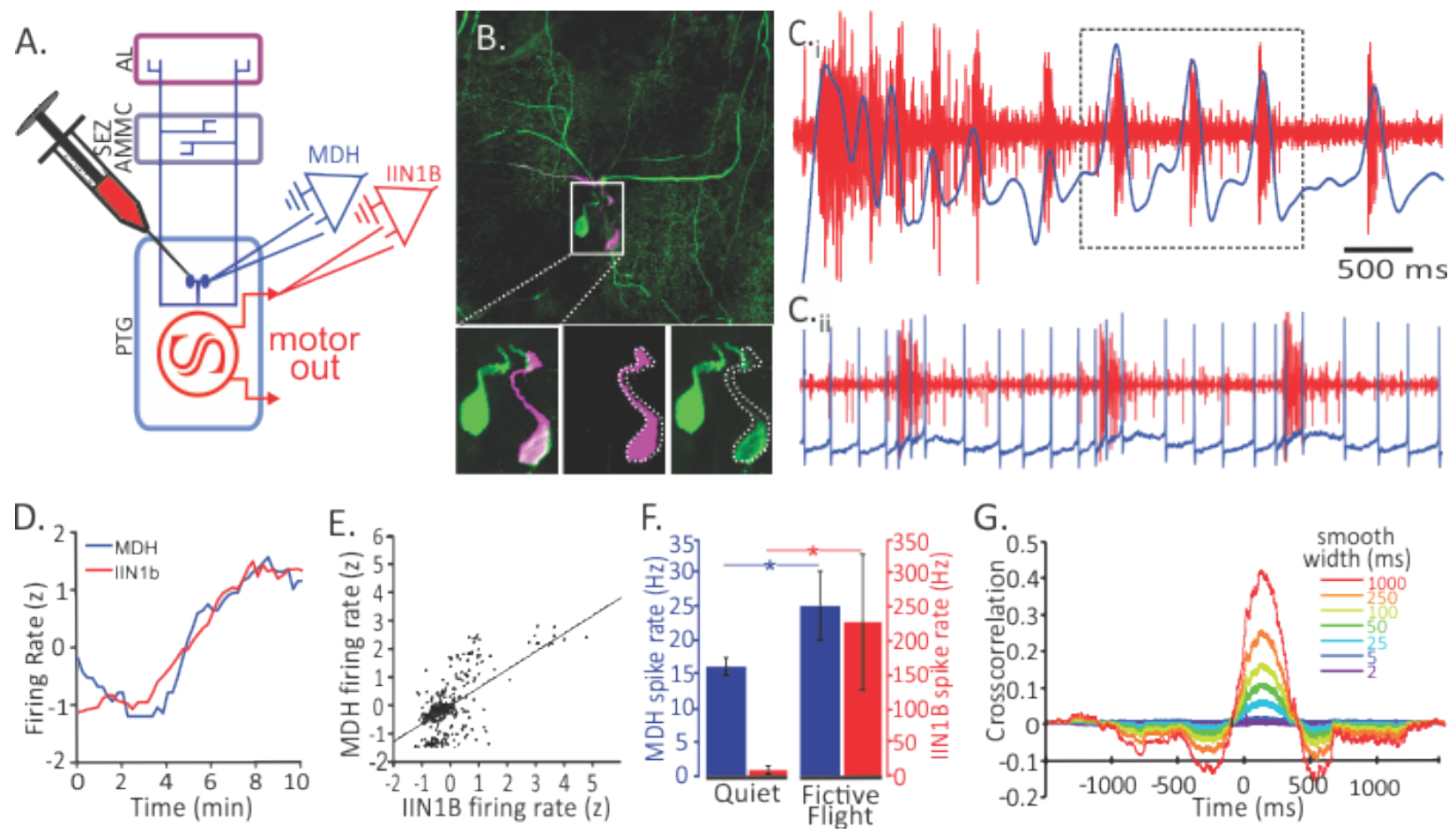

G.

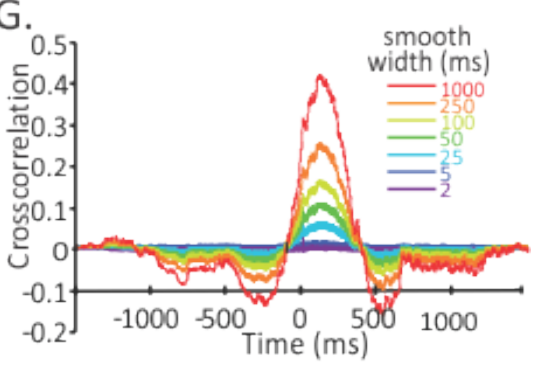




\section{Figure 2}

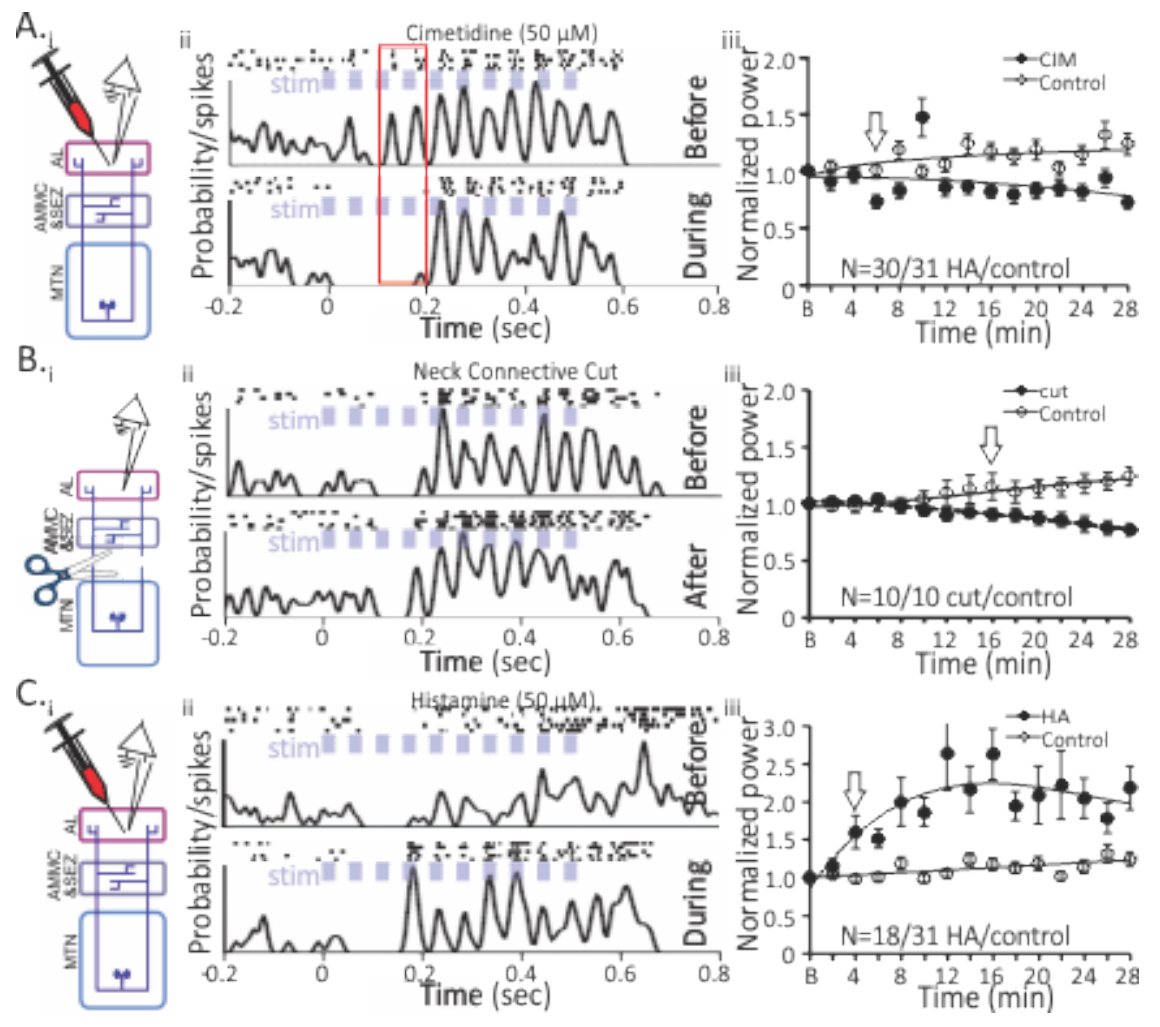




\section{Figure 3}
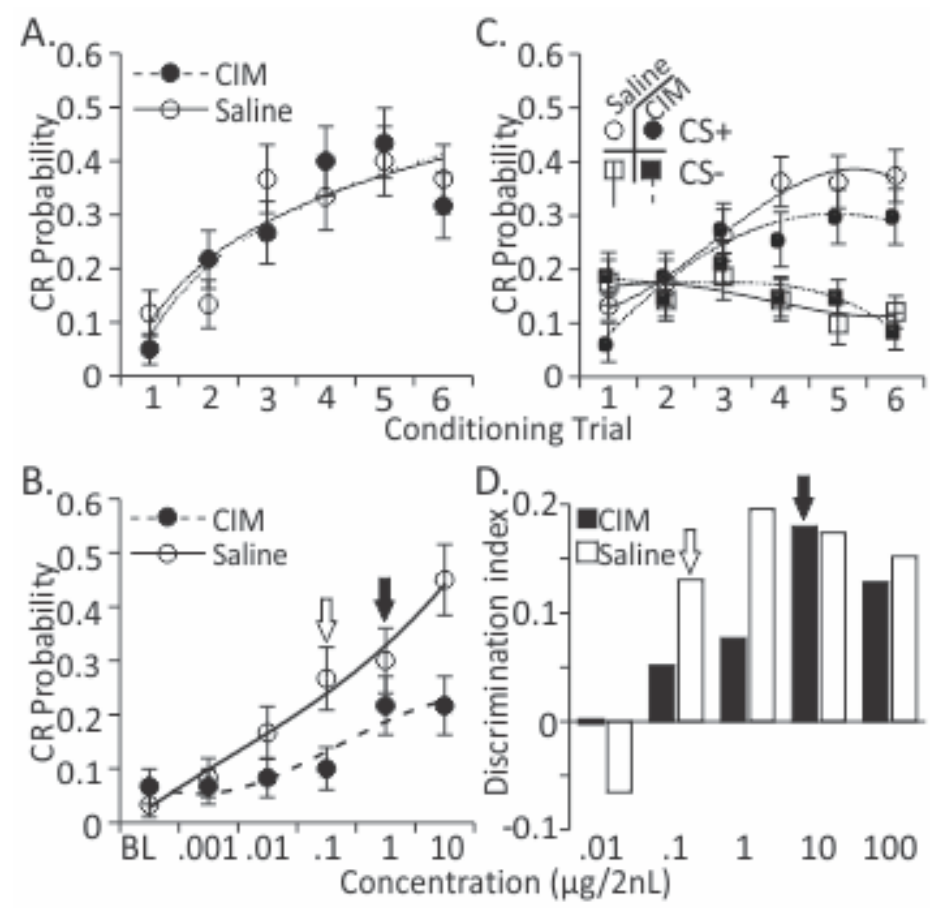


\section{Appendix D}

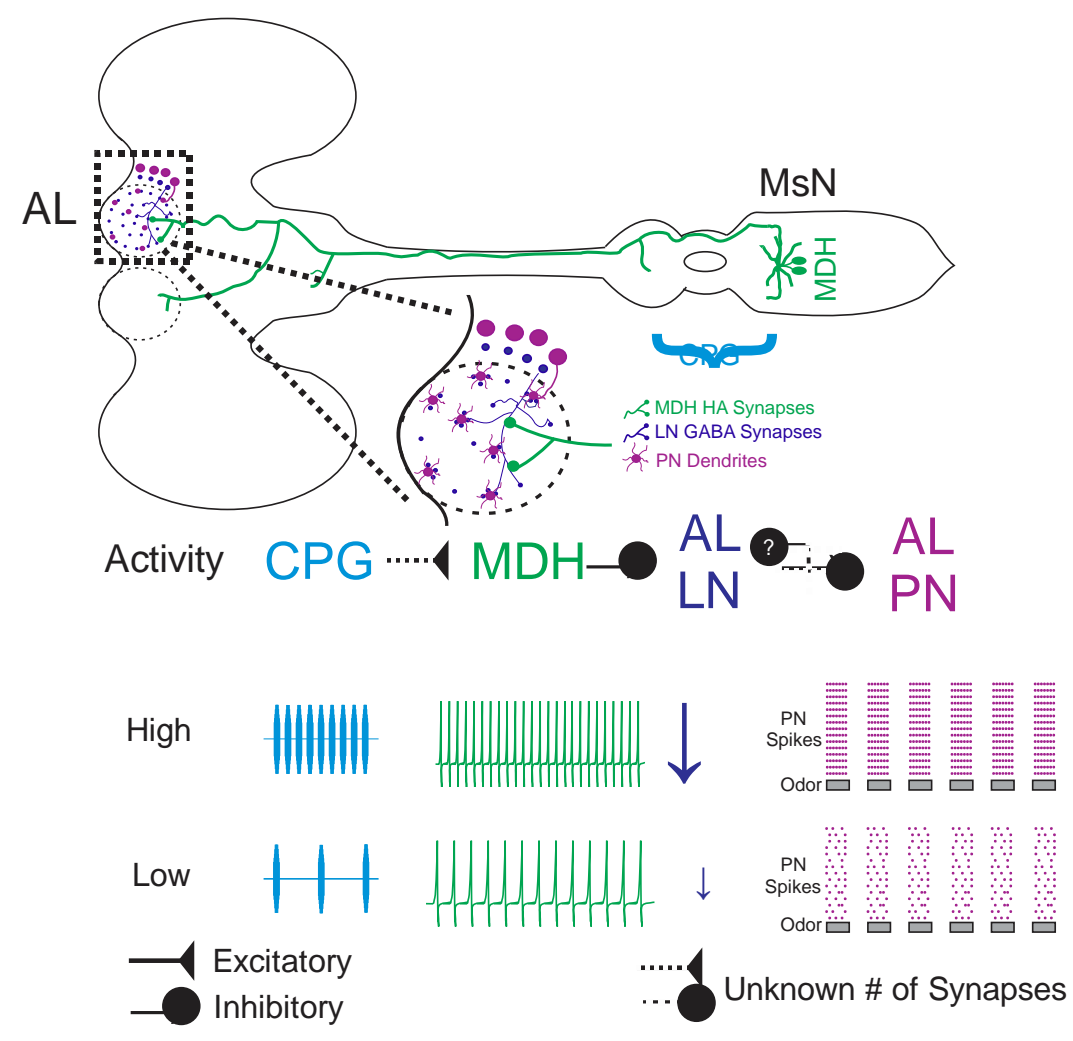

Figure 1: Current Model of MDH Olfactory Modulation. Upper: MDH morphology, projections and connections in the AL. Lower: Mechanism of increased pulse tracking in AL PNs is due to disinhibiton. $\mathrm{CPG}=$ Central Pattern Generator $\mathrm{MDH}=$ Mesothoracic to Deutocerebral Histamine Neuron. AL LN= Antennal Lobe Local Interneurons. AL PN=Antennal Lobe Projection Neurons. MsN=Mesothoracic Neuromere. 


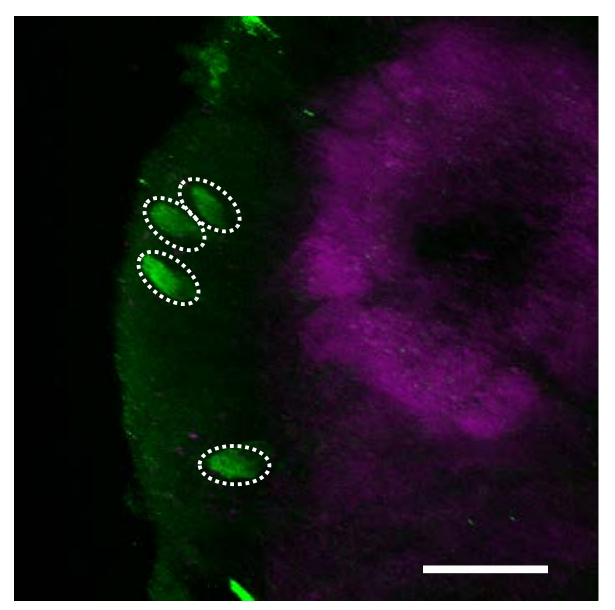

Figure 2: Histamine Receptors Expressed by Pupal State 6. Green= MsClB receptor antibody. Magenta= Bruchpilot antibody. Dashed Lines=MsClB receptor cell bodies. Scale Bar=100um. 

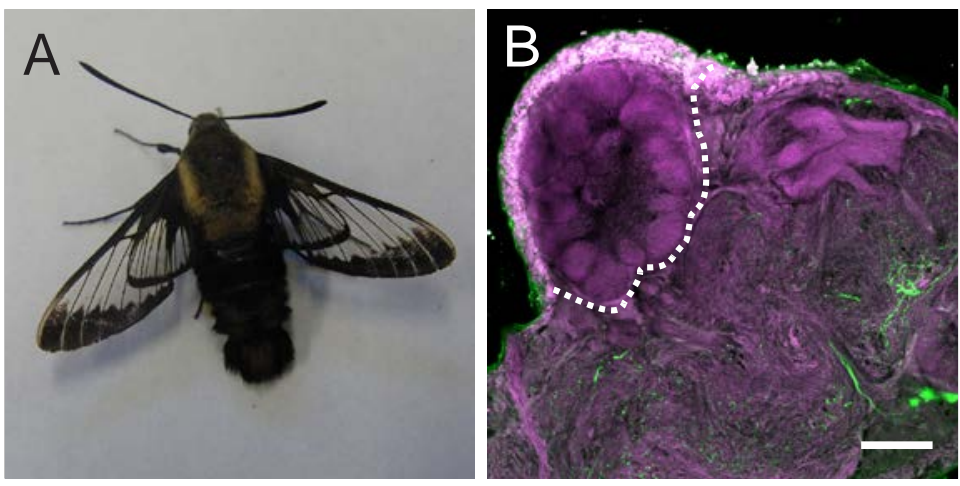

Figure 3: AL HA Absent in Day Flying Moths. A. Image of a hummingbird moth. Animals were caught in the Core Arboretum at West Virginia Universtiy. B. Antennal lobe and brain of a hummingbird moth. No HA is present within the boundaries of the AL. Green=HA, Magenta=Bruchpilot, Dashed line $=$ AL boundary . 